San Jose State University

SJSU ScholarWorks

Master's Projects

Master's Theses and Graduate Research

Spring 2014

\title{
Sidestepping Equity? A Case Study on the Provision and Quality of Sidewalks in Fremont, California
}

Joel Manning

San Jose State University

Follow this and additional works at: https://scholarworks.sjsu.edu/etd_projects

Part of the Urban Studies and Planning Commons

\section{Recommended Citation}

Manning, Joel, "Sidestepping Equity? A Case Study on the Provision and Quality of Sidewalks in Fremont, California" (2014). Master's Projects. 370.

DOI: https://doi.org/10.31979/etd.r5zy-tmtw

https://scholarworks.sjsu.edu/etd_projects/370

This Master's Project is brought to you for free and open access by the Master's Theses and Graduate Research at SJSU ScholarWorks. It has been accepted for inclusion in Master's Projects by an authorized administrator of SJSU ScholarWorks. For more information, please contact scholarworks@sjsu.edu. 


\section{Sidestepping Equity? of Sidewalks in Fremont, California}

\section{Joel Manning}

San José State University

May 2014

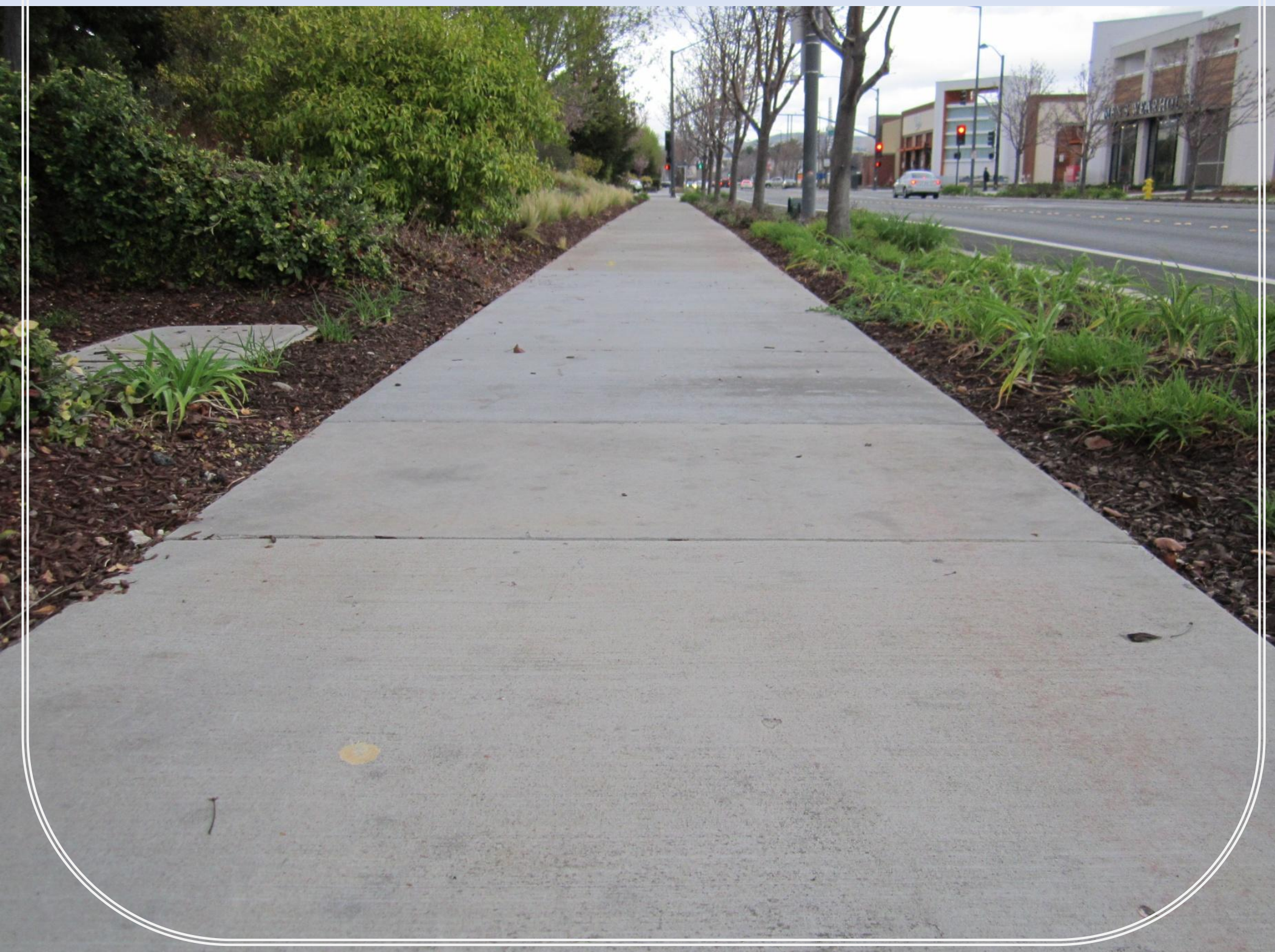


This work is protected by U.S. copyright. Please contact author prior to reproducing any of the content. 
SIDESTEPPING EQUITY? A CASE STUDY ON THE PROVISION AND QUALITY OF SIDEWALKS IN FREMONT, CALIFORNIA

\author{
A Planning Report \\ Presented to \\ The Faculty of the Department of \\ Urban and Regional Planning
}

San José State University

In Partial Fulfillment

Of the Requirements for the Degree

Master of Urban Planning

By

Joel Manning

May 2014

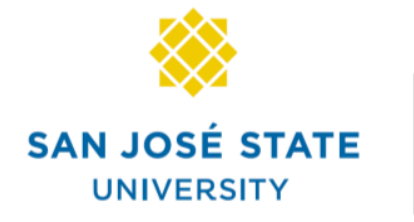

URBAN AND

REGIONAL PLANNING 


\section{GRATITUDE}

I am in debt to the following individuals. Without them, you would be reading a very different report and one of much lower quality. Big a "Thank you” goes to...

My wife, Annie, for your support, patience, and enthusiasm since this journey began (none of this would be possible without you); Dr. Asha Weinstein Agrawal, for facilitating the preliminary research design and for the brilliant suggestion to do "on-the-ground" research rather than staying glued to a computer for the duration of the project; Dr. Hilary Nixon, for all the guidance and honest feedback down the final stretch; Brish and Janice Miler, for sacrificing your time and resources in helping with the data collection (I hope that you will never look at sidewalks the same way again!); Prof. Rick Kos, for the much needed and hugely appreciated emergency GIS assistance; and my proofreaders, Mike Reisler and Jeannie Chen, for taking the time to wade through Draft 1 and offer your feedback. 
io 
Give careful thought to the paths for your feet and be steadfast in all your ways.

Do not turn to the right or the left; keep your foot from evil.

-King Solomon

Proverbs 4:26-27 


\section{TABLE OF CONTENTS}

EXECUTIVE SUMMARY __ V

1 | INTRODUCTION TO THE SIDEWALK: ORIGINS, IMPORTANCE AS A TRANSPORTATION FACILITY, LOCAL AND REGIONAL POLICY

1.1 A BRIEF HISTORY OF THE AMERICAN SIDEWALK

1.2 AN OVERVIEW OF U.S. POLICY AND THE IMPORTANCE OF SIDEWALKS AND WALKING 1

1.3 AN OVERVIEW OF PEDESTRIAN POLICIES IN CALIFORNIA AND THE SAN FRANCISCO BAY AREA 2

1.4 THE INFLUENCE OF INCOME AND LAND USE ON PUBLIC TRANSPORTATION FACILITIES AND OPTIONS 4

5

1.5 THE INFLUENCE OF INCOME ON HOW MUCH PEOPLE WALK ___ 8

1.6 BACKGROUND ON THE STUDY AREA ___ 10

1.7 AN OVERVIEW OF PEDESTRIAN POLICIES IN FREMONT ___ 12

2 | DESCRIPTION OF DATA COLLECTION INSTRUMENT AND RESEARCH METHODOLOGY___ 15

2.1 A SIDEWALK AUDIT IS THE MOST BASIC WALKABILITY ASSESSMENT _

2.2 TOOLS AND STRATEGIES FOR PERFORMING SIDEWALK AUDITS __ 17

2.3 DESCRIPTION OF THE SELECTED AUDIT INSTRUMENT 18

2.4 METHOdOlogy FOR SELECTING STREET SEGMENTS 20

2.5 METHODOLOGY FOR POST-AUDIT INCOME SPATIAL ANALYSIS ___ 26

3 | SUMMARY OF SIDEWALK AUDIT FINDINGS_ 28

3.1 SUMMARY OF SIDEWALK AUDIT FINDINGS: VARIATION BY ZONING CATEGORY ___ 28

3.2 SUMMARY OF SIDEWALK AUDIT FINDINGS: VARIATION BY INCOME CATEGORY ___ 31

4 | DISCUSSION AND POSSIBLE IMPLICATIONS OF SIDEWALK AUDIT FINDINGS __ 34

4.1 DISCUSSION AND IMPLICATIONS OF VARIATION BY LAND USE __ 34

4.2 DISCUSSION AND IMPLICATIONS OF VARIATION BY INCOME — 37

5 | POLICY RECOMMENDATIONS AND CONCLUSIONS_ 38

5.1 POLICY RECOMMENDATIONS FOR MTC_ 38

5.2 POLICY RECOMMENDATIONS FOR CITY OF FREMONT _ 39

5.3 FINAL THOUGHTS_ 40

BIBLIOGRAPHY _ 41

APPENDICES__ 49

APPENDIX 1: INSTITUTIONAL REVIEW BOARD (IRB) EXEMPTION LETTER __ 49

APPENDIX 2: PEDESTRIAN ENVIRONMENTAL DATA SCAN (PEDS) FULL AUDIT INSTRUMENT, VERSION $2 \_50$

APPENDIX 3: AUDITED FREMONT STREET SEGMENTS WITHOUT SIDEWALKS, BY ZONING____ 51

APPENDIX 4: AUDITED FREMONT STREET SEGMENTS WITHOUT CROSSWALKS, BY ZONING _ 52

APPENDIX 5: FREMONT SIDEWALKS IN POOR TO FAIR CONDITION OR UNDER CONSTRUCTION, BY ZONING __ 53

APPENDIX 6: FREMONT SIDEWALKS IN POOR TO FAIR CONDITION OR UNDER CONSTRUCTION, BY INCOME___ 54 


\section{EXECUTIVE SUMMARY}

The sidewalk is the starting place for walkability. It should then be of concern to policy makers that numerous studies have found decreasing levels of access to public transportation infrastructure, including pedestrian facilities, as neighborhood incomes decrease. Land use has also been found to affect the provision and quality of transportation infrastructure. Furthermore, a vast amount of research has demonstrated some variation in the travel patterns and mode choice among poor and non-poor individuals, whether the mode is walking, transit, or personal vehicle.

In order to examine these patterns of variability by income and land use, this research investigates existing conditions in the San Francisco Bay Area suburb of Fremont, California. This was done through an audit of sidewalk provision and quality on 100 public street segments in Fremont (50 from residential areas and 50 from nonresidential areas). A 9-question audit instrument was designed based on the Pedestrian Environment Data Scan tool and used to collect data on basic pedestrian features along selected segments. Income by Census block group was also examined for each audited segment through a post-audit geospatial analysis using ArcGIS. Audited locations were classified by low, medium, or high income.

By first framing the research with an overview of the history and scope of pedestrian policy at the federal, state, regional, and local levels, the audit findings and their possible implications for the Metropolitan Transportation Commission and the City of Fremont are discussed and several modest policy recommendations are made. Audit findings show that Fremont sidewalks may be fairly uniform when looking at income, while more stark contrasts occur when investigating land use. Overall, findings are consistent with literature demonstrating variability in transportation infrastructure depending on land use, but mostly inconclusive regarding the effect of income. Audit findings suggest that sidewalk provision and quality is generally higher in residential areas than in non-residential areas, but that connections to other sidewalks are less common in residential areas. Medium income block groups were observed to have the most variability, while still being in good overall condition. Because this income category had the largest sample size, and was defined by the median income of Fremont residents, these findings may be more worthy of consideration than those of the other two income categories. If medium income segments were to be taken as the average and the low and high income segments as the outliers, then the implication would be that provision in Fremont is fairly equitable, albeit sometimes inadequate. Additional research would be required to draw definitive conclusions yet findings from this case study seem to support such an assertion.

Due to its small sample size and non-random selection, audit findings should only be taken as a preliminary overview of current conditions in Fremont. Some regional and local recommendations can be made nonetheless. The Metropolitan Transportation Commission may be right in supporting Fremont's policy of first targeting commercial areas for improvement in pedestrian infrastructure and would likely do well to continue assisting the City in the build-up of its downtown. However, it may also need to encourage the City to address the older, narrower sidewalks in its large, established residential areas. In light of audit findings, three possible recommendations for the City of Fremont emerged: Emphasize the importance of bringing residential sidewalks up to a higher level of quality rather than focusing almost exclusively on improving commercial areas; Incentivize or fund the widening and set-back of sidewalks, particularly in residential areas; Encourage non-residential property owners to improve sidewalks abutting their property through creative incentives. 
Vii 


\section{1 | INTRODUCTION TO THE SIDEWALK: ORIGINS, IMPORTANCE AS A TRANSPORTATION FACILITY, LOCAL AND REGIONAL POLICY}

\subsection{A brief history of the American sidewalk}

Sidewalks are often taken for granted; we use them all the time, expect them to be available to us when we step out of our car or walk across the street, yet we rarely give them a second thought until a crisis arises. Early in the year 1800, the land now known as Washington, D.C. had served as the United States' capital for only a few months, the government having just relocated from Philadelphia after the death of President Washington. On a rainy, winter day that year, members of Congress were said to have been unable to make it to their homes from the Capitol building because Pennsylvania Avenue, one of the few cleared paths in the new city, was too muddy. ${ }^{1}$ In response, one of the first acts of Congress in the new capital was voting to apportion $\$ 10,000$ for the installation of sidewalks on the north and south sides of the dirt road. ${ }^{2}$ Today, Pennsylvania Avenue is a National Historic Site of the Park Service, constantly bustling with foot traffic. Part ironic, part prophetic, this account mirrors the many stories of how pedestrian travel came to be accommodated across the country. These stories have been told over and over again since and continue to be written today before our eyes. Until something prevents us from walking - real or perceived - we probably won't think twice about the ground we are setting our feet upon.

Flash forward to the 1870's: most American cities had very few traffic regulations, but the regulations that did exist were primarily aimed at serving the needs of pedestrians since walking was still the most common way to move about. ${ }^{3}$ In fact, a common ordinance around this time required that sidewalks be free from obstructions for pedestrians. ${ }^{4}$ However, with the advent of streetcars at the end of the $19^{\text {th }}$ century, followed by the introduction of the automobile at the beginning of

\footnotetext{
${ }^{1}$ Lawrence A. Staron, untitled correspondence,

http://www.fhwa.dot.gov/infrastructure/parambler.cfm (Accessed December 2, 2013).

${ }^{2}$ Ibid.

${ }^{3}$ Asha Weinstein, "Traveler or Pesky Impediment to Travel? Pedestrians and Traffic Regulations in the U.S. and France, 1870 - 1930,” Paper presented at the 46th Annual Conference of the Association of Collegiate Schools of Planning, October 27-30, 2005, Kansas City, MO, 1.

${ }^{4}$ Ibid., 1.
}

the $20^{\text {th }}$ century, new conflicts arose between users of these modes and the pedestrian. As new modes were introduced to cities, planners, traffic engineers, and city officials began to perceive pedestrians as the obstruction. ${ }^{5}$ Even though the majority of people in cities still relied on walking for their transportation, traffic regulations began to emerge which gave increasing priority to streetcars and then to automobiles. By the 1920's and 30's, the restriction of pedestrian travel in cities and a preference for motorized vehicles began to be firmly established, with the trend continuing for many more years afterward. ${ }^{6}$

The post-World War II baby boom, suburbanization, widespread subdivision of land, and construction of the Interstate Highway System worked together to reverse some of the neglect for traveling by foot. In this era, sidewalks were recognized as offering safety to pedestrians, especially children in residential areas. ${ }^{7}$ To provide this infrastructure, it began to become commonplace for cities to require developers to construct sidewalks on new properties, while utilizing "special assessment" bonds to finance them in established areas where none existed. ${ }^{8}$ By the late 1950's, sidewalks were considered "here to stay" because "the trends that make sidewalks desirable or necessary now show no signs of declining in the future."

${ }^{5}$ Ibid., 1 .

${ }^{6}$ Ibid., 1-2.

${ }^{7}$ American Society of Planning Officials, Planning Advisory Service,

"Sidewalks in the Suburbs," Information Report 95, February 1957, http: / / www.planning.org/pas/at60/report95.htm (Accessed December 2, 2013).

${ }^{8}$ Ibid.

${ }^{9}$ Ibid. 


\subsection{An overview of U.S. policy and the importance of sidewalks and walking}

Over the past two decades the United States has experienced a rise in environmental concern and popular movements advocating for less automobile use and more equitable transportation access. ${ }^{10}$ For many cities and states across the country, enacting legislation aimed at fostering more walking has played a key strategy in addressing these concerns. While the health benefits of walking are relatively obvious for individuals, much of the emphasis today is on overall community health and sustainability. For instance, walking for transportation is now widely recognized as essential public policy for combating the increasing levels of carbon dioxide being emitted into the atmosphere-31 percent of which are attributed to motor vehicles. ${ }^{11}$ Promoting walking is also seen as synonymous with promoting equity and community vitality given that it offers a free/low cost mobility option for the nearly 10 percent of households without a car, ${ }^{12}$ and a cheaper alternative for the rest of population who spend around 18 percent of their income to keep their car running each year. ${ }^{13}$

In many ways, the Intermodal Surface Transportation Efficiency Act (ISTEA) of 1991 helped usher in this new emphasis on walking by enshrining a "new vision for surface transportation in America" that allowed states to use federal funding from the U.S. Department of Transportation (DOT) for pedestrian projects and other "activities that contribute to meeting air quality standards." ${ }^{14}$ This act, signed by Republican President

\footnotetext{
${ }^{10}$ Congress for the New Urbanism, "Charter of the New Urbanism," http: / / www.cnu.org/charter (Accessed February 13, 2013); Sierra Club, "Sierra Club Conservation Policies: Transportation,

http://www.sierraclub.org/policy/conservation/trans.aspx (Accessed February 14, 2013).

${ }^{11}$ University of North Carolina Highway Safety Research Center, Pedestrian and Bicycle Information Center, "Environmental/Energy Benefits," http://www.walkinginfo.org/why/benefits environment.cfm (Accessed December 2, 2013).

${ }^{12}$ University of North Carolina Highway Safety Research Center, Pedestrian and Bicycle Information Center, "Transportation Benefits http://www.walkinginfo.org/why/benefits transportation.cfm (Accessed December 2, 2013).

${ }^{13}$ University of North Carolina Highway Safety Research Center, Pedestrian and Bicycle Information Center, "Economic Benefits," http://www. walkinginfo.org/why/benefits economic.cfm (Accessed December 2, 2013).

${ }^{14}$ Bureau of Transportation Statistics, National Transportation Library, "Intermodal Surface Transportation Efficiency Act of 1991 - Summary," http://ntl.bts.gov/DOCS/ste.html (Accessed December 1, 2013).
}

George Bush Sr., permitted the use of Federal Highway Administration (FHA) funds for non-highway projects for the first time. Previously, these funds were dispersed to states and earmarked for highway maintenance and expansion. As a result of ISTEA, funds from the federal government could be used "to provide the mix of projects which will best meet air quality, congestion, mobility, and other national goals" such as those that support pedestrian travel. ${ }^{15}$ Federal support for pedestrian infrastructure continued and was expanded in 1998 by the Transportation Equity Act for the 21 st Century (TEA-21). ${ }^{16}$ This was followed by the Safe, Accountable, Flexible, Efficient Transportation Equity Act: A Legacy for Users (SAFETEA-LU) in 2005 which continued the same support for multimodal transportation and put an increased emphasis on ensuring the safety of pedestrian travel. ${ }^{17}$ At $\$ 286.4$ billion, it remains the single largest financial investment in non-air transportation in U.S. history. The federal commitment to emphasizing pedestrian travel as a vital component of American transportation was recently reaffirmed in July 2012 with President Obama's signing of the Moving Ahead for Progress in the 21st Century Act (MAP-21), which replaced the previous Acts. While MAP-21 keeps with the tradition of allowing federal funds to be used for all modes, bicycle and pedestrian advocates criticize the Act for significantly reducing the funding for non-motorized transportation projects, making the receipt of funding for these projects a competitive process at the state level, and generally making the channels of financial support more complicated. ${ }^{18}$

\footnotetext{
${ }^{15}$ Barry Cullingworth and Roger W. Caves, Planning in the USA: Policies, Issues, and Processes (Third Edition) (New York: Routledge, 2009), 244.

${ }^{16}$ U.S. Department of Transportation, Federal Highway Administration, "A Summary - Protecting Our Environment," from the Transportation Equity Act for the 21st Century: Moving Americans into the 21st Century, http: / / www. fhwa.dot.gov/tea21/sumenvir.htm\#btapw (Accessed December 1, 2013).

${ }^{17}$ U.S. Department of Transportation, Federal Highway Administration, "A Summary of Highway Provisions in SAFETEA-LU," By Office of Legislation and Intergovernmental Affairs, Program Analysis Team, August 25, 2005, https://www.fhwa.dot.gov/safetealu/summary.htm (Accessed December 2, 2013).

${ }^{18}$ Advocacy Advance, Navigating MAP-21: Transportation Alternatives Advocacy Tool Kit,

http://www.advocacyadvance.org/site images/content/Navigating_MA P21 toolkit FINAL revised 9-23.pdf (Accessed December 2, 2013); America Bikes, "Analysis of the New Transportation Bill, MAP-21,"
} 
While these Acts were laying the legal framework for supporting walking and pedestrian infrastructure, parallel legislation was being enacted which emphasized the importance of sidewalks and paths for users of all physical ability, not just the able bodied. The Americans with Disabilities Act of 1990 (ADA), a dramatic expansion of the Architectural Barriers Act of 1968, ${ }^{19}$ brought with it construction and design guidelines to ensure that, among many other things, sidewalks serve the transportation needs of those with disabilities. This Act highlighted the challenges faced by pedestrians who use wheelchairs, have ambulatory impairments, have low vision, and who are blind and provides guidance to help planners and engineers assess whether or not a sidewalk or street crossing meets accessibility requirements. ${ }^{20}$ These standards cover width, slope, obstructions, curbs cuts, and much more. The regulations pertaining to sidewalks concern not only the public right-of-way but now also apply to areas within private developments, requiring at least one accessible pathway from "Site Arrival Points" to the entrance of buildings. ${ }^{21}$

Despite the criticism and shortcomings of MAP-21, there now exists a two-decade-long policy heritage of supporting pedestrian transportation in the U.S, and it is very probable that this shift away from only funding automobile-related infrastructure was permanent. The U.S. DOT, for example, today acknowledges that "walking networks can help meet goals for cleaner, healthier air; less congested roadways; and more livable, safe, cost-efficient communities," and that "walking and bicycling provide low-cost mobility options that place fewer demands on local roads and highways. ${ }^{22}$ It affirms

http://www.americabikes.org/analysis of the new transportation bill map 21 (Accessed December 2, 2013).

${ }^{19}$ United States Access Board, "Architectural Barriers Act (ABA) of 1968," http://www.access-board.gov/the-board/laws/architectural-barriers-actaba (Accessed December 3, 2013).

${ }^{20}$ United States Access Board, “Accessible Sidewalk Video Series,” Adobe

Flash video files. http://www. access-board.gov/guidelines-and-

standards/streets-sidewalks/public-rights-of-way/guidance-andresearch/accessible-sidewalks-video-series (Accessed April 7, 2013); United States Access Board, "Revised Draft Guidelines for Accessible Public Rights-of-Way,” http://www.access-board.gov/guidelines-andstandards/streets-sidewalks/public-rights-of-way/background/reviseddraft-guidelines (Accessed December 3, 2013).

${ }^{21}$ United States Access Board, "ADA Standards," http://www.accessboard.gov/guidelines-and-standards/buildings-and-sites/about-the-adastandards/ada-standards-single-file (Accessed December 3, 2013).

${ }^{22}$ U.S. Department of Transportation, Federal Highway Administration, "Policy Statement on Bicycle and Pedestrian Accommodation Regulations that "sidewalks separated from the roadway are the preferred accommodation for pedestrians" and that sidewalks result in safer, healthier, and more mobile communities. $^{23}$ As a result, the Federal Highway Administration has declared that "accessible sidewalks or pathways should be provided and maintained along both sides of streets and highways in urban areas, particularly near school zones and transit locations, and where there is frequent pedestrian activity." ${ }^{24}$ It is in light of this history of policy support for walking that periodic, local assessments, such as the one described in this report, are needed for judging whether the advocacy and legislation are truly creating an America where sidewalks are readily available and walking is a viable form of transportation. and Recommendations,"

http://www. fhwa.dot.gov/environment/bicycle pedestrian/overview/p olicy accom.cfm (Accessed February 11, 2013).

${ }^{23}$ U.S. Department of Transportation, Federal Highway Administration, "Safety Benefits of Walkways, Sidewalks, and Paved Shoulders," http://safety.fhwa.dot.gov/ped bike/tools solve/walkways trifold/ (Accessed December 1, 2013).

${ }^{24}$ Ibid. 


\subsection{An overview of pedestrian policies in California and the San Francisco Bay Area}

While the federal government has made tremendous progress in moving away from an auto-obsessed national transportation policy, it does not necessarily require that sidewalks be constructed everywhere, in every state, on every street. The role of the federal government, as in other areas of policy making, is to create a vision and standards while leaving implementation and enforcement up to individual states. In practice, the U.S. DOT delegates the responsibility of creating and maintaining "walking networks" to state and regional Metropolitan Planning Organizations (MPOs) while providing only general recommendations for their inclusion in local plans. The MPOs are specifically charged with distributing MAP-21 funds to local governments, and therefore have a relative amount of influence in affecting local policy by establishing a regional vision for pedestrian transportation.

Even with regional guidance, the levels of sidewalk quality and quantity will still vary from city to city depending on the policies of the municipality. For the State of California, this emphasis on local responsibility is acknowledged by the California Department of Transportation (Caltrans) which states that "the design of sidewalks and walkways varies depending on the setting, standards, and requirements of local agencies." 25 The land use patterns and types of development that are permitted in a city greatly affect this variability because, as the State's Streets and Highways Code explains, in general, property owners - not government-are responsible for the construction and maintenance of public sidewalks along their property. ${ }^{26}$ Possibly the only area of sidewalk policy where the State and federal governments do have significant influence is in regards to the ADA requirements discussed in the previous section. Similar to environmental laws, all local projects done with federal monies must comply with federal standards. Caltrans is responsible for ensuring that such projects meet the federal nondiscriminatory regulations contained in ADA legislation. Local agencies must also take it upon themselves to comply with ADA standards whenever they undertake projects regardless of whether

\footnotetext{
${ }^{25}$ State of California, California Department of Transportation, Caltrans Highway Design Manual, Sixth Edition, by the Division of Design, May 7, 2012, 100-6.

${ }^{26}$ State of California, Streets and Highways Code, Sections 5610 and 5875.
}

they receive federal funds. ${ }^{27}$ At minimum, all local projects (including alterations and improvements) have to meet federal requirements though they may also be subject to more stringent state regulations. ${ }^{28}$

In the San Francisco Bay Area, the Oakland-based Metropolitan Transportation Commission (MTC) serves as the MPO for the 9-county region. It has articulated a vision where all pedestrian facilities in the region "are safe and well-maintained and take us when and where we need to go." 29 Additionally, MTC has recently adopted targeted goals - compliance is voluntary for local municipalities - to "increase the average daily time walking or biking per person for transportation by 70 percent (for an average of 15 minutes per person per day)" and "increase non-auto mode share by 10 percentage points (to 26 percent of trips). ${ }^{30}$ Despite such regional goals, in the end, the onus of providing pedestrian access must be borne by local agencies, which must in turn rely largely on compliant developers and property owners to construct and maintain proper walking paths.

Thus, to truly understand pedestrian policy in the Bay Area we must look to the individual cities which normally articulate their own visions and goals for walking in general plans and accompanying pedestrian master plans. First, prior to drilling down to the local level, it is possible to predict what the effect of local policy may be on pedestrian conditions in a given city. We may do this by discussing how income levels and land use patterns tend to affect transportation infrastructure and how much people walk. This will help frame any assessment of how successful a given set of pedestrian policies may be.

\footnotetext{
${ }^{27}$ State of California, California Department of Transportation, Local Assistance Procedures Manual: Processing Procedures for Implementing Federal and / or State Funded Local Public Transportation Projects, Central Publication Distribution Unit, 2008, 11-8-11-12.

${ }^{28}$ Ibid.

${ }^{29}$ Metropolitan Transportation Commission, Transportation 2035 Plan for the San Francisco Bay Area, April 2009, 6.

${ }^{30}$ Metropolitan Transportation Commission, Draft Plan Bay Area, March 2013, 19 .
} 


\subsection{The influence of income and land use on public transportation facilities and options}

Neighborhood income affects not just pedestrian facilities but access to public transportation infrastructure more broadly. Much scholarly research has validated this and some noteworthy examples are cited here. Clifton and Handy's analysis of transportation access in Austin, for example, shows that not only is access a factor in determining the travel behavior of low-income populations, ${ }^{31}$ but that transportation in general is "more time consuming, less convenient, and more of a hindrance" to the upward mobility of the poor. ${ }^{32}$ The chief reason for this is that more than $15 \%$ of low-income American households do not have access to a car (compared to less than $1 \%$ among higher income households), ${ }^{33}$ thus creating more dependence on walking and transit. ${ }^{34}$ Through auditing street segments along 210 randomly selected block groups in St. Louis, Kelly et al. found that unevenness, obstructions, and physical disorder were much more common on African-American block groups. ${ }^{35}$ Additionally, their study found that neighborhoods which were predominantly African-American were more than 15 times as likely to have a large number of obstructions along street segments. ${ }^{36}$ This study is illustrative of income determining infrastructure because while the sample population was from only one city, it was chosen randomly and the African-American neighborhoods also happened to be the low-income neighborhoods.

Studies from Europe show similar findings. By studying an evenly urbanized area in Belgium, De Meester et al. observed that low-income neighborhoods tend to be less compact and lacking in complete sidewalk networks

${ }^{31}$ Kelly Clifton and Susan Handy, "Limits on Access in Low-Income Neighborhoods and the Travel Patterns of Low-Income Households," Research Report, University of Texas at Austin, Center for Transportation Research and Southwest Region University Transportation Center, Texas Transportation Institute, September 2001, viii.

${ }^{32}$ Ibid., 3.

${ }^{33}$ Ibid., ix; Caitlin E. Caspi et al., "The Social Environment and Walking Behavior among Low-Income Housing Residents," Social Science \& Medicine 80 (March 2013): 80.

${ }^{34}$ Hiroyuki Iseki et al., "Thinking Outside the Bus," ACCESS Magazine 40 (Spring 2012): 9-15.

${ }^{35}$ Cheryl M. Kelly et al., "The Association of Sidewalk Walkability and Physical Disorder with Area-Level Race and Poverty," Journal of Epidemiology \& Community Health 61, no. 11 (November 1, 2007): 978. ${ }^{36}$ Ibid., 980. than high-income neighborhoods. ${ }^{37}$ As a result, these low-income neighborhoods were deemed less walkable. ${ }^{38}$ Similarly, Bostock found that low-income mothers in central England are commonly "forced to walk through areas that are often littered, neglected and depressed" as a result of inferior pedestrian facilities and a lack of personal alternatives to walking. ${ }^{39}$

Neckerman et al., comparing commercially zoned streets in poor $(20 \%$ of residents below the 2000 national poverty level) and non-poor neighborhoods in New York City, also found variation among neighborhoods of differing income. Specifically, while non-poor streets were cleaner, ${ }^{40}$ they were actually narrower, ${ }^{41}$ had more limited walking space due to obstructions, ${ }^{42}$ and had less bicycle lanes or greenways. ${ }^{43}$ However, non-poor blocks were also found to have nine times as many bicycle racks and slightly better transit access. ${ }^{44}$ Zhu and Lee, who performed similar research a year earlier in Austin, Texas found that high poverty areas do indeed have worse sidewalk maintenance than wealthier, low-crime areas, ${ }^{45}$ but that sidewalk network completeness was greater in the low-income, Hispanic neighborhoods they audited. ${ }^{46}$

It should be noted that the findings from Neckerman et al. and Zhu and Lee which show better pedestrian environments in some low-income areas likely do not undermine findings from the other studies showing worse sidewalks and transportation access in lowincome neighborhoods. Instead, these two studies highlight the role that contextual and regional

${ }^{37}$ Femke De Meester et al., "Do Psychosocial Factors Moderate the Association Between Neighborhood Walkability and Adolescents' Physical Activity?" Social Science \& Medicine 81, (March 15, 2013): 7.

${ }^{38}$ Ibid.

${ }^{39}$ Lisa Bostock, "Pathways of Disadvantage? Walking as a Mode of

Transport Among Low-Income Mothers," Health \& Social Care in the Community 9, no. 1 (January 2001): 14.

${ }^{40}$ Kathryn M. Neckerman, et al., "Disparities in Urban Neighborhood Conditions: Evidence from GIS Measures and Field Observation in New

York City," Journal of Public Health Policy 30 (March 2, 2009): 271.

${ }^{41}$ Ibid., 273.

${ }^{42}$ Ibid.

${ }^{43}$ Ibid., 271.

${ }^{44}$ Ibid., 272-3.

${ }^{45}$ Xuemei Zhu and Chanam Lee, "Walkability and Safety Around Elementary Schools: Economic and Ethnic Disparities," American Journal of Preventive Medicine 34, no. 4 (April 2008): 285-6.

${ }^{46}$ Ibid., 289. 
differences play. For Neckerman et al., one could point to the fact that this study looked only at commercial streets while the others mentioned looked at residential streets. In the case of New York City, it could be reasoned that non-poor, commercial streets are more economically vibrant than poor streets (imagine a hip Brooklyn street vs. a desolate street in the South Bronx), therefore these sidewalks have more activity which restricts walking space. These streets might also be older and more compact, which is highly desirable by the urban affluent, and thus more narrow - which in turn could prevent the installation of striped bike lanes. In the case of Zhu and Lee, low-income Austin neighborhoods may have also been in older, more walkable areas. Such differences in land use are important considerations and are revisited throughout this report.

Further evidence of access being affected by land use is shown by Chaudhury et al.'s walking audits in Portland and Vancouver, British Columbia which found that highdensity neighborhoods have much higher percentages of continuous sidewalks on both sides than do lower density neighborhoods, and that they are in much better condition. ${ }^{47}$ High density neighborhoods in this region also have wider sidewalks (over 4 feet) and are slightly less sloped. $^{48}$ These findings are supported by Blumenberg et al., ${ }^{49}$ Cullingworth and Caves, ${ }^{50}$ Litman, ${ }^{51}$ and Taylor, ${ }^{52}$ which each demonstrate that compact, high-density areas of older, mixed-used neighborhoods are the most supportive of walking and transit and have the best access to such infrastructure. This type of land use has been found to be more supportive of walking even when it occurs in rural areas. ${ }^{53}$

\footnotetext{
${ }^{47}$ Habib Chaudhury et al., "Use of a Systematic Observational Measure to Assess and Compare Walkability for Older Adults in Vancouver, British Columbia and Portland, Oregon Neighbourhoods," Journal of Urban Design 16, no. 4 (November 2011): 445.

${ }^{48}$ Ibid., 445.

${ }^{49}$ Evelyn Blumenberg et al., "Travel of Diverse Populations," California PATH Working Paper, UCB-ITS-PWP-2007-5, September 2007: 15, 23.

${ }^{50}$ Barry Cullingworth and Roger W. Caves, 252-5.

${ }^{51}$ Todd Litman, "Smart Congestion Relief: Comprehensive Analysis of Traffic Congestion Costs and Congestion Reduction Benefits." Paper presented at the Transportation Research Board 2012 Annual Meeting, P12-5310, September 12, 2012: 8.

${ }^{52}$ Brian D. Taylor, "Rethinking Traffic Congestion," ACCESS Magazine 21 (Fall 2002): 14-5.

${ }^{53}$ Julian Hine et al., "Weekly Activity-Travel Behaviour in Rural Northern Ireland: Differences by Context and Socio-Demographic," Transportation 39, no. 1 (January 2012): 192.
}

Furthermore, Frank assessed the economic drivers influencing transportation investment, travel behavior, and settlement patterns and found that transportation investment decisions within a region tend to favor outlying areas over cities because land is cheaper and a greater impact can be made with fewer dollars spent. ${ }^{54}$ Consequently, the study noted that less funding is available to meet the transportation needs of urban centers which have much greater potential for supporting walking, bicycling, and transit (because of their density). ${ }^{55}$ Frank's assessment of transportation literature concludes that land use patterns in North American cities favor cars and that the market has generally failed to create multimodal access irrespective of location. ${ }^{56}$ As a result, this trend has made making walking an unattractive and inefficient mode. This is supported by Sisson et al. which analyzed walkability on two Arizona college campuses and concluded that the key to environmental support of walking is to disfavor the car by means of limiting parking and other measures. $^{57}$

Wells and Yang's comparison of suburbs and "neotraditional” (i.e., New Urbanist) developments also supports Frank's observation that outlying areas have received more funding and that this has tended to come in the form of car-centric investment. Wells and Yang's findings that outlying suburbs have less sidewalks is evidence of this. ${ }^{58}$ The interesting caveat is that the authors declared their findings to be inconclusive about whether land use has any effect on walking. ${ }^{59}$ This is likely due to the small sample size, which varied over the course of the study, and an experimental methodology.

Finally, regarding the effect of income on overall access to public transportation infrastructure, the available

\footnotetext{
${ }^{54}$ Lawrence D. Frank, "Economic Determinants of Urban Form: Resulting Trade-Offs Between Active and Sedentary Forms of Travel," American Journal of Preventive Medicine 27, no. 3, Supplement (October 2004): 152.

${ }^{55}$ Ibid.

${ }^{56}$ Ibid.

${ }^{57}$ Susan B. Sisson et al., "Campus Walkability, PedometerDetermined Steps, and Moderate-to-Vigorous Physical Activity: A Comparison of 2 University Campuses," Journal of American College Health 56, no. 5 (March 2008): 589-90.

${ }^{58}$ Nancy M. Wells and Yizhao Yang, "Neighborhood Design and

Walking: A Quasi-Experimental Longitudinal Study," American Journal of Preventive Medicine 34, no. 4 (April 2008): 314.

${ }^{59}$ Ibid., 317.
} 
literature mostly shows the trend of decreasing access with decreasing neighborhood incomes. For example, policy research by Dessauer shows that low-income neighborhoods not only have lower levels of access to transit but are often served by routes that are overcrowded and do not meet their travel needs. ${ }^{60}$ However, two studies suggest the opposite: transit access may be superior in low-income neighborhoods because these areas tend to be dense, central urban areas. First, Fuller et al. found that the areas of Montreal with higher concentrations of low-education, low-income residents actually have better access to the city's subway and its bike share locations. ${ }^{61}$ Furthermore, the study found no location-specific differences in street accessibility and that, overall, the city has "relatively few disparities" in terms of transportation access." ${ }^{\text {"62 }}$ Second, Glaeser et al., based on a review of American literature and statistical analysis of the role of public transportation in determining urban demographics, is generally coincident with Fuller et al. This study concluded that the reason many poor remain in central, urban areas is because transportation access is better there. ${ }^{63}$ However, Glaeser et al. does not agree that access levels are equitable across urban areas and this is likely because this study focused exclusively on American cities, not the often more equitable Canadian cities like Montreal. This fact probably limits the generalizability of Fuller et al. to some degree.

\footnotetext{
${ }^{60}$ Mark Dessauer, "Low Income Populations and Physical Activity: An Overview of Issues Related to Active Living," Document prepared for Together on Diabetes Summit in Atlanta, February 28-29, 2012: 2.

${ }^{61}$ Daniel Fuller et al., "Individual- and Area-Level Disparities in Access to the Road Network, Subway System and a Public Bicycle Share Program on the Island of Montreal, Canada," Annals of Behavioral Medicine 45, (February 2, 2013): 98 .

${ }^{62}$ Ibid.

${ }^{63}$ Edward L. Glaeser et al., "Why Do the Poor Live in Cities? The Role of Public Transportation," Journal of Urban Economics 63, no. 1 (May 2008):

20 .
} 


\subsection{The influence of income on how much people walk}

A vast amount of research has demonstrated some variation in the travel patterns and mode choice among poor and non-poor individuals, whether the mode is walking, transit, or personal vehicle. With respect to walking, Clifton and Handy, found that the poor in the Austin metropolitan area travel within their neighborhood by walking much more frequently than do the non-poor. ${ }^{64}$ This was determined through an analysis of travel survey data and an assessment of access to retail and services in seven low-income Austin neighborhoods. In a more recent Austin study, Zhu and Lee found that Hispanic children use walking as a means to get to school because they may have no other form of transportation available to them. ${ }^{65}$ Research in Europe has found similar phenomena. Bostock observed an identical trend to Zhu and Lee among low-income mothers in urban England, ${ }^{66}$ noting that bus transit was too expensive for this population while walking was free. ${ }^{67}$ Hine et al.'s analysis of rural mobility in Northern Ireland was consistent with this, noting that the poor walk more if they do not have access to cars. ${ }^{68}$ In Boston, Caspi et al. observed the same trend in their analysis of social capital and safety among low-income populations, where the split between those owning a car and those who did not was nearly even. ${ }^{69}$ Here, it was found that low income led to low social capital, which in turn led to low levels of walking and, in turn, low levels of health. ${ }^{70}$ However, it was also found the unemployed, car-less poor walked the most among the groups studied as a result of their greater need to access economic and social opportunities. ${ }^{71}$

These five sources identify a trend of low-income populations walking the most. Studies of national trends in the U.S. confirm these findings and demonstrate their generalizability. For example, Pucher and Renne analyzed the 2001 National Household Travel Survey (NHTS) and observed that Americans in the lowest income bracket $(<\$ 20,000 /$ year) use walking for 16.2

\footnotetext{
${ }^{64}$ Kelly Clifton and Susan Handy, 8.

${ }^{65}$ Xuemei Zhu and Chanam Lee, 289.

${ }^{66}$ Lisa Bostock, 15.

${ }^{67}$ Ibid., 13.

${ }^{68}$ Julian Hine et al., 192-3.

${ }^{69}$ Caitlin E. Caspi et al., 80.

${ }^{70}$ Ibid., 81-82.

${ }^{71}$ Ibid., 80
}

percent of all their trips - more than double the rate of all other incomes. ${ }^{72}$ Besser and Dannenberg, also making use of 2001 NHTS data, analyzed how far transit users walk to gain access and found that the average walking time to transit decreases as income and access to a car increase. ${ }^{73}$ And, because 41 percent of transit users were found to not own a car, this group did a lot of walking. ${ }^{74}$ Scholl identified similar findings through research on transportation affordability issues for low-income populations. This study observed that walking constitutes a large portion of trips for minorities and that this mode is also a major form of commuting for welfare mothers who do not own cars. ${ }^{75}$ Dessauer observed the same trend at the national level, noting that people in the lowest 20 percent in income are the most likely to walk because they also use transit the most and must access it on foot. ${ }^{76}$ Blumenberg et al.'s research yielded similar findings, observing that low-income and non-white children in the U.S. make as many as 1.5 times more walking trips on average than white children (in statistically higher income groups). ${ }^{77}$

Together, these 10 sources show similar trends for walking as a mode of transportation for low-income populations and for minorities - which are synonymous here. This is significant as each observe this trend using a different methodology; six capture data on a broad spectrum of the population (Besser and Dannenberg, Dessauer, Hine et al., Pucher and Renne, Scholl, Zhu and Lee), two focus exclusively on poor populations (Bostock and Caspi et al.), and one does both (Clifton and Handy). However, a review of relevant literature also identified an opposite trend among four studies:

\footnotetext{
${ }^{72}$ John Pucher and John L. Renne, "Socioeconomics of Urban Travel: Evidence from the 2001 NHTS," Transportation Quarterly 57, No. 3 (Summer 2003): 59.

${ }^{73}$ Lilah M. Besser and Andrew L. Dannenberg, "Walking to Public Transit: Steps to Help Meet Physical Activity Recommendations," American Journal of Preventive Medicine 29, no. 4 (April 2005): 276. ${ }^{74}$ Ibid.

${ }^{75}$ Lynn Scholl, "Transportation Affordability for Low-Income Populations: A Review of the Research Literature, Ongoing Research Projects, and San Francisco Bay Area Transportation Assistance Programs," PPIC Working Paper, Public Policy Institute of California, October 2002: 5

http://www.mtc.ca.gov/planning/lifeline/Affordability ref.pdf (Accessed October 21, 2013).

${ }^{76}$ Mark Dessauer, 3.

${ }^{77}$ Evelyn Blumenberg et al., 63.
} 
higher income populations walk more than lowerincome populations.

First, Wells and Yang's experimental study of 70 mostly overweight, low-income black women in the Southeastern U.S. found that while low-income black women with children walk a lot, low-income white women walk even more. ${ }^{78}$ The implication was that black populations walk significantly less than non-black populations because walking actually increases as income rises, not vice versa. ${ }^{79}$ Next, Shelton et al., another study of low-income communities in Boston, found that the poor may actually walk less as a result of having smaller social networks. ${ }^{80}$ This was found to be especially true for Hispanics and those 18-35 years old, ${ }^{81}$ while the average amount of walking per day for all groups was so low it could be considered sedentary. ${ }^{82}$ Thirdly, Booth et al., in a study of neighborhood walkability and its association with diabetes, found that low-income individuals live in less walkable areas and have higher rates of diabetes - the implication being because they walk less. ${ }^{83}$ Lastly, De Meester et al.'s study of walking among Belgian adolescents living in neighborhoods of differing walkability found that, regardless of walkability, those in high-income neighborhoods will tend to walk more than those in low-income neighborhoods. ${ }^{84}$ Nevertheless, an explanation for this occurrence was only conjecture.

While these four studies may show an alternate trendwalking increases with income-the reason for the conflicting findings may be the result of some obvious limitations. In particular, the conclusions of Wells and Yang may be somewhat spurious due to the extremely small sample size and experimental methodology. Shelton et al., along with the findings mentioned, observed that work, childcare, and other demands, all

\footnotetext{
${ }^{78}$ Nancy M. Wells and Yizhao Yang, 316.

${ }^{79}$ Ibid.

${ }^{80}$ Rachel C. Shelton et al., "The Association Between Social Factors and Physical Activity Among Low-Income Adults Living in Public Housing," American Journal of Public Health 101, no. 11 (November 2011): 2105, 2107.

${ }^{81}$ Ibid., 2105, 2107.

${ }^{82}$ Ibid., 2107.

${ }^{83}$ Gillian L. Booth et al., "Unwalkable Neighborhoods, Poverty, and the Risk of Diabetes Among Recent Immigrants to Canada Compared With Long-Term Residents," Diabetes Care 36, no. 2 (February 2013): 302 .

${ }^{84}$ Femke De Meester et al., 7.
}

increase the amount walking per day. ${ }^{85}$ This seems to be more consistent with the trend of the poor needing to walk more because they have no other transportation options, as discussed above. It is also consistent with Caspi et al.'s observation that pedestrian travel among the poor varies depending on their level of economic and social activity. Meanwhile, Booth et al. implies, but does not observe that the poor walk less, and De Meester et al.'s Belgian analysis only focused on 13- to15-yearolds so it is clearly limited in scope. Because of these limitations, it is safer and more prudent to draw generalizable conclusions from the first 10 studies discussed here, which is to say that lower income populations are likely to walk the most.
${ }^{85}$ Rachel C. Shelton et al., 2107. 


\subsection{Background on the study area}

This research detailed in this report sought to assess whether the trends discussed above hold true in Fremont, California and then consider what the policy implications might be for the City and the region. (Disclosure: I am a resident of Fremont and have lived in the city since July 2012). Fremont is located at the southern end of Alameda County in the southeast corner of the San Francisco Bay. It is bordered by Union City and Hayward to the north, unincorporated County land to the east, Milpitas to the south, and Newark and the San Francisco Bay to the west. Its 2012 total population was estimated at 214,089, equating to 71,004 total households. ${ }^{86}$ Fremont is the $4^{\text {th }}$ largest city in the Bay Area and the $15^{\text {th }}$ largest in California. ${ }^{87}$ According to the 2010 U.S. Census, it is the $2^{\text {nd }}$ largest city by land area in the 9-county region after San Jose. Because of its large land area and moderate population, Fremont has the lowest population density of any California city over 160,000 , at 2,443.7 people per square mile. ${ }^{88}$ The City's topography is generally flat but also includes hilly areas to the east which consist mostly of single-family residential developments.

Fremont's population is noted for being racially diverse as well as "affluent, tech-savvy and highly educated with [an] urban mentality." 89 Demographically, Fremont residents are 50 percent Asian, 33 percent white, 14 percent Hispanic, and 3 percent black. ${ }^{90}$ Residents have an average household income of $\$ 114,684$, an average household size of three persons, and a median age of 37 years. ${ }^{91}$ Fifty percent of Fremont residents have at least a college degree. ${ }^{92}$ Fremont's racial diversity reflects that of the region, ${ }^{93}$ and, despite its local reputation as a

\footnotetext{
${ }^{86}$ City of Fremont, Office of Economic Development, Fremont Community Profile 2014, Informational report, January 21, 2014,

http://www.fremont.gov/DocumentCenter/Home/View/6859

(Accessed March 3, 2014).

${ }^{87}$ Ibid.

${ }^{88}$ World Media Group, LLC., "California Population Density City Rank," http://www.usa.com/rank/california-state--population-density--cityrank.htm (Accessed December 5, 2013).

${ }^{89}$ City of Fremont, Office of Economic Development.

${ }^{90}$ Ibid.

${ }^{91}$ Ibid.

92 Urban Land Institute, A ULI Advisory Services Panel Report: Strategies for the Development around the Warm Springs/South Fremont Station, June 11-14, 2012, http://www.fremont.gov/DocumentCenter/View/18322 (Accessed November 18, 2012).

${ }^{93}$ MTC-ABAG Library, Bay Area Census, "Race/Ethnicity Percentage by County, 1980-2010,"
}

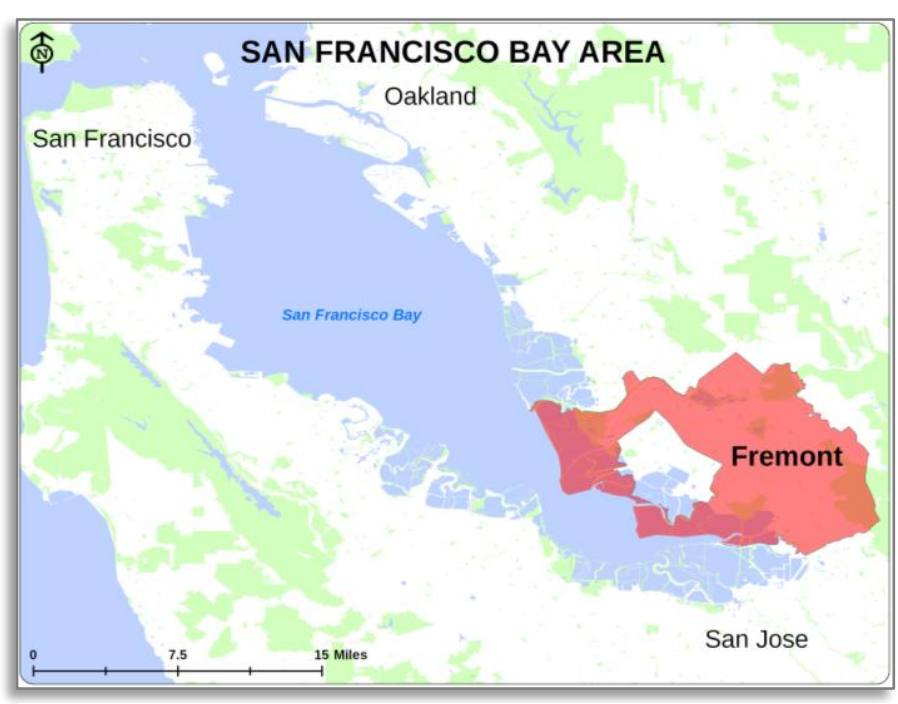

Figure 1. Fremont, California.

(Author: Joel Manning. Sources: City of Fremont, City and County of San Francisco, U.S. Department of the Interior, U.S. Geological Survey)

wealthy bedroom community with some of the best schools in the state, ${ }^{94}$ it has a median household income which places it in the middle of Bay Area cities according to 2010 Census figures - reflecting a fairly economically diverse population. Perhaps as a result of its population or its proximity to the high-tech culture to the south, the City self-identifies as a part of "Silicon Valley" despite being situated far outside the traditional center and some South Bay officials not sharing the same sentiment. ${ }^{95}$

http://www.bayareacensus.ca.gov/historical/shrcorace.htm (Accessed August 31, 2013).

${ }^{94}$ U.S. News \& World Report, "Fremont Unified School District," http://www.usnews.com/education/best-high-

schools/california/districts/fremont-unified-school-district (Accessed August 31, 2013).

${ }^{95}$ City of Fremont, Think Fremont California, South Fremont / Warm Springs Strategy: Building Tomorrow's Employment-Focused Transit Oriented Development Today, Promotional pamphlet, October 2012,

https://www.fremont.gov/DocumentCenter/View/18691 (Accessed October 17, 2012); Gus Morrison, Mayor of Fremont, speech at BART Warm Springs Extension Project Milestone Event and Subway Walk, Fremont, CA, October 26, 2012; Ken Yeager, VTA Chairman, speech at BART Warm Springs Extension Project Milestone Event and Subway Walk, Fremont, CA, October 26, 2012; The precise boundaries of Silicon Valley are contentious but generally center around Palo Alto, Santa Clara and North San Jose. 
Fremont has played a prominent role in the region's transportation history and continues to be in the spotlight today. The city was the original terminus of the Bay Area Rapid Transit (BART) rail line when the system began operation in 1972 and today is serving as the starting point for the Silicon Valley Extension project which will add one (possibly two) new BART station to the city and extend rapid transit to San Jose by 2018. Fremont is also home to the production plant for electric vehicle maker Tesla Motors, the state's only car manufacturer and winner of the 2013 Motor Trend Car of the Year award along with a legion of admiring fans across the country. ${ }^{96}$ After the closure of the New United Motor Manufacturing, Inc. (NUMMI) auto plant in 2010 (see figure 2), Tesla purchased the massive facility and has since become the pride-and-joy of the City of Fremont and is seen by City officials as its economic redevelopment anchor and key to long-term, citywide success and prosperity. ${ }^{97}$

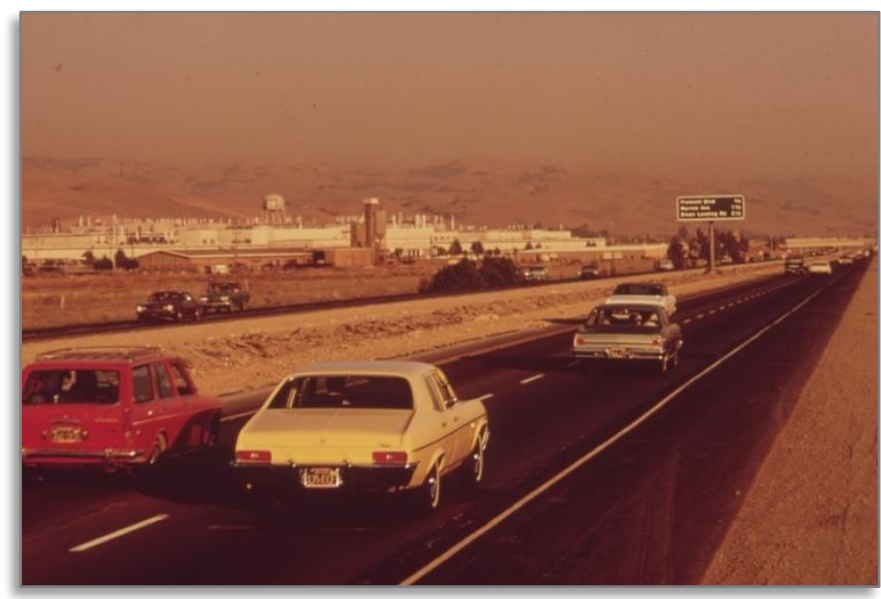

Figure 2. Fremont Assembly plant in 1972, seen from I-880 southbound. The plant was operated by General Motors from 1962 to 1982. As a joint venture of Toyota and GM from 1982 to 2010, the plant was known as NUMMI. The facility is now the Tesla Factory. (Source: Belinda Rain, U.S. National Archives and Records Administration, 1972, http://upload.wikimedia.org/wikipedia/commons/0/05/CALIF ORNIA-NEAR SAN FRANCISCO BAY - NARA 544723.jpg, Accessed December 1, 2013.)

\footnotetext{
${ }^{96}$ Farhad Manjoo, “The Genius of Tesla," Slate Magazine, May 10, 2013, http://www.slate.com/articles/technology/technology/2013/05/tesla model s the electric car company is a little bit apple a little bit.ht $\underline{\mathrm{ml}}$ (Accessed August 31, 2013).

${ }^{97}$ Lauren Hepler, "Life After Solyndra: Fremont Pumps Its Cleantech Agenda," Silicon Valley Business Journal, May 3, 2013, http://www.fremont.gov/documentcenter/view/19990 (Accessed August 31, 2013);

Chris De Benedetti, "Fremont Leaders, Congressmen Tout City's Tech Companies, Planned Warm Springs BART Development Development," The Argus, May 5, 2013,

http://www.fremont.gov/documentcenter/view/19984 (Accessed August 31, 2013)
} 


\subsection{An overview of pedestrian policies in Fremont}

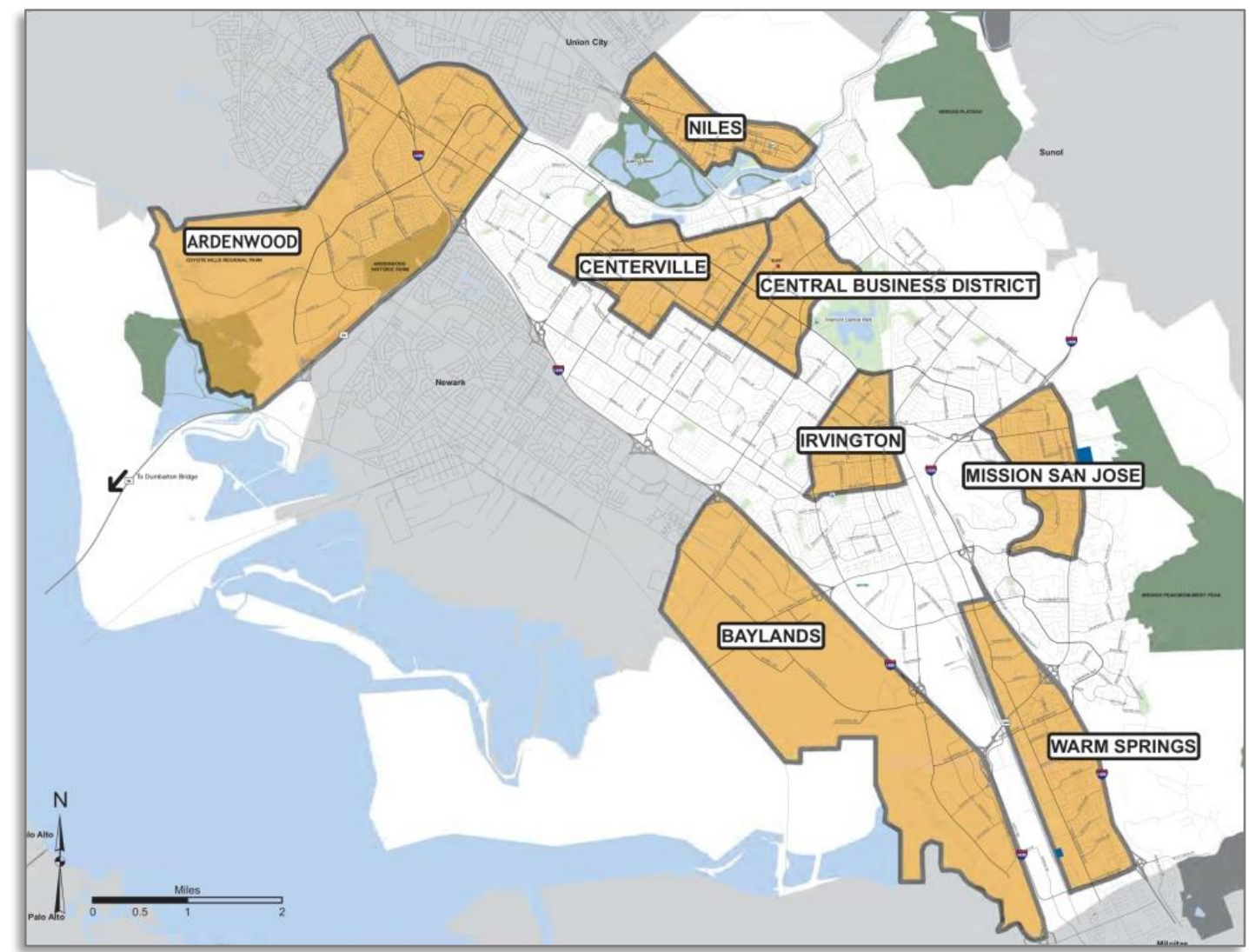

Figure 3. Eight Study Districts of the Fremont Pedestrian Plan.

(Source: City of Fremont, Fremont Pedestrian Master Plan, Prepared by Alta Planning + Design, 2007.)

The City of Fremont, like many cities in California, developed around the automobile, establishing land use patterns and transportation infrastructure that are explicitly car-centric. ${ }^{98}$ With the adoption of its General Plan in 1991 - the same year ISTEA was enacted - the City began requiring the installation of sidewalks whenever new development occurs on public streets. ${ }^{99}$ Even with this regulation, pedestrian travel has been a lesser priority, leaving "some parts of the city [that] lack sidewalks, creating gaps in the system that tend to hinder walking."

Today, the City has stated that it is "committed to ensuring that future growth results in a city with a truly multi-modal transportation network, where pedestrian facilities are fully integrated and residents can walk

\footnotetext{
${ }^{98}$ City of Fremont, Fremont Pedestrian Master Plan, Prepared by Alta Planning + Design, 2007, 5-1; City of Fremont, General Plan, December 2011, 3-3.

${ }^{99}$ City of Fremont, Fremont Pedestrian Master Plan, 5-1.

${ }^{100}$ City of Fremont, General Plan, December 2011, 3-20.
}

comfortably and pleasurably between a variety of destinations." ${ }^{\prime 101}$ To realize this commitment, Fremont adopted the goal of increasing the mode share of pedestrian trips from 9 to 13.5 percent by $2025,{ }^{102}$ and has chosen to target five planning areas for increasing walking: the Central Business District, Niles, Centerville, Irvington, and Mission San Jose (see figure 3 ). These areas were chosen because they were deemed "most suitable for walking" due to their "short blocks with main streets and mixed-land uses." "103 They were also selected as candidates for future Complete Streets retrofitting, provided that funding is available. ${ }^{104}$ What makes these areas unique, however, is that they contain the City's key "commercial districts" which it believes have "greatest potential for pedestrian activity." 105 In other words, supporting walking in these areas is likely

${ }^{101}$ City of Fremont, Fremont Pedestrian Master Plan, 1-1.

${ }^{102}$ City of Fremont, General Plan, 3-48.

${ }^{103}$ City of Fremont, Fremont Pedestrian Master Plan, 4-8.

${ }^{104}$ City of Fremont, General Plan, 3-41, 3-42.

${ }^{105}$ City of Fremont, Fremont Pedestrian Master Plan, 4-8; City of Fremont, General Plan, 3-44. 
to yield the highest return-on-investment because 1) the infrastructure and land use in these areas already favors walking, and 2) an increase in walking will provide an economic and cultural benefit to the districts.

Despite targeting these areas for walking, the City's policy and development focus is mostly on the Central Business District - the equivalent of its "downtown" and home to the City offices and BART station - and on the planned transit-oriented development hub around the future Warm Springs/South Fremont BART station (scheduled to open in 2015). There are a number of reasons for this, yet one core motivation is worth mentioning here. Fremont's municipal origins as an incorporation of five disparate towns in 1956 (Centerville, Niles, Irvington, Mission San Jose, and Warm Springs) has created a rather large, sprawling city without a center. This has given rise to the perception that there is no central area, downtown, or a most prominent "main street." ${ }^{\text {106 }}$ Focusing on these two areas looks to rectify this.

To support its efforts to enhance pedestrian connections in the Central Business District, MTC awarded Fremont with a $\$ 5.8$ million grant in September 2013 as part of MAP-21. ${ }^{107}$ Construction of the new BART station is also progressing. ${ }^{108}$ However, this approach of targeting two very different areas will build up the Central Business District yet also create an additional "center" in an unpopulated, industrial section of Fremontcoincidentally, adjacent to the Tesla Factory (see figure 4). This strategy may ultimately prove problematic for helping pedestrians walk to a "variety of destinations" because it directs investment not to areas which desperately lack pedestrian facilities, but to the City's core - the most built-out district-and to a small

\footnotetext{
${ }^{106}$ Urban Land Institute, "Report on Warm Springs/South Fremont Area Positioned as 21st Century Workplace, Mixed Use Transit-Oriented Development," June 14, 2012. Presentation to City of Fremont officials and community members, http: / / www. youtube.com/watch?v=YEzeXcgN6NE\&feature=plcp (Accessed October 3, 2012); City of Fremont, Fremont Pedestrian Master Plan, 4-8.

${ }^{107}$ City of Fremont, "Grant Will Kick-Start Downtown Enhancements," City News, Issue 62 (Winter 2013), 1.

${ }^{108}$ San Francisco Bay Area Rapid Transit District, "Warm Springs

Extension Construction Updates,"

http://www.bart.gov/about/projects/wsx/updates (Accessed December 7, 2013).
}

mixed-used area surrounded by manufacturing and heavy rail which does not yet exist. ${ }^{109}$

Because of Fremont's immense geographical size and the already numerous plazas and strip malls scattered throughout, adding new centers in new locations may only increase the amount of "gaps in the system" by attracting people to points of interest which are not adequately connected to the rest of the city. ${ }^{110}$ Conversely, this strategy may also shorten the gaps between "destinations" because developments like the one occurring in the Warm Springs district will be required, as mentioned above, to provide new sidewalks in areas where none have ever existed. Regardless, targeting key areas may be a more viable option for an expansive and relatively low-density city like Fremont, although it does highlight the paradoxical nature of the City's new emphasis on pedestrians: the City has been, and remains fixated on cars (Tesla) and mega infrastructure (BART). Time will tell if this strategy is effective at "expanding transportation choices, reducing dependence on single passenger automobiles, and making it easier to walk" in the City. ${ }^{111}$

\footnotetext{
${ }^{109}$ City of Fremont, Fremont Pedestrian Master Plan, 1-1.

${ }^{110}$ City of Fremont, General Plan, 3-20.

${ }^{111}$ City of Fremont, General Plan, 3-3.
} 


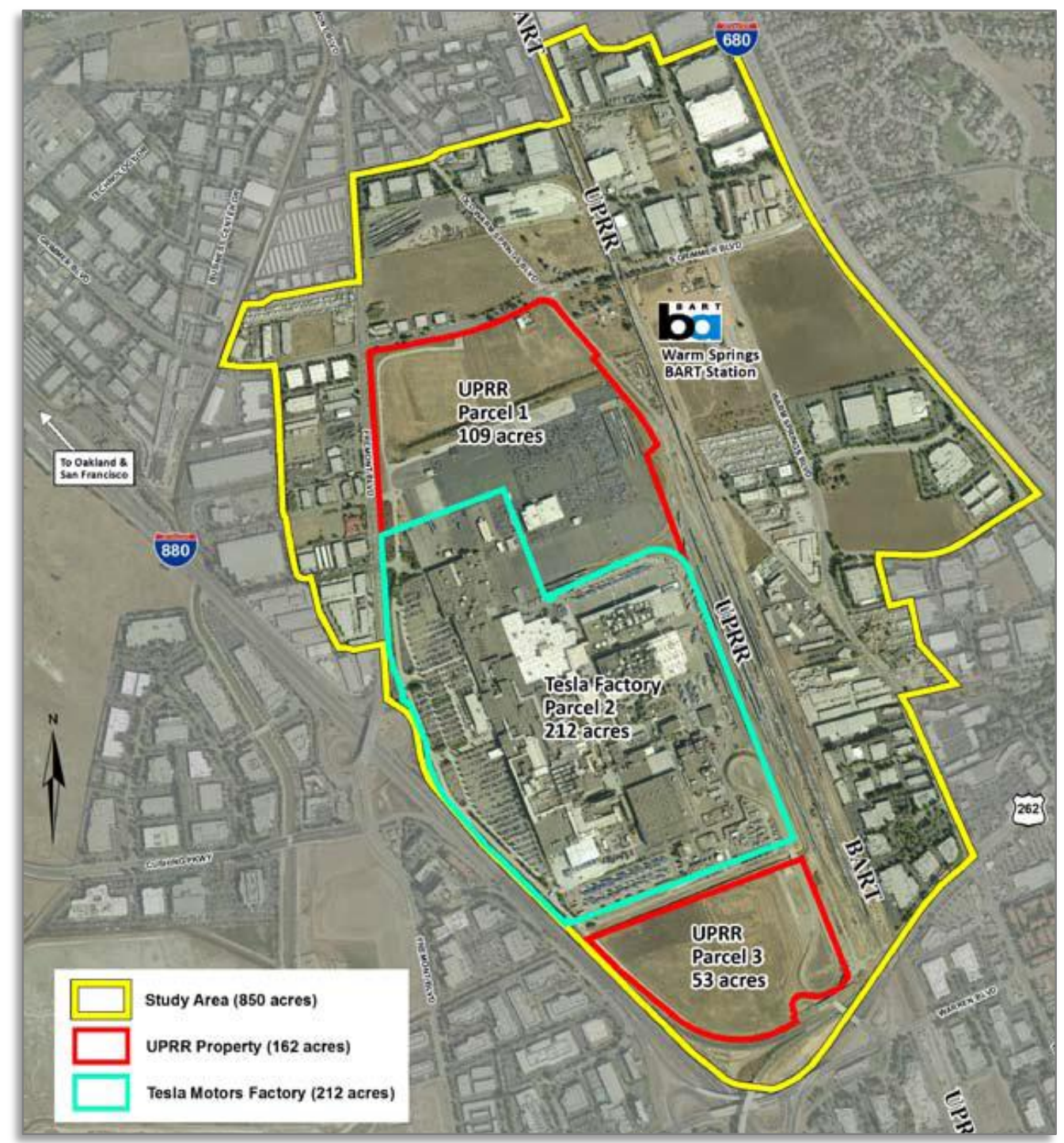

Figure 4. Area around the future South Fremont/Warm Springs BART station, October 2012. This study area by the Urban Land Institute assessed development opportunities. A total of 3,850 multi-family units are planned to be built around the BART station along with a mixed-use plaza. All but 20 acres of the red Union Pacific (UPRR) parcels will remain in UPRR use. New industrial development has already begun on the south UPRR parcel.

(Source: City of Fremont, Think Fremont California, South Fremont / Warm Springs Strategy: Building Tomorrow's Employment-Focused Transit Oriented Development Today, October 2012,

http://www.fremont.gov/DocumentCenter/View/18691, Accessed October 20, 2012.) 


\section{2 | DESCRIPTION OF DATA COLLECTION INSTRUMENT AND RESEARCH METHODOLOGY}

\subsection{A sidewalk audit is the most basic walkability assessment}

Because pedestrian policies are established at the regional level by MTC and then implemented by county and city plans, any assessment of existing conditions in the Bay Area should be performed at the local level first. The findings from such an assessment will then have implications for the entire region as they can be measured against conditions in other cities within the region while providing a snapshot of MTC's success in influencing local policy. The particular assessment conducted for this research attempts to shine the spotlight on the existing conditions in one of the Bay Area's most populous and geographically expansive cities: Fremont.

The assessment strategy employed is a sidewalk audit. Unlike the popular "walkability" assessments which take an inventory of a wide range of tangible and intangible elements which could affect walking in a particular area, ${ }^{112}$ this audit focuses exclusively on sidewalks. It therefore does not assess the more peripheral and subjective elements such as noise, lighting, and landscaping that a walkability assessment would. Instead, the primary questions being asked by this audit are whether or not a sidewalk exists and what condition it is in.

The reason for this narrower focus is that the sidewalk is the starting place for walkability. Regardless of the land use or economic conditions along a street, when walking is not efficient or safe it is less likely to occur. As studies have shown, walking time and safety outweigh all other factors for pedestrians in choosing which routes to take. ${ }^{113}$ The implication is that an easyto-use sidewalk, strategically connected to other paths, is desirable and more likely to be utilized. Yet, for a variety of reasons, pedestrians sometimes do not use sidewalks and take the risk of walking in the street or in other areas without paths. The danger of doing so

\footnotetext{
${ }^{112}$ University of North Carolina Highway Safety Research Center, Pedestrian and Bicycle Information Center, "Audits,"

http://www.pedbikeinfo.org/planning/tools audits.cfm (Accessed April 16, 2013).

${ }^{113}$ Zhan Guo and Becky P. Y. Loo, "Pedestrian Environment and Route Choice: Evidence from New York City and Hong Kong," Journal of Transport Geography 28 (April 2013): 132.
}

cannot be overstated: research has found that not walking on a sidewalk is on par with being intoxicated as the most common cause of pedestrian fatalities. ${ }^{114}$ These fatalities become even more common when walking at night in urban, residential areas, ${ }^{115}$ especially for the elderly. ${ }^{116}$

Areas without sidewalks are not only unsafe, but less desirable for pedestrians as demonstrated by studies showing a clear preference for walkways that are separated from high traffic volumes and include crosswalks, ${ }^{117}$ plus have smooth, even walking surfaces. ${ }^{118}$ Adequate sidewalk width is also an important factor for prompting people to walk, ${ }^{119}$ and, in fact, both the Federal Highway Administration and the influential Institute of Transportation Engineers (ITE) now recommend a 5 -foot minimum width for sidewalks to allow two people to comfortably pass each other or walk side-by-side. ${ }^{120} 5$-foot sidewalks are likely adequate in residential areas, but even greater widths (6 ft. +) are recommended for areas with high concentrations of pedestrians, such as schools, at transit stops, and city centers. ${ }^{121}$ However, even with adequate

\footnotetext{
${ }^{114}$ Richard C. Harruff, et al., "Analysis of Circumstances and Injuries in 217 Pedestrian Traffic Fatalities,” Accident Analysis \& Prevention 30, no. 1 (January 1998): 12-13; Mats Öström and Anders Eriksson, "Pedestrian Fatalities and Alcohol," Accident Analysis \& Prevention 33, no. 2 (March 1, 2001): 173-180; U.S. Department of

Transportation, Federal Highway Administration, "Safety Benefits of Walkways, Sidewalks, and Paved Shoulders.”

${ }^{115}$ U.S. Department of Transportation, National Highway Traffic Safety Administration, Pedestrian Roadway Fatalities, April 2003, 2; Harruff, et al., 12-14.

${ }^{116}$ Harruff, et al., 12-13.

${ }^{117}$ C. E. Kelly et al., "A Comparison of Three Methods for Assessing the Walkability of the Pedestrian Environment," Journal of Transport Geography 19, no. 6 (November 2011): 1503.

${ }^{118}$ Chanam Lee, et al., "Neighborhood Walking among Overweight and Obese Adults: Age Variations in Barriers and Motivators," Journal of Community Health 38, no. 1 (February 2013): 17.

${ }^{119}$ Fang Wang, et al., "Urban Planning and Design of Pedestrian Space from Perspectives of Fitness," Procedia Engineering 21 (2011): 365.

${ }^{120}$ University of North Carolina Highway Safety Research Center, Pedestrian and Bicycle Information Center, "Sidewalks and Walkways,"

http://www.pedbikeinfo.org/planning/facilities ped sidewalks.cf m (Accessed February 23, 2014).

${ }^{121}$ Ibid.; U.S. Department of Transportation, Federal Highway

Administration, "Designing Sidewalks and Trails for Access," 4.3.3
} 
width, speed and overall efficiency often trumps everything when it comes to choosing to walk versus utilizing other modes of travel. ${ }^{122}$ In other words, if people have to walk some distance just to get to a sidewalk which then takes them on a circuitous path to their destination then it is likely they will find other means to get where they are going. In light of these factors, assessing the adequacy of the sidewalk itself in a given location is the most basic of walkability assessments because it is the sidewalk that is the most critical element in the pedestrian environment.

Width,

http://www.fhwa.dot.gov/environment/bicycle pedestrian/public ations/sidewalks/chap4a.cfm (Accessed February 23, 2014); University of North Carolina Highway Safety Research Center, National Center for Safe Routes to School, "How Wide Should a Safe Routes to School Sidewalk be to Meet ADA Specifications?," http://www. saferoutesinfo.org/program-tools/how-wide-should$\underline{\text { safe-routes-school-sidewalk-be-meet-ada-specifications (Accessed }}$ February 23, 2014).

${ }^{122}$ Puay Ping Koh and Yiik Diew Wong, "Comparing Pedestrians' Needs and Behaviours in Different Landuse Environments," Journal of Transport Geography 26 (January 2013): 50. 


\subsection{Tools and strategies for performing sidewalk audits}

Analyses of sidewalks can be performed for a myriad of reasons, therefore, audit tools and methodologies from one study to another can be expected to be different as well. However, the majority of the readily-available academic literature on this topic consists of the broader walkability assessments described above, not of sidewalk audits. ${ }^{123}$ A large number of such studies were consulted prior to the audit of Fremont sidewalks and many of these, perhaps due to their broader focus, use flexible assessment techniques which can be modified and tailored to suit the needs of the research. While there appears to be no single or clear best practice, a common tool that is used for assessing walking environments is the checklist or questionnaire format where a reviewer performs an assessment on foot. Frequently, the results from these types of "walking audits" are tabulated in some way and used for a statistical analysis and ensuing discussion. A huge number of tools using some variation of this format has been developed and tested, ${ }^{124}$ and there seems to be no limit to the ability of researchers to customize, combine, and/or create new instruments. Indeed, many studies have been undertaken for this very reason: assessing a walking environment but only as a by-product of their main objective of testing the reliability of their assessment tool. ${ }^{125}$

Along with this format, many walkability studies highlight the advantage of combining manual, on-theground data collection with mapping technology such as geographic information systems (GIS) and Street View

\footnotetext{
${ }^{123}$ A possible reason for this is that sidewalk assessments may fall under the realm of Transportation Asset Management Plans administered at a local level. For example, cities may create an inventory of all sidewalks in their jurisdiction and periodically assess and record their condition. Such data may also be made available in publically available Pedestrian Master Plans. Sidewalk data could therefore already be available to researchers without having to perform their own analysis. In the case of Fremont, no such data was available at the time this project was undertaken.

${ }^{124}$ University of North Carolina Highway Safety Research Center, Pedestrian and Bicycle Information Center, "Audits."

${ }^{125}$ Marlon Boarnet, et al., "The Street Level Built Environment and Physical Activity and Walking," Environment and Behavior 43, no. 6 (November, 1 2011): 735-775; Ross C. Brownson et al., "Reliability of Two Instruments for Auditing the Environment for Physical Activity, "Journal of Physical Activity and Health 1 (2004): 189-207; Matthew P. Buman et al., "The Stanford Healthy Neighborhood Discovery Tool: A Computerized Tool to Assess Active Living Environments," American Journal of Preventive Medicine 44, no. 4 (April 2013): 41-47; C. E. Kelly et al., 1500-1508; Habib Chaudhury et al., 433-454.
}

in Google Maps. ${ }^{126}$ These can aid in selecting audit areas, provide a deeper level of analysis, or replace onthe-ground data collection altogether. Another common strategy is finding ways to increase the ease and speed of data collection by using portable electronics in the field to record audit results. ${ }^{127}$ Tablets, smart phones, and other tools can all provide technologically savvy users with a more efficient alternative to pen and paper data collection, although their upfront costs can be prohibitive for some people. Additionally, several smartphone applications have been recently developed (e.g., Walk Score and Walkanomics) which can provide users with simple, informal ratings of the walking environment in a given area.

As mentioned, there is no recognized best practice for choosing an audit tool, or, if developing your own, what the exact contents of one should be. Differing sample sizes, research objectives, locations, and more can create enough uniqueness from study to study that each could warrant the development of its own customized technique and tool. Because the questionnaire format is easy, flexible, and inexpensive, it is likely one of the most commonly utilized techniques, and is why it was employed for this study. User skill and financial resources can also dictate an audit's level of technological sophistication and integration of the available tools. This study was mindful of these constraints while making use of technology where it yielded time and cost savings and strengthened research activities. As will be discussed, GIS was utilized for segment selection and post-audit analysis, Google Maps was utilized for pre-audit analysis, and portable devices (Acer netbook and Apple iPad) were used for data collection in the field.

\footnotetext{
${ }^{126}$ Terri J. Pikora et al., "Developing a Reliable Audit Instrument to Measure the Physical Environment for Physical Activity," American Journal of Preventive Medicine 23, no. 3 (October 2002): 187-194; Ross C. Brownson et al., 189-207; Xuemei Zhu and Chanam Lee: 282-90; Andrew G. Rundle et al., "Using Google Street View to Audit Neighborhood Environments," American Journal of Preventive Medicine 40, no. 1 (January 2011): 94-100.

${ }^{127}$ Matthew P. Buman et al.; UCLA, Center for Occupational and Environmental Health, "About P.E.Q.I.,"

http://www.peqiwalkability.appspot.com/about.jsp (Accessed December 1, 2013).
} 


\subsection{Description of the selected audit instrument}

After extensive research on the topic of pedestrian travel and reviewing many studies where audit tools were used, the Pedestrian Environment Data Scan (PEDS) Tool was chosen for auditing sidewalks in Fremont, though in a significantly abbreviated form. This tool was developed in 2004 by Kelly J. Clifton, $\mathrm{PhD}$ and Andrea D. Livi Smith, PhD of the University of Maryland, Urban Studies and Planning Program. It was developed "to measure environmental features that relate to walking in varied environments in the U.S... [and] to specifically address pedestrian concerns as well as minimize [audit] cost and implementation time.”128

The PEDS Tool uses a questionnaire format consisting of 35 questions covering four categories (Environment, Pedestrian Facility, Road Attributes, Walking/Cycling Environment) which are used to capture quantitative and qualitative data on a single street segment (i.e., intersection to intersection, both sides of the street). ${ }^{129}$ Clifton and Smith's description of the methodology used to develop the tool along with a discussion of the tool's accuracy was published in a Landscape and Urban Planning article in March 2007 and can be consulted for more background. ${ }^{130}$ Additionally, the PEDS Tool was used in February 2013, prior to the design of this research, to audit eight Fremont street segments as part of an assignment for a graduate course in the Department of Urban and Regional Planning at San José State University. ${ }^{131}$ The tool's ease of use and accuracy was confirmed during this assignment.

Along with being chosen for its familiarity, the tool was chosen because it is simple and has an easily customizable structure. This flexibility was important because the full PEDS Tool is essentially designed for holistic walkability assessments and not for assessing just

${ }^{128}$ Kelly J. Clifton, "PEDS - Pedestrian Environment Data Scan," http://kellyjclifton.com/products/peds/ (Accessed December 1, 2013). ${ }^{129}$ Kelly J. Clifton, "PEDS Instrument v.2,"

http: / / www.kellyjclifton.com/PEDS/PEDSInstrument.v.2.pdf (Accessed February 16, 2013).

${ }^{130}$ Kelly J. Clifton, Andréa D. Livi Smith, and Daniel Rodriguez, "The Development and Testing of an Audit for the Pedestrian

Environment," Landscape and Urban Planning 80, no. 1-2 (March 2007): 95110.

${ }^{131}$ Audit performed by author for URBP 256, a master's course at San José State University. The course was taught in the Spring 2013 semester by Eduardo C. Serafn, PE, AICP. the sidewalk. Using the tool's Pedestrian Facility category as a template, a 9-question audit was developed which focused exclusively on the basic condition and continuity of sidewalks (see table 1). These nine questions were based on questions which appear in the PEDS Tool and were selected for their relevance and importance in addressing the critical factors for walking discussed in section 2.1. While a strength of PEDS Tool is its reliance on both objective and subjective analysis on the part of the auditor, the selected questions were nonetheless modified to avoid as much ambiguity during data collection as possible and add an additional measure of objectivity. This was also done to ensure that audit questions would be clear to the two non-specialist assistants who were recruited to aid in the data collection.

Unlike the PEDS Tool, these nine questions were asked of only one side of the street rather than both. This was due to the research aim of exploring zoning as a determinant of provision and quality-zoning can be different depending on the side of the street so auditing both sides in such a situation would give conflicting results. This will be discussed in more detail in the next section. The audit was performed over a nine day period in early February 2014. 
Table 1. Final 9-Question Audit Instrument used to assess sidewalks in Fremont in February 2014

\begin{tabular}{|c|c|}
\hline Question & Answer \\
\hline $\begin{array}{l}\text { 1. Is there a paved or stone public } \\
\text { pedestrian sidewalk along the segment? }\end{array}$ & $\begin{array}{l}\text { A. Yes (go to Question 2) } \\
\text { B. No (STOP - audit is complete) }\end{array}$ \\
\hline $\begin{array}{l}\text { 2. What is the sidewalk } \\
\text { condition/maintenance like? }\end{array}$ & $\begin{array}{l}\text { A. Poor (many bumps/cracks/holes/vandalism): A } \\
\text { stroller or wheelchair cannot be pushed along the } \\
\text { sidewalk without many jarring motions; and/or } \\
\text { sidewalk clearly needs to be replaced (patches would } \\
\text { not be sufficient) } \\
\text { B. Fair (some bumps/cracks/holes/vandalism): A } \\
\text { stroller or wheelchair can easily be pushed along the } \\
\text { sidewalk with few jarring motions to the passenger; } \\
\text { and/or sidewalk only needs patches or other minor } \\
\text { repair. } \\
\text { C. Good (very few bumps/cracks/holes/vandalism): A } \\
\text { stroller or wheelchair can easily be pushed along the } \\
\text { sidewalk without jarring motions to the passenger; } \\
\text { and/or sidewalk needs no repair at this time. } \\
\text { D. Under Repair (being resurfaced/reconfigured/etc.): } \\
\text { There is evidence of work being done to } \\
\text { improve/repair the sidewalk itself, not the } \\
\text { surrounding area or ground under the sidewalk such as } \\
\text { for utilities. }\end{array}$ \\
\hline $\begin{array}{l}\text { 3. Is the path fully or partially obstructed by } \\
\text { a permanent/semi-permanent object } \\
\text { (e.g., signs, power poles, tree roots, } \\
\text { etc.)? }\end{array}$ & $\begin{array}{ll}\text { A. } & \text { Yes } \\
\text { B. No }\end{array}$ \\
\hline $\begin{array}{l}\text { 4. What is the sidewalk width along most of } \\
\text { this segment? }\end{array}$ & $\begin{array}{l}\text { A. Less than } 5 \text { feet } \\
\text { B. B. Greater than } 5 \text { feet }\end{array}$ \\
\hline $\begin{array}{l}\text { 5. What is the average grade and cross slope } \\
\text { of the sidewalk along this segment, not } \\
\text { including the natural slope/topography } \\
\text { where the path lies (i.e., on a hill) }\end{array}$ & $\begin{array}{l}\text { A. Flat (little to no variation in grade) } \\
\text { B. Some minor variations in grade (resulting from a few } \\
\text { natural or manmade features, including driveways } \\
\text { through the path) } \\
\text { C. Many significant variations in grade (resulting from a } \\
\text { few natural or manmade features) }\end{array}$ \\
\hline $\begin{array}{l}\text { 6. What is the average distance from the } \\
\text { curb along this segment? }\end{array}$ & $\begin{array}{l}\text { A. At curb } \\
\text { B. } 0-4 \text { feet } \\
\text { C. } 5-8 \text { feet } \\
\text { D. More than } 8 \text { feet } \\
\text { E. Varies too greatly for meaningful average (e.g., } \\
\quad \text { irregular shaped landscaped parking strip, meandering } \\
\text { path, etc.) }\end{array}$ \\
\hline 7. Is the sidewalk complete? & $\begin{array}{l}\text { A. Yes (does not have any breaks within the segment) } \\
\text { B. No (ends or has gaps within the segment) }\end{array}$ \\
\hline $\begin{array}{l}\text { 8. Are there curb cuts at BOTH the ends of } \\
\text { this segment (i.e., at the intersections), } \\
\text { or at one end of the segment if on a dead- } \\
\text { end or cul-de-sac? }\end{array}$ & $\begin{array}{l}\text { A. Yes } \\
\text { B. No }\end{array}$ \\
\hline $\begin{array}{l}\text { 9. Is there a marked crosswalk present at AT } \\
\text { LEAST ONE segment intersection, } \\
\text { within the segment itself, or within the } \\
\text { immediately adjacent segments that can } \\
\text { be seen from this segment? }\end{array}$ & $\begin{array}{l}\text { A. } \quad \text { Yes } \\
\text { B. No }\end{array}$ \\
\hline
\end{tabular}




\subsection{Methodology for selecting street segments}

As discussed in section 1.4, land use will often have a direct impact on walking and other transportation options. With regard to pedestrian infrastructure like sidewalks, anecdotal experience tells us that paths look and feel different depending on whether we are walking on a street with single-family homes, grocery stores and banks, or factories. The hypothesis of this undertaking was that there is indeed a quantitative difference which can be illustrated by assessing an equal number of Fremont street segments which are zoned either residential or non-residential.
For statistical simplicity, and due to time limitations, it was decided that 100 total segments would be audited - 50 residential and 50 non-residential. By consulting the City of Fremont's current Zoning Ordinance and utilizing its free, online Public GIS Mapping Application showing zoning districts defined in the current Ordinance, ${ }^{132}$ these segments were selected somewhat randomly. Due to this study's deviation from the PEDS methodology of auditing both sides of street segment, it was necessary to qualify what would constitute a segment (see figure 5).
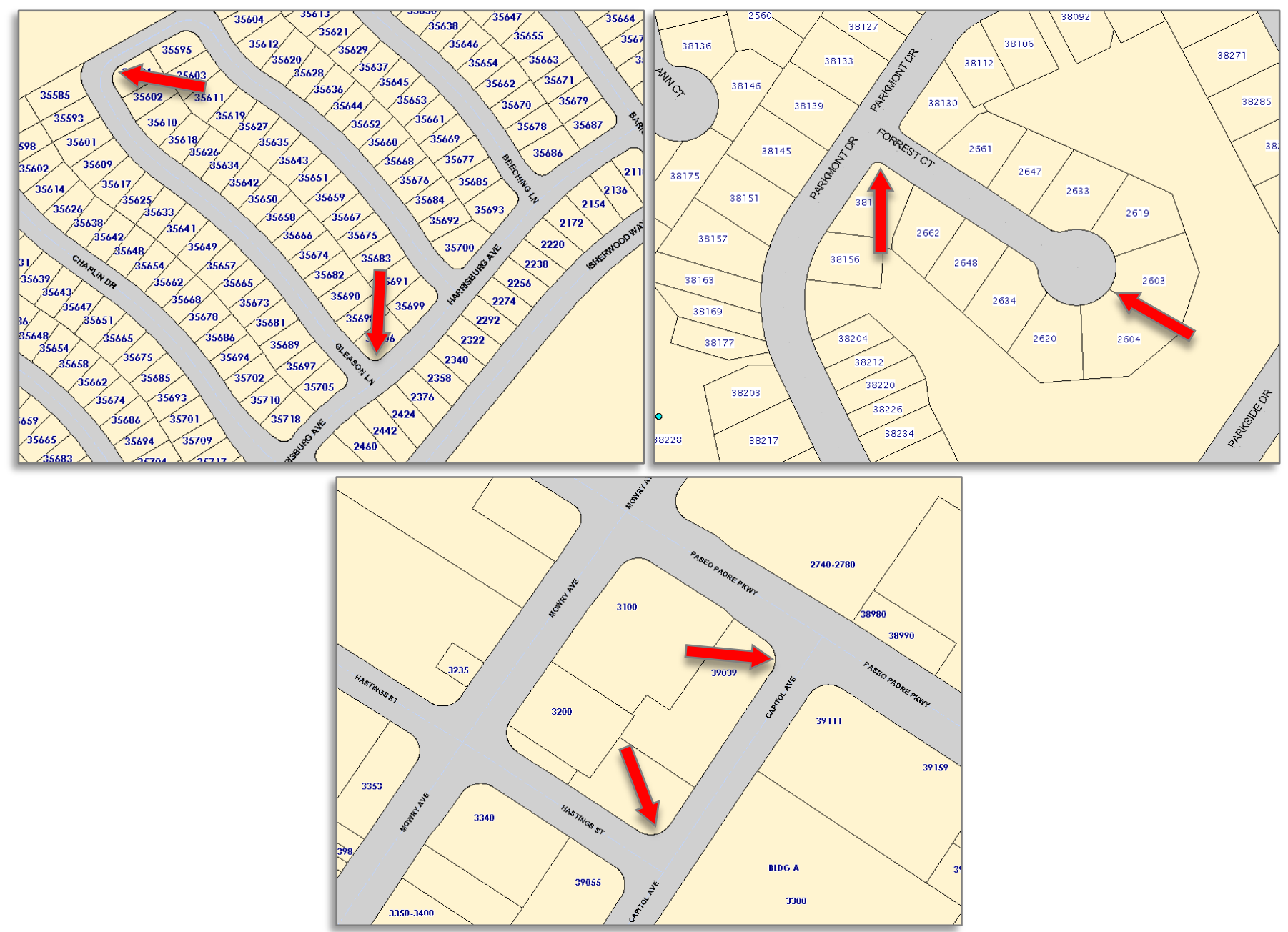

Figure 5. Locating segment termini using the Public GIS Mapping Application. The research objective of auditing a single side of a street, plus Fremont's many asymmetrical blocks, required that the end of a segment also include any 90-degree turn. Red arrows indicate segment termini. (Source: City of Fremont, "Public GIS Mapping Application,” February 2014, http:/ /gis.ci.fremont.ca.us/public/mapindex.cfm, Accessed February 1, 2014)

132 City of Fremont, "Public GIS Mapping Application," February 2013, http:// gis.ci.fremont.ca.us/public/mapindex.cfm (Accessed February 1, 2013); City of Fremont HelpDesk, I.T. Services, email message, September 23, 2013. 


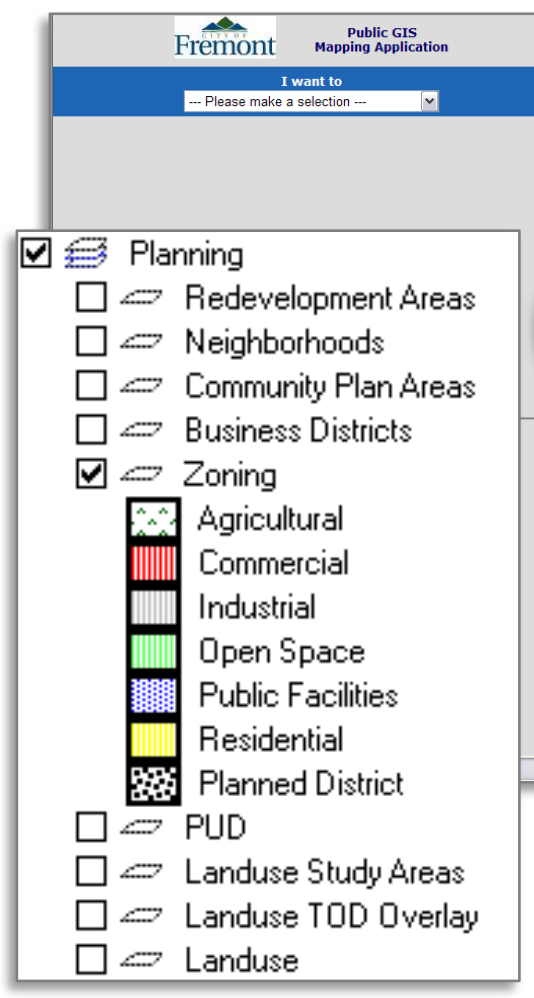

"Segments" are normally defined as being from intersection to intersection and include both sides of the street. Such a definition is not suited to audits which consider zoning because zoning districts are drawn across a city in a patchwork manner, changing midblock and often varying according to the side of the street. To account for this, and ensure that a diversity of locations around the city could be chosen without being limited to streets wholly within a single zoning district, it was judged more effective to select and audit only one side of the street. It was therefore necessary to restrict a "street segment" to only a single side of the street and expand the definition of segment termini to include not only breaks in the sidewalk due to an intersection but also to any 90 degree change in sidewalk direction (i.e., a corner). This expanded definition of termini was also needed to accommodate the dominant asymmetrical, suburban street design and land use patterns in Fremont which consist of a large number of cul-de-sacs, many smaller "island" blocks, and virtually no areas with a grid design or symmetrical blocks. Figures 5 and 7 show how these challenges were overcome and how segments were defined and then selected.

Based on this definition, 50 residential and 50 nonresidential street segments were initially selected using the Public GIS Mapping Application. The "residential" category included areas zoned for single- or multifamily dwellings. The "non-residential" category essentially included all other Fremont zoning districts (i.e., industrial, institutional, public facilities, agricultural, open space, etc.). This selection process was greatly simplified by the Mapping Application's reduction of the City's 26 districts into seven general districts (see figure 6): Agricultural, Commercial, Industrial, Open Space, Public Facilities, Residential, and Planned District (an overlay district mostly consisting of commercial, residential and public facilities zoning). Regardless of land use, only sidewalks along public streets were selected. This excluded paths that do not follow the public right-of-way, such as those through parks, shopping centers, office buildings, and private housing developments. ${ }^{133}$

As a rule, in order to take into consideration the potential impact of commercial, industrial, and agricultural activity on transportation infrastructure, mixed-use residential segments (i.e., residential and non-residential zoning along a single segment) were

\footnotetext{
${ }^{133}$ While such paths, if they exist, are subject to the ADA requirements discussed in Chapter 1 , they do not constitute the majority of sidewalks in most cities or the most easily accessible ones, and their construction may not necessarily be required per local law. However, analysis of such paths could warrant a relevant, future investigation.
} 
categorized as non-residential if at least 25 percent of the segment contained non-residential zoning. In other words, if a segment was less than 75 percent residential zoning it would be categorized as non-residential. Due to an inability to automatically generate percentages, these calculations were rough approximations based on visual inspection of the segment using the Mapping Application. In the process of selecting the 100 segments, this rule was needed in only a few instances. Figure 7 illustrates the initial street segment selection process using the Mapping Application.

As mentioned, the research objective was to assess only those sidewalks which were along public streets. Therefore, after making an initial selection with the
Application, Google Maps Street View was utilized to verify whether the initially selected segment was along the public right-of-way (see figure 8). As a policy, Google only displays Street View images along public roads, ${ }^{134}$ therefore it is an ideal tool for quick verification of this sort. It also has the added value of having excellent, 360-degree imagery and has been demonstrated to be an efficacious tool for analyzing the built environment. ${ }^{135}$ After final verification of a street segment, a mid-block street address was obtained using the Mapping Application (corresponding street addresses are displayed for all parcels) and recorded in a Microsoft Excel master spreadsheet. The applicable side of the street (e.g., N, NE, NW, etc.) was also recorded. ${ }^{136}$

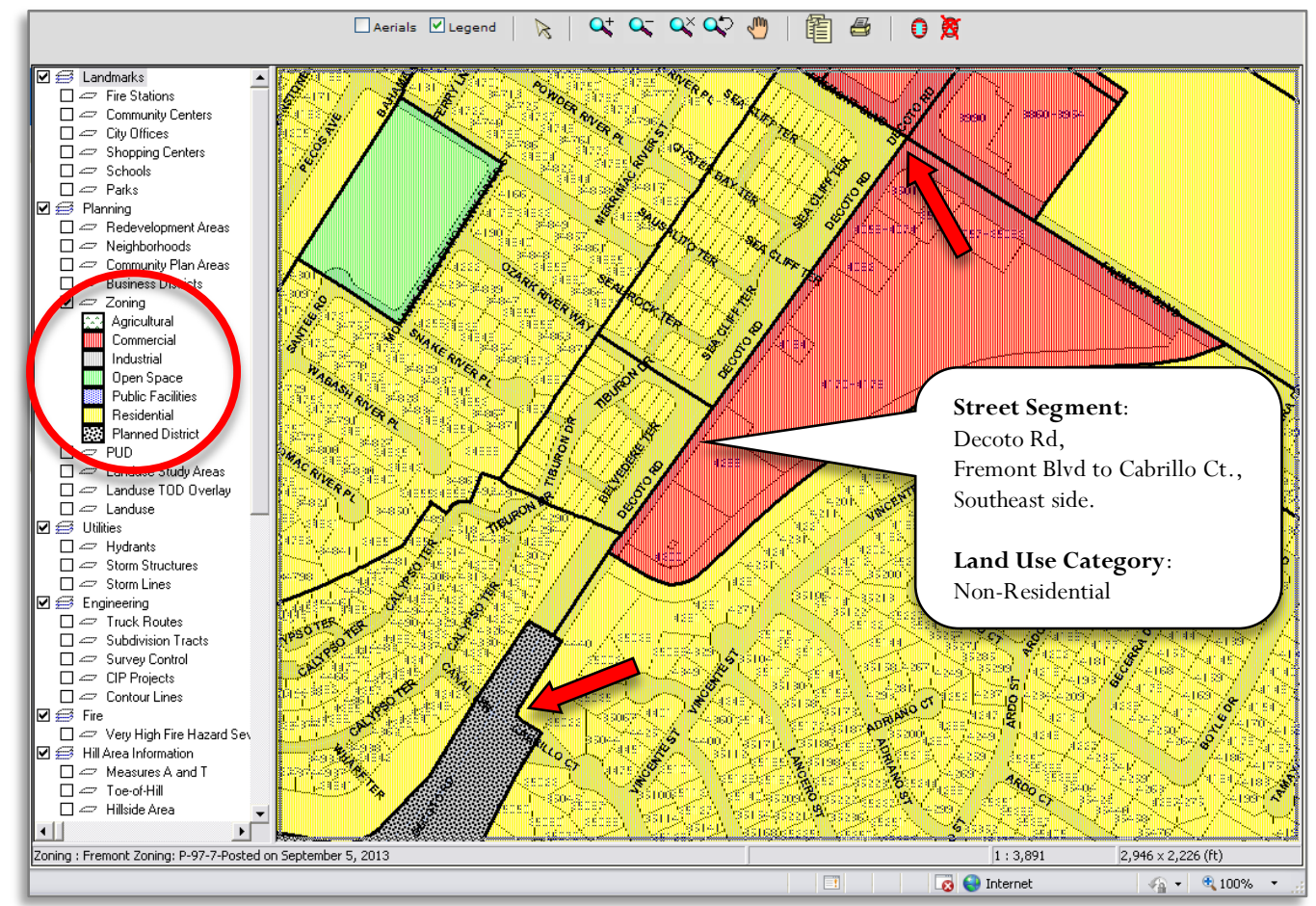

Figure 7. Street segment selection using the Public GIS Mapping Application.

(Source: City of Fremont, "Public GIS Mapping Application," February 2014, http://gis.ci.fremont.ca.us/public/mapindex.cfm, Accessed February 1, 2014)

Mapping Application, each segment needed to be verified as being publically accessible, that is, along the public right-of-way. This was required because the Mapping Application displays all streets, public and private, without providing the user an ability to differentiate. Final verification was especially necessary when selecting residential segments due to the many private housing developments and gated communities in Fremont. Because of this limitation of the Mapping
In initially-selected areas where both sides of the street are within the same zoning district, whether residential

\footnotetext{
${ }^{134}$ Google, "Privacy and Security,"

http://www.google.com/maps/about/behind-thescenes/streetview/privacy/ (Accessed February 16, 2014).

${ }^{135}$ Andrew G. Rundle et al.

${ }^{136}$ It was interesting to observe that there are very few north-south or east-west oriented streets in Fremont. Instead, street design and land use patterns follow the northwest-southeast orientation of much of East Bay, as dictated by its corresponding boundaries of the Diablo Range to the east and the San Francisco Bay shoreline to the west.
} 


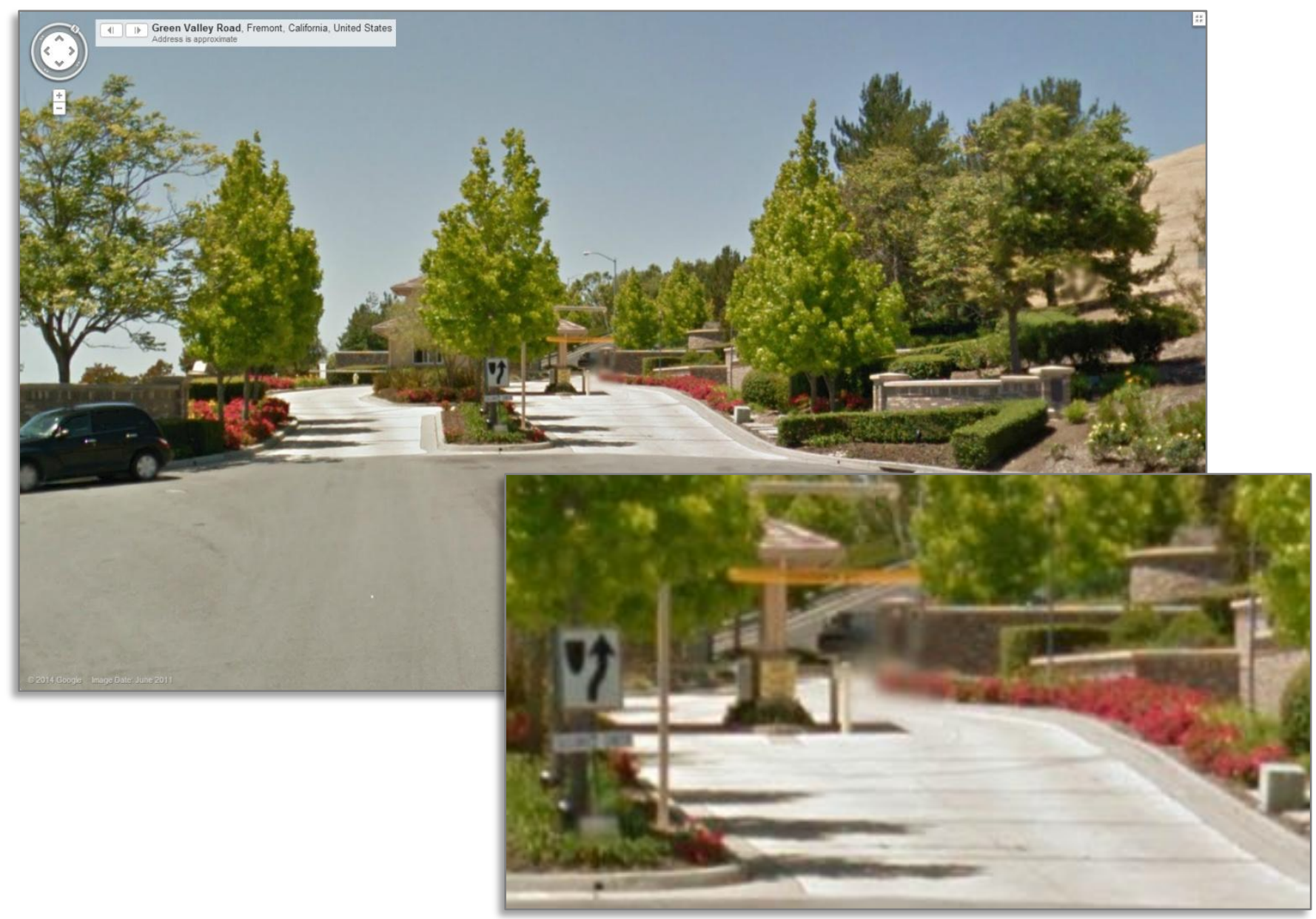

Figure 8. Beginning of a private road in Fremont. Many streets displayed in Fremont's Public GIS Mapping Application are private streets in multi-family developments or are in gated, single-family communities with restricted access, such as this one. Google Maps Street View is one of the quickest and best ways to verify whether a street is public or private. Note the presence of a security gate and markedly different pavement as the cul-de-sac ends. (Source: Google Maps, "Green Valley Rd, Fremont, CA 94539,"

http://maps.google.com, February 1, 2014)

or non-residential, either side of street would naturally be viable for auditing. In these instances, after verifying that the street was public, the side of the street for auditing was chosen arbitrarily, but with some effort to vary the side that was being selected relative to previously selected segments - the objective being to select a diverse mix of study segments from all possible street sides.

The primary goal in forming the list of study segments was to select segments in a fairly even geographic distribution across the vast city of Fremont, yet also allow for chance in the selection process. To do so, using the methods described thus far, study segments were selected by randomly focusing on an area of the city shown in the Mapping Application, zooming in to identify a suitable zoning district, then zooming in further in order to select a suitable street segment.
Additional locations were then chosen through a combination of arbitrarily navigating to a new area of the map and/or starting from the map's full extent and zooming to a new part of the city. In this way, audit locations were not systematically chosen (to allow some randomness) and the likelihood of selecting many segments in close proximity to one another was limited (to achieve somewhat even geographic distribution). ${ }^{137}$

Because this process was not automated and based on subjective approximations of what an "even" geographic distribution looked like at the time of selection, this method can only be described as somewhat-random.

\footnotetext{
${ }^{137}$ Selecting segments in close proximity to each other was permitted but care was taken to not select the same segment twice.
} 


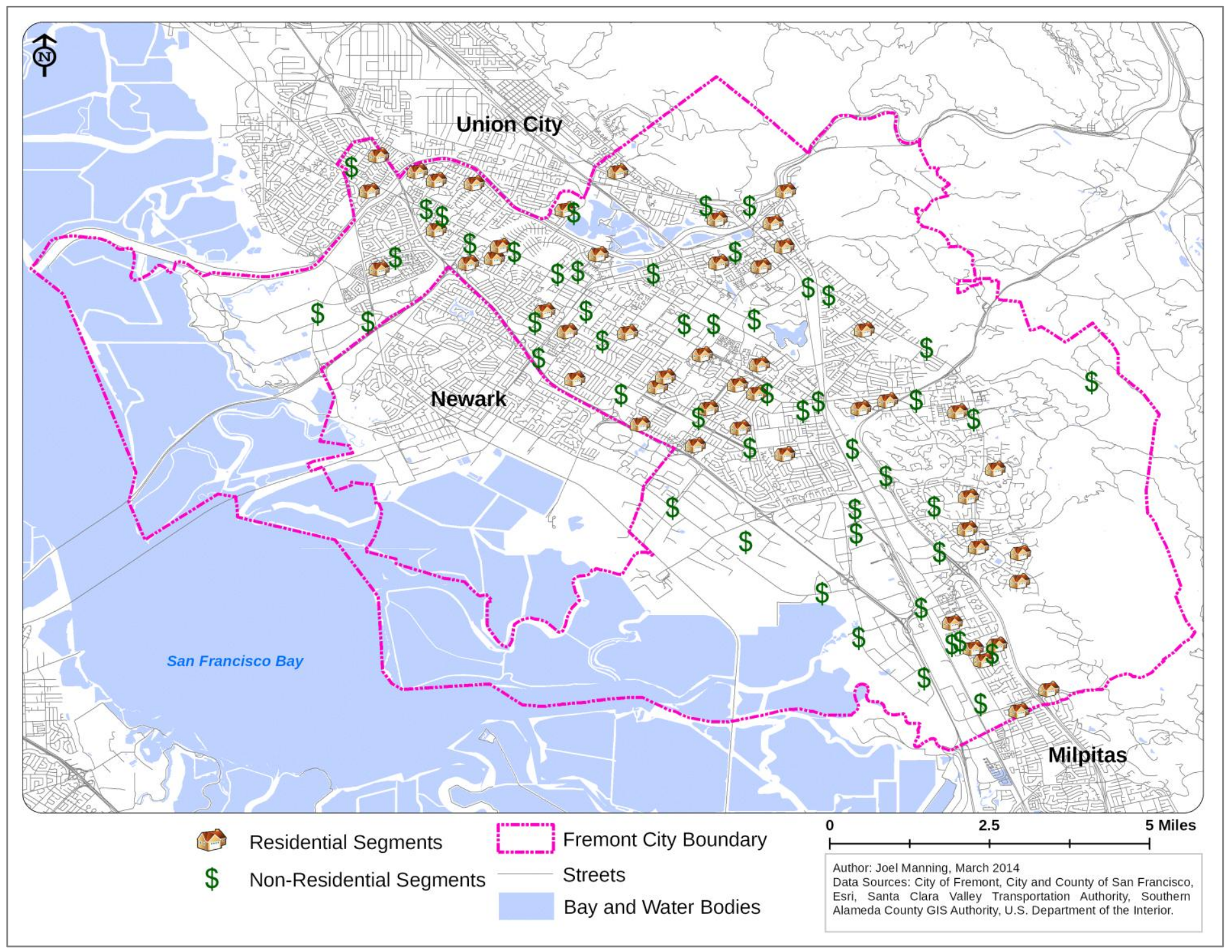

Figure 9. Final audited street segment locations in Fremont. (Source: Joel Manning)

Lastly, because this analysis was of segments within two distinct zoning categories, the list of study segments for each category was created independently of each other, that is, without respect to the geographic location of the segments in the other category. This was done by first selecting all 50 non-residential segments, followed by all 50 residential segments. ${ }^{138}$ However, this is not to suggest that selecting segments within both categories was done with the same level of ease. For example, selecting an even distribution of non-residential segments was more challenging given that there are much fewer areas of the city that are zoned nonresidential and have streets, thereby limiting the number of viable non-residential segments to choose from compared to residential segments.
As a result of choosing only one side of a street to audit, coupled with the necessity to verify the segment with Street View, automating the selection process was not a viable option. While it would be possible to randomly select entire street segments (i.e., intersection to intersection) in ArcGIS using advanced script writing, the streets shapefile provided by the City of Fremont, which is the most complete geospatial data available for the city, does not include sidewalks nor does it include sufficient information for selecting only one side of a particular street segment. Therefore, automated selection, at best, would only provide an initial list of street segments which would still have to be inspected one-by-one to ensure that there existed an auditable segment per the requirements described above.

\footnotetext{
${ }^{138}$ This order is inconsequential and was chosen arbitrarily.
} 


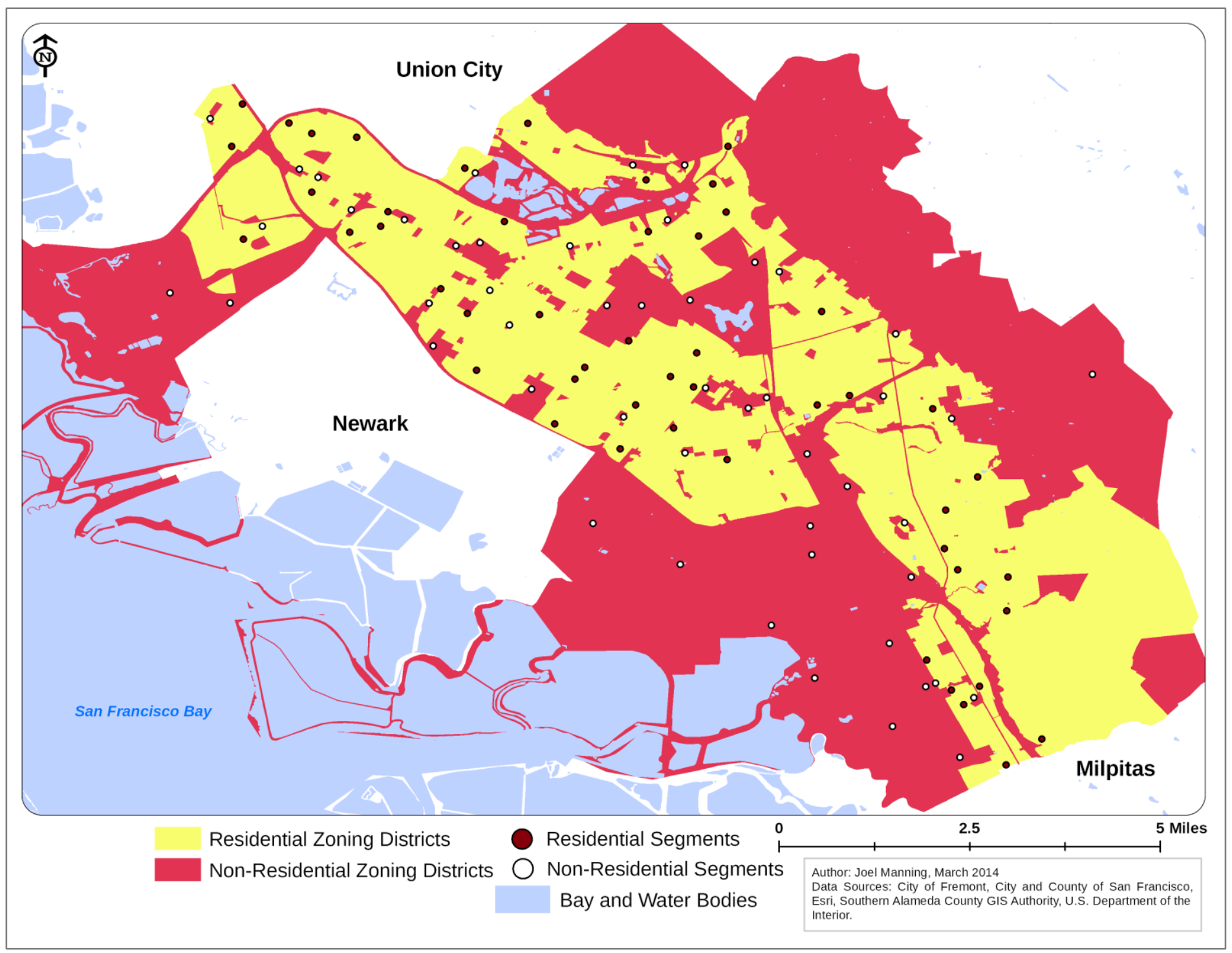

Figure 10. Audited segment locations and current City of Fremont zoning. (Source: Joel Manning)

Furthermore, such a process would also have to incorporate current zoning data from the City which would be slightly problematic because the City's zoning shapefile is less complete than the data shown in the Public GIS Mapping Application-the Mapping Application displays some very small zoning districts which the stand alone data omits (see figure 10). Additionally, the Mapping Application is updated regularly by the City, while the stand alone data is static. So, while the static data is useful for ascertaining an overview of the City's zoning, it had the potential to exclude some very small districts from the selection process. ${ }^{139}$

\footnotetext{
${ }^{139}$ A post-audit spatial analysis using the City's zoning shapefile revealed that of the segments chosen from these very small districts using the Mapping Application, all of them could have theoretically
}

To summarize, after preliminary investigation, the methodology that was used was determined to be faster and more accurate than employing automation processes in ArcGIS. Lastly, the chosen selection methodology is also advantageous because it relies heavily on a free, publically available, web-based mapping application which any Fremont resident could utilize to replicate the research reported here.

still been chosen using the shapefile because those particular districts are in fact included in the shapefile. Thus, while using the Mapping Application proved to be a more cautious approach and was therefore warranted, utilizing the shapefile for some aspect of the selection process would have been unlikely to be detrimental in any way. Consult the zoning map (figure 10) for more detail. 


\subsection{Methodology for post-audit income spatial analysis}

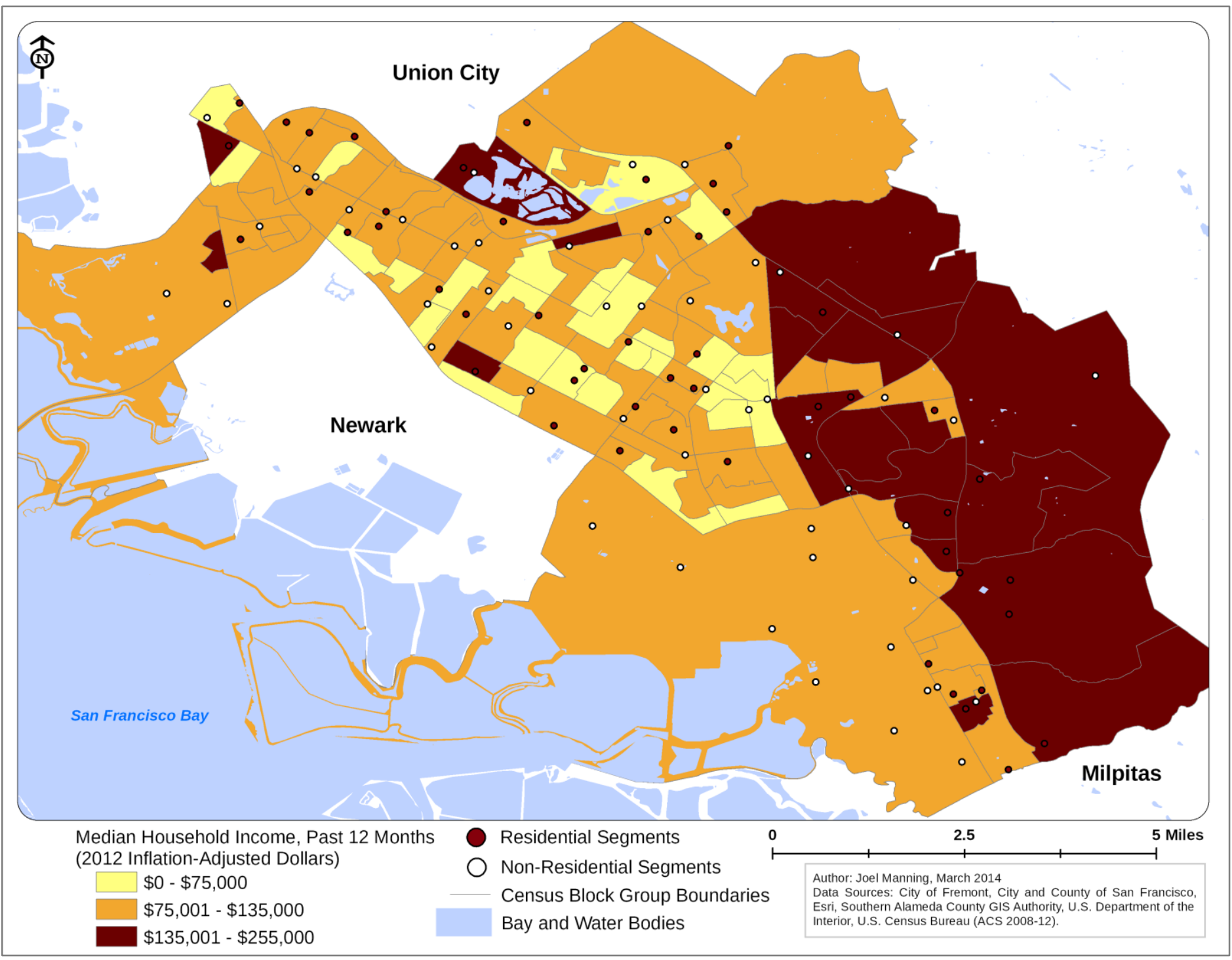

Figure 11. Audited segment locations with median household income by block group, American Community Survey (20082012). (Source: Joel Manning)

Sections 1.4 and 1.5 demonstrate that land use and income affect walking. For this reason, it was instructive to compare the collected audit data on each Fremont segment against the income levels within that segment's corresponding Census block group. This analysis was done in ArcGIS by overlaying 2012 American Community Survey (ACS) data (Median Household Income In The Past 12 Months, In 2012 InflationAdjusted Dollars) onto the segment location map (see figure 11). For simplicity of analysis, income was grouped into three defined categories (Low, Medium, and High) with each representing one third of the range of Fremont incomes reported in the ACS. In deciding what the range for these three categories should be, two points were taken into consideration. First, the 2012 ACS median household income for the State of California is $\$ 58,328$, while Alameda County is much higher at $\$ 70,500^{140}$ Second, the 2012 ACS median income for the City of Fremont was $\$ 101,648$ (versus a reported household average of $\$ 114,684) .{ }^{141}$ Because

\footnotetext{
${ }^{140}$ Amanda Noss, U.S. Census Bureau, Household Income: 2012, American Community Survey Briefs, September 2013, https://www.census.gov/prod/2013pubs/acsbr12-02.pdf (Accessed March 2, 2014); American FactFinder, U.S. Census Bureau, "Selected Economic Characteristics, 2012 American Community Survey 1-Year Estimates," http://factfinder2.census.gov/faces/tableservices/jsf/pages/produc tview.xhtml?src $=$ bkmk (Accessed March 3, 2014).

${ }^{141}$ City of Fremont, Office of Economic Development.
} 
Fremont's income range is higher than that of the State and County, the upper threshold for low income was rounded up from the County median and set at $\$ 75,000$. In order to place the City median in the middle of the income ranges, the upper threshold for medium income was set to $\$ 135,000$. The upper threshold high income was set to $\$ 255,000$, based on the highest level reported in the ACS. This categorization, while unsophisticated, initially appeared to create a fairly even spatial balance of the three income ranges. However, because Fremont is generally a higher income community, these ranges resulted in High and Medium Income block groups being more numerous than Low Income block groups. The results of this analysis are discussed in section 3.2.

Section 2.4 describes the methodology used for ensuring segments were selected from a relatively even geographic distribution of residential and nonresidential zoning districts. Ensuring that these same selections were also pulled from an even distribution of low, medium, and high income areas, however, was not an objective. Instead it was intended that segments be selected blindly with respect to income by means of selecting audit locations from a map without any demographic information (i.e., the Mapping Application map). Additionally, no demographic spatial analysis was done until after all 100 segments were selected. In this way, the objective was to ensure that income would be chosen more randomly than were the initial audit locations, which, as described, were not truly random selections due to data limitations. In other words, because no automation was used, the selected audit locations can only be considered somewhat-random with respect to land use, but "nearly-random" with respect to income. ${ }^{142}$

\footnotetext{
${ }^{142}$ As a Fremont resident and urban planning student, it is possible that my knowledge of the City's demographics may have skewed some of my selections toward areas I knew to have certain income levels. However, I am confident this is very unlikely due to my described methodology which restricted my selections to geographically diverse locations, and due to the limited number of non-residential street segments to choose from.
} 


\section{3 | SUMMARY OF SIDEWALK AUDIT FINDINGS}

\subsection{Summary of sidewalk audit findings: variation by zoning category}

The data collected from the early-February 2014 sidewalk audit was tabulated and organized by audit question. Table 2 summarizes the audit findings by zoning category.

Table 2. Summary of audit findings by zoning category

\begin{tabular}{|c|c|c|c|c|c|c|}
\hline Audit Question & $\begin{array}{l}\text { Total } \\
\text { Res. }\end{array}$ & $\begin{array}{l}\% \text { of } \\
\text { Res. }\end{array}$ & $\begin{array}{l}\text { Total } \\
\text { Non- } \\
\text { Res. }\end{array}$ & $\begin{array}{c}\% \text { of } \\
\text { Non- } \\
\text { Res. }\end{array}$ & $\begin{array}{c}\text { Total } \\
\text { Res. \& } \\
\text { Non- } \\
\text { Res. }\end{array}$ & $\begin{array}{l}\% \text { of } \\
\text { Total }\end{array}$ \\
\hline \multicolumn{7}{|l|}{ Question 1: Presence of sidewalk } \\
\hline Segments with sidewalk & 48 & $96 \%$ & 38 & $76 \%$ & 86 & $86 \%$ \\
\hline Segments without sidewalk & 2 & $4 \%$ & 12 & $24 \%$ & 14 & $14 \%$ \\
\hline Total & 50 & $100 \%$ & 50 & $100 \%$ & 100 & $100 \%$ \\
\hline \multicolumn{7}{|l|}{ Question 2: Condition } \\
\hline Poor condition & 1 & $2.1 \%$ & 0 & $0.0 \%$ & 1 & $1.2 \%$ \\
\hline Fair condition & 12 & $25.0 \%$ & 13 & $34.2 \%$ & 25 & $29.1 \%$ \\
\hline Good condition & 35 & $72.9 \%$ & 24 & $63.2 \%$ & 59 & $68.6 \%$ \\
\hline Under construction & 0 & $0.0 \%$ & 1 & $2.6 \%$ & 1 & $1.2 \%$ \\
\hline Total & 48 & $100 \%$ & 38 & $100 \%$ & 86 & $100 \%$ \\
\hline \multicolumn{7}{|l|}{ Question 3: Obstructions } \\
\hline Fully or partially obstructed & 3 & $6.3 \%$ & 15 & $39.5 \%$ & 18 & $20.9 \%$ \\
\hline Sidewalks unobstructed & 45 & $93.8 \%$ & 23 & $60.5 \%$ & 68 & $79.1 \%$ \\
\hline Total & 48 & $100 \%$ & 38 & $100 \%$ & 86 & $100 \%$ \\
\hline \multicolumn{7}{|l|}{ Question 4: Average width } \\
\hline Narrower than 5 feet & 46 & $95.8 \%$ & 28 & $73.7 \%$ & 74 & $86.0 \%$ \\
\hline Wider than 5 feet & 2 & $4.2 \%$ & 10 & $26.3 \%$ & 12 & $14.0 \%$ \\
\hline Total & 48 & $100 \%$ & 38 & $100 \%$ & 86 & $100 \%$ \\
\hline \multicolumn{7}{|l|}{ Question 5: Average grade and cross-slope } \\
\hline Overall flatness & 29 & $60.4 \%$ & 20 & $52.6 \%$ & 49 & $57.0 \%$ \\
\hline Minor variations in grade/cross-slope & 17 & $35.4 \%$ & 16 & $42.1 \%$ & 33 & $38.4 \%$ \\
\hline Many significant variations in grade/cross-slope & 2 & $4.2 \%$ & 2 & $5.3 \%$ & 4 & $4.7 \%$ \\
\hline Total & 48 & $100 \%$ & 38 & $100 \%$ & 86 & $100.0 \%$ \\
\hline
\end{tabular}




\begin{tabular}{|c|c|c|c|c|c|c|}
\hline Audit Question & $\begin{array}{c}\text { Total } \\
\text { Res. }\end{array}$ & $\begin{array}{l}\% \text { of } \\
\text { Res. }\end{array}$ & $\begin{array}{c}\text { Total } \\
\text { Non- } \\
\text { Res. }\end{array}$ & $\begin{array}{c}\% \text { of } \\
\text { Non- } \\
\text { Res. }\end{array}$ & $\begin{array}{c}\text { Total } \\
\text { Res. \& } \\
\text { Non- } \\
\text { Res. }\end{array}$ & $\begin{array}{c}\% \text { of } \\
\text { Total }\end{array}$ \\
\hline \multicolumn{7}{|c|}{ Question 6: Average distance from curb } \\
\hline At curb & 19 & $39.6 \%$ & 5 & $13.2 \%$ & 24 & $27.9 \%$ \\
\hline $0-4$ feet from curb & 5 & $10.4 \%$ & 9 & $23.7 \%$ & 14 & $16.3 \%$ \\
\hline 5-8 feet from curb & 19 & $39.6 \%$ & 11 & $28.9 \%$ & 30 & $34.9 \%$ \\
\hline More than 8 feet from curb & 1 & $2.1 \%$ & 1 & $2.6 \%$ & 2 & $2.3 \%$ \\
\hline Too great of variation for estimates & 4 & $8.3 \%$ & 12 & $31.6 \%$ & 16 & $18.6 \%$ \\
\hline Total & 48 & $100 \%$ & 38 & $100 \%$ & 86 & $100.0 \%$ \\
\hline \multicolumn{7}{|l|}{ Question 7: Completeness } \\
\hline Without breaks/gaps & 41 & $85.4 \%$ & 23 & $60.5 \%$ & 64 & $74.4 \%$ \\
\hline With breaks/gaps & 7 & $14.6 \%$ & 15 & $39.5 \%$ & 22 & $25.6 \%$ \\
\hline Total & 48 & $100 \%$ & 38 & $100 \%$ & 86 & $100.0 \%$ \\
\hline \multicolumn{7}{|l|}{ Question 8: Curb cuts } \\
\hline Ending with curb cuts & 35 & $72.9 \%$ & 33 & $86.8 \%$ & 68 & $79.1 \%$ \\
\hline Ending without curb cuts & 13 & $27.1 \%$ & 5 & $13.2 \%$ & 18 & $20.9 \%$ \\
\hline Total & 48 & $100 \%$ & 38 & $100 \%$ & 86 & $100.0 \%$ \\
\hline \multicolumn{7}{|l|}{ Question 9: Crosswalks } \\
\hline At least one crosswalk & 13 & $27.1 \%$ & 30 & $78.9 \%$ & 43 & $50.0 \%$ \\
\hline No crosswalks & 35 & $72.9 \%$ & 8 & $21.1 \%$ & 43 & $50.0 \%$ \\
\hline Total & 48 & $100 \%$ & 38 & $100 \%$ & 86 & $100.0 \%$ \\
\hline
\end{tabular}

The results of Question 1 show that 14 of the 100 audited segments did not have sidewalks, with a higher percentage of residential areas having sidewalks than non-residential areas (96\% vs. $76 \%)$. Therefore, the data collected using the eight subsequent questions concerns only the remaining 86 segments.

Overall, the audited Fremont sidewalks were found to be mostly in good $(68.6 \%)$ or fair $(29.1 \%)$ condition. The distribution between "fair" and "good" condition shows that the residential sidewalks are in slightly better condition than the non-residential sidewalks. Sidewalk obstructions were found to be much more common in non-residential areas with 39.5 percent being fully or partially obstructed compared to only 6.3 percent in residential areas. However, a much greater percentage of non-residential sidewalks (26.3\%) were found to be five feet or wider while only two such sidewalks (4.2\%) were observed along residential segments. Regardless, 86 percent of the total audited segments were found to have sidewalks narrower than five feet.
Average grade and cross-slope was similar on residential and non-residential sidewalks, and overall findings show that significant variations were uncommon $(4.7 \%)$. The average distances from the curb that were most commonly observed along all segments were five to eight feet (34.9\%) followed by at curb/none (27.9\%). Residential sidewalks were much more likely to be at curb (39.6\%) than non-residential (13.2\%) while nonresidential sidewalks were more likely to have the minimal 0-4-foot distance (23.7\%) than were residential sidewalks (10.4\%). Non-residential sidewalks also exhibited much more extreme variations in distance from the curb along a single segment than residential sidewalks (31.6\% vs. $8.3 \%)$. Overall, sidewalks more than eight feet from curb were rare with only two such instances observed.

The majority (74.4\%) of all audited sidewalks did not have breaks or gaps although path incompleteness was found to be much greater along non-residential segments where 39.5 percent had breaks or gaps (versus 
14.6 percent on residential segments). Curb cuts at both ends of a segment were slightly more common in non-residential areas $(86.8 \%)$ than in residential (72.9\%). Overall, segments ending without curb cuts were relatively uncommon among all audited sidewalks at 20.9 percent. Meanwhile, the audit observed an exactly even split between segments with and without crosswalks (43 and 43). This split was also almost exactly inverted among residential and non-residential segments, where 78.9 percent of non-residential segments had at least one crosswalk and 72.9 percent of residential segments had none. 


\subsection{Summary of sidewalk audit findings: variation by income category}

Table 3. Distribution of audit segments by income.

\begin{tabular}{|l|r|r|r|r|}
$\begin{array}{l}\text { Segment } \\
\text { Type }\end{array}$ & $\begin{array}{c}\text { Total } \\
\text { Low } \\
\text { Income }\end{array}$ & $\begin{array}{c}\text { Total } \\
\text { Medium } \\
\text { Income }\end{array}$ & $\begin{array}{c}\text { Total } \\
\text { High } \\
\text { Income }\end{array}$ & Total \\
\hline Res. & 5 & 31 & 14 & 50 \\
\hline Non-Res. & 7 & 35 & 8 & 50 \\
Total & $\mathbf{1 2}$ & $\mathbf{6 6}$ & $\mathbf{2 2}$ & 100 \\
\hline
\end{tabular}

A post-audit spatial analysis was performed in ArcGIS by overlaying the geocoded segment locations on a map displaying ACS income data by U.S. Census block group (see figure 11), where income was categorized as Low, Medium or High in the manner described in section 2.5. Because segments were chosen without respect to income, the distribution of audit segments by income was not known until the geocoded locations were overlaid and a summarizing analysis performed. Table 3 summarizes this distribution.

Because Medium and High Income block groups were more numerous, the likelihood of selecting segments within these two categories was much higher than from the Low Income category even with the nearly-random selection process that was used. As table 3 shows, 12 percent of audited segments were in Low Income block groups $(\$ 0-\$ 75,000), 66$ percent were in Medium Income block groups $(\$ 75,001-\$ 135,00)$, and 22 percent were in High Income block groups $(\$ 135,001$ $\$ 255,000)$. The full summary of the geospatial analysis is shown in table 4.

Table 4. Summary of audit findings by block group income range.

\begin{tabular}{|c|c|c|c|c|c|c|c|c|}
\hline Audit Question & $\begin{array}{c}\text { Total } \\
\text { Low } \\
\text { Income }\end{array}$ & $\begin{array}{c}\% \text { of } \\
\text { Low } \\
\text { Income }\end{array}$ & $\begin{array}{c}\text { Total } \\
\text { Med. } \\
\text { Income }\end{array}$ & $\begin{array}{c}\% \text { of } \\
\text { Med. } \\
\text { Income }\end{array}$ & $\begin{array}{c}\text { Total } \\
\text { High } \\
\text { Income }\end{array}$ & $\begin{array}{c}\% \text { of } \\
\text { High } \\
\text { Income }\end{array}$ & Total & $\begin{array}{l}\% \text { of } \\
\text { Total }\end{array}$ \\
\hline \multicolumn{9}{|l|}{ Question 1: Presence of sidewalk } \\
\hline Segments with sidewalk & 12 & $100 \%$ & 55 & $83 \%$ & 19 & $86 \%$ & 86 & $86 \%$ \\
\hline Segments without sidewalk & 0 & $0 \%$ & 11 & $17 \%$ & 3 & $14 \%$ & 14 & $14 \%$ \\
\hline Total & 12 & $100 \%$ & 66 & $100 \%$ & 22 & $100 \%$ & 100 & $100 \%$ \\
\hline \multicolumn{9}{|l|}{ Question 2: Condition } \\
\hline Poor condition & 0 & $0.0 \%$ & 1 & $1.5 \%$ & 0 & $0.0 \%$ & 1 & $1.2 \%$ \\
\hline Fair condition & 3 & $25.0 \%$ & 13 & $19.7 \%$ & 9 & $47.4 \%$ & 25 & $29.1 \%$ \\
\hline Good condition & 9 & $75.0 \%$ & 40 & $60.6 \%$ & 10 & $52.6 \%$ & 59 & $68.6 \%$ \\
\hline Under construction & 0 & $0.0 \%$ & 1 & $1.5 \%$ & 0 & $0.0 \%$ & 1 & $1.2 \%$ \\
\hline Total & 12 & $100 \%$ & 55 & $83 \%$ & 19 & $100 \%$ & 86 & $100 \%$ \\
\hline
\end{tabular}




\begin{tabular}{|c|c|c|c|c|c|c|c|c|}
\hline Audit Question & $\begin{array}{c}\text { Total } \\
\text { Low } \\
\text { Income }\end{array}$ & $\begin{array}{c}\% \text { of } \\
\text { Low } \\
\text { Income }\end{array}$ & $\begin{array}{c}\text { Total } \\
\text { Med. } \\
\text { Income }\end{array}$ & $\begin{array}{c}\% \text { of } \\
\text { Med. } \\
\text { Income }\end{array}$ & $\begin{array}{c}\text { Total } \\
\text { High } \\
\text { Income }\end{array}$ & $\begin{array}{c}\% \text { of } \\
\text { High } \\
\text { Income }\end{array}$ & Total & $\begin{array}{l}\% \text { of } \\
\text { Total }\end{array}$ \\
\hline \multicolumn{9}{|l|}{ Question 3: Obstructions } \\
\hline Fully or partially obstructed & 2 & $16.7 \%$ & 13 & $23.6 \%$ & 3 & $15.8 \%$ & 18 & $20.9 \%$ \\
\hline Sidewalks unobstructed & 10 & $83.3 \%$ & 42 & $76.4 \%$ & 16 & $84.2 \%$ & 68 & $79.1 \%$ \\
\hline Total & 12 & $100 \%$ & 55 & $100 \%$ & 19 & $100 \%$ & 86 & $100 \%$ \\
\hline \multicolumn{9}{|l|}{ Question 4: Average width } \\
\hline Narrower than 5 feet & 10 & $83.3 \%$ & 46 & $83.6 \%$ & 18 & $94.7 \%$ & 74 & $86.0 \%$ \\
\hline Wider than 5 feet & 2 & $16.7 \%$ & 9 & $16.4 \%$ & 1 & $5.3 \%$ & 12 & $14.0 \%$ \\
\hline Total & 12 & $100 \%$ & 55 & $100 \%$ & 19 & $100 \%$ & 86 & $100 \%$ \\
\hline \multicolumn{9}{|l|}{ Question 5: Average grade and cross-slope } \\
\hline Overall flatness & 9 & $75.0 \%$ & 31 & $56.4 \%$ & 9 & $47.4 \%$ & 49 & $57.0 \%$ \\
\hline Minor variations in grade/cross-slope & 3 & $25.0 \%$ & 21 & $38.2 \%$ & 9 & $47.4 \%$ & 33 & $38.4 \%$ \\
\hline Many significant variations in grade/cross-slope & 0 & $0.0 \%$ & 3 & $5.5 \%$ & 1 & $5.3 \%$ & 4 & $4.7 \%$ \\
\hline Total & 12 & $100 \%$ & 55 & $100 \%$ & 19 & $100 \%$ & 86 & $100.0 \%$ \\
\hline \multicolumn{9}{|l|}{ Question 6: Average distance from curb } \\
\hline At curb & 1 & $8.3 \%$ & 21 & $38.2 \%$ & 2 & $10.5 \%$ & 24 & $27.9 \%$ \\
\hline $0-4$ feet from curb & 5 & $41.7 \%$ & 8 & $14.5 \%$ & 1 & $5.3 \%$ & 14 & $16.3 \%$ \\
\hline 5-8 feet from curb & 3 & $25.0 \%$ & 16 & $29.1 \%$ & 11 & $57.9 \%$ & 30 & $34.9 \%$ \\
\hline More than 8 feet from curb & 0 & $0.0 \%$ & 2 & $3.6 \%$ & 0 & $0.0 \%$ & 2 & $2.3 \%$ \\
\hline Too great of variation for estimates & 3 & $25.0 \%$ & 8 & $14.5 \%$ & 5 & $26.3 \%$ & 16 & $18.6 \%$ \\
\hline Total & 12 & $100 \%$ & 55 & $100 \%$ & 19 & $100 \%$ & 86 & $100.0 \%$ \\
\hline \multicolumn{9}{|l|}{ Question 7: Completeness } \\
\hline Without breaks/gaps & 9 & $75.0 \%$ & 39 & $70.9 \%$ & 16 & $84.2 \%$ & 64 & $74.4 \%$ \\
\hline With breaks/gaps & 3 & $25.0 \%$ & 16 & $29.1 \%$ & 3 & $15.8 \%$ & 22 & $25.6 \%$ \\
\hline Total & 12 & $100 \%$ & 55 & $100 \%$ & 19 & $100 \%$ & 86 & $100.0 \%$ \\
\hline \multicolumn{9}{|l|}{ Question 8: Curb cuts } \\
\hline Ending with curb cuts & 10 & $83.3 \%$ & 44 & $80.0 \%$ & 14 & $73.7 \%$ & 68 & $79.1 \%$ \\
\hline Ending without curb cuts & 2 & $16.7 \%$ & 11 & $20.0 \%$ & 5 & $26.3 \%$ & 18 & $20.9 \%$ \\
\hline Total & 12 & $100 \%$ & 55 & $100 \%$ & 19 & $100 \%$ & 86 & $100.0 \%$ \\
\hline \multicolumn{9}{|l|}{ Question 9: Crosswalks } \\
\hline At least one crosswalk & 8 & $66.7 \%$ & 31 & $56.4 \%$ & 4 & $21.1 \%$ & 43 & $50.0 \%$ \\
\hline No crosswalks & 4 & $33.3 \%$ & 24 & $43.6 \%$ & 15 & $78.9 \%$ & 43 & $50.0 \%$ \\
\hline Total & 12 & $100 \%$ & 55 & $100 \%$ & 19 & $100.0 \%$ & 86 & $100.0 \%$ \\
\hline
\end{tabular}


Of the 100 total segments, all Low Income locations had sidewalks, 55 Medium Income segments (83\%) had sidewalks, and 19 High Income segments (83\%) had sidewalks. The only sidewalks found to be in poor condition or under construction were in a Medium Income block groups while sidewalks in good condition were prevalent in all income categories. Noticeable variation in condition occurred only with High Income segments where the number of sidewalks in either fair or good condition was nearly the same.

Obstructions were least common along High and Low Income segments, while 23.6 percent of Medium Income sidewalks were fully or partially obstructed. Sidewalk width was observed to be relatively similar in Low and Medium Income block groups with more than 80 percent of sidewalks being narrower than five feet. Sidewalks wider than 5 feet were even less common in High Income block groups where only one such sidewalk was found.

The majority of Low and Medium Income sidewalks were found to be flat, while an even number of High Income sidewalks were either flat or had minor variations in grade and/or cross-slope. Overall, Low Income sidewalks were observed to be the flattest. Sidewalks within this income range and the High Income category were scarcely observed to have no buffer between the path and the curb, while 38.2 percent of those in Medium Income block groups abutted the curb. Low Income block groups had the highest percentage of sidewalks between zero and four feet from curb, at 41.7 percent. Meanwhile, the greatest percentage of sidewalks five to eight feet from curb was found in High Income block groups, at 57.9 percent.

Sidewalk completeness was found to be relatively balanced across the three income ranges. However, High Income block groups were found to have the smallest percentage of breaks and gaps with just under 16 percent. Sidewalks ending with curb cuts were also found with equal frequency. For this feature, High Income block groups were found to have largest percentage with 26.3 percent of sidewalks ending without curb cuts. Segments within this income range also had the fewest crosswalks with 78.9 percent having no crosswalk at all. This is in contrast to Medium Income segments where over half had at least one crosswalk, and Low Income segments where two-thirds had a crosswalk. 


\section{4 | DISCUSSION AND POSSIBLE IMPLICATIONS OF SIDEWALK AUDIT FINDINGS}

\subsection{Discussion and implications of variation by land use}

The audit of 100 somewhat-random Fremont street segments yielded both surprising and predictable findings with respect to land use. However, overall findings are consistent with literature demonstrating variability in transportation infrastructure depending on land use. And as a newer, car-oriented suburb, Fremont is typical of the outlying areas discussed by Frank and Wells and Yang which tend to be less supportive of walking than older, urban areas. ${ }^{143}$

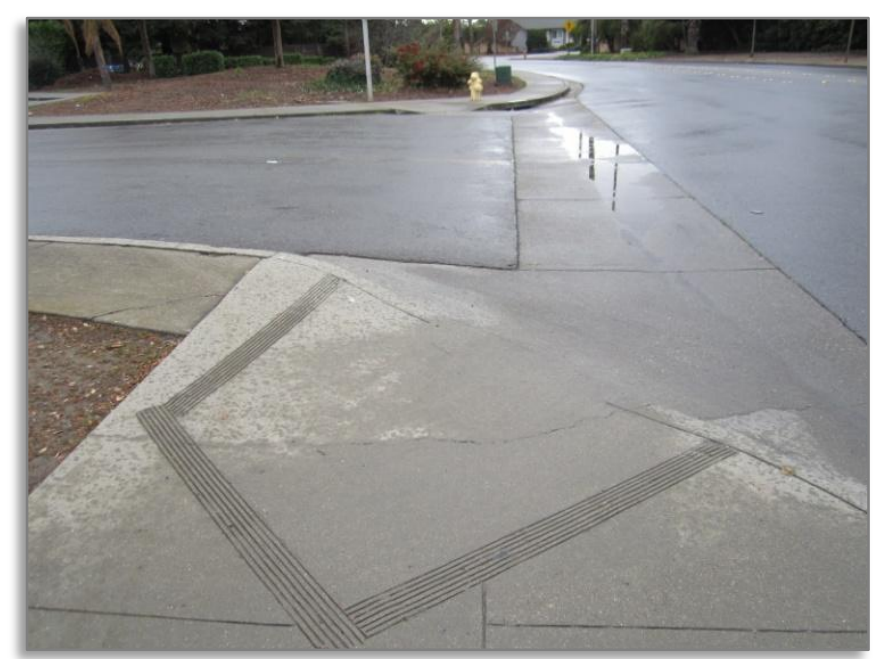

Figure 12. Break in sidewalk due to commercial driveway. This sidewalk near 40100 Las Palmas Ave is representative of the many driveways leading onto commercial properties and into parking lots which create gaps in the path. Note the curious strip of surface material through the gap which seems to signify that pedestrians are to zig-zag into the street, closer to traffic, then back onto the sidewalk. (Photo by author, February 2, 2014)

Starting from the first audit question, it was interesting to note that the segments without sidewalks were more common in non-residential areas. One factor which could partially explain this is that segments selected in open space zones were included in the non-residential category. This zoning district includes areas of Fremont with parks and less-developed land which may not be as likely to have sidewalks. Another factor is that many of the non-residential segments were in industrial districts, which make up a large portion of land use in Fremont. These areas tend to cater almost exclusively to automobiles, especially semi-trailer trucks. While there were exceptions to this, segments

\footnotetext{
${ }^{143}$ Nancy M. Wells and Yizhao Yang, 314; Lawrence D. Frank.
}

in these area were observed to be the least likely to have sidewalks. Interestingly, when sidewalks were present in industrial areas, they tended to very high quality, perhaps the result of being relatively new and unused.

As it was beyond the scope of this study, further investigation would be required to determine the relationship between each zoning district and the pedestrian infrastructure present. Such analysis may provide insights into some of the variability observed here. However, these findings suggest that Fremont does not currently offer the same amount of walking space in non-residential areas which may justify its current policy focus on the five key commercial areas described in section 1.7.

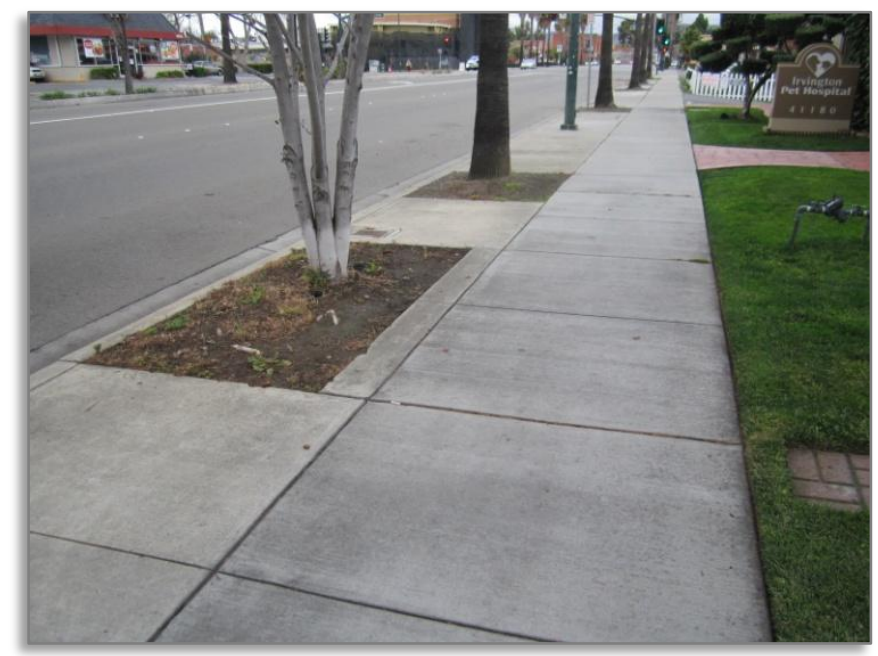

Figure 13. Alternating landscaping plots in parking strip. Plots like these near 41300 Fremont Blvd result in large variations in the distance from the curb. Since these areas are partially paved, who is to disagree with the pedestrian who walks here and sees the landscaping as an obstruction? (Photo by author, February 9, 2014)

Moreover, incompleteness was found to be greater along non-residential segments. Some of the breaks and gaps can be attributed to the inclusion of open space districts. But most of the incompleteness in nonresidential and residential areas was due to driveways cutting through paths. Such a break completely interrupts the path by greatly altering the cross-slope and/or making the sidewalk indistinguishable. This occurrence is especially common in front of commercial parcels where driveways tend to be much wider to accommodate vehicles entering and exiting a parking lot 
(see figure 12). As a result, such areas, which may attract a higher number of pedestrians, have a surprisingly large number of breaks and gaps which make them unpleasant for walking.

Equally surprising was the higher percentage of obstructions in non-residential areas, which presumably could have more pedestrian activity. This may be partially explained by the inclusion of the open space and industrial districts mentioned, although obstructions were found at relatively the same frequency throughout all the non-residential segments. This observation was also related to sidewalks in these areas having more extreme variations in distance from the curb. The most common causes of both obstructions and variation in distance along a segment were foliage and utilities. One especially common feature in commercial areas in Fremont is the presence of palm trees or other foliage planted in square plots along the path (see figure 13). While foliage could provide shade and enhance the path's aesthetic beauty, obstructions ultimately reduce the amount of available walking space and inhibit a pedestrian's ability to walk in a straight line. Another obstruction, common in both commercial and industrial, is from the placement of utility poles and traffic control cabinets in the middle of sidewalks (see figure 14).

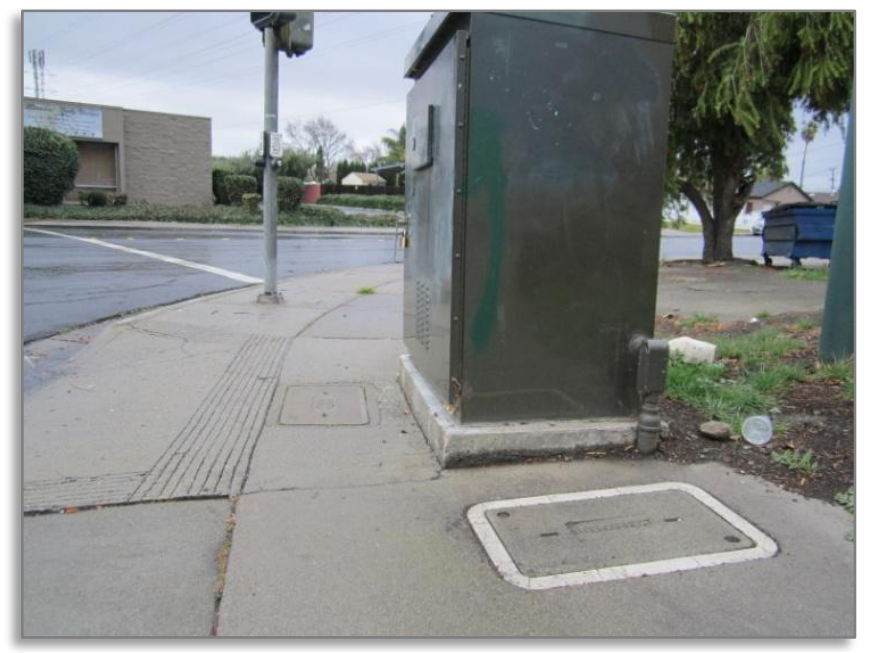

Figure 14. Obstruction due to traffic signal control

cabinet. Obstructions like this one near 40675 Grimmer Blvd are particularly common at crosswalks in commercial areas. (Photo by author, February 2, 2014)

Conversely, more crosswalks were observed on nonresidential segments, with the highest frequency being noted in commercial zones. This might be expected given that such areas may have a higher volume of pedestrians which in turn creates more potential for pedestrian-vehicle conflict. More cross-walks would thus be justified in these areas. However, fewer crosswalks in residential areas could imply that pedestrian safety is of lesser priority there, which is certainly not the message any city wants to send to its residents.

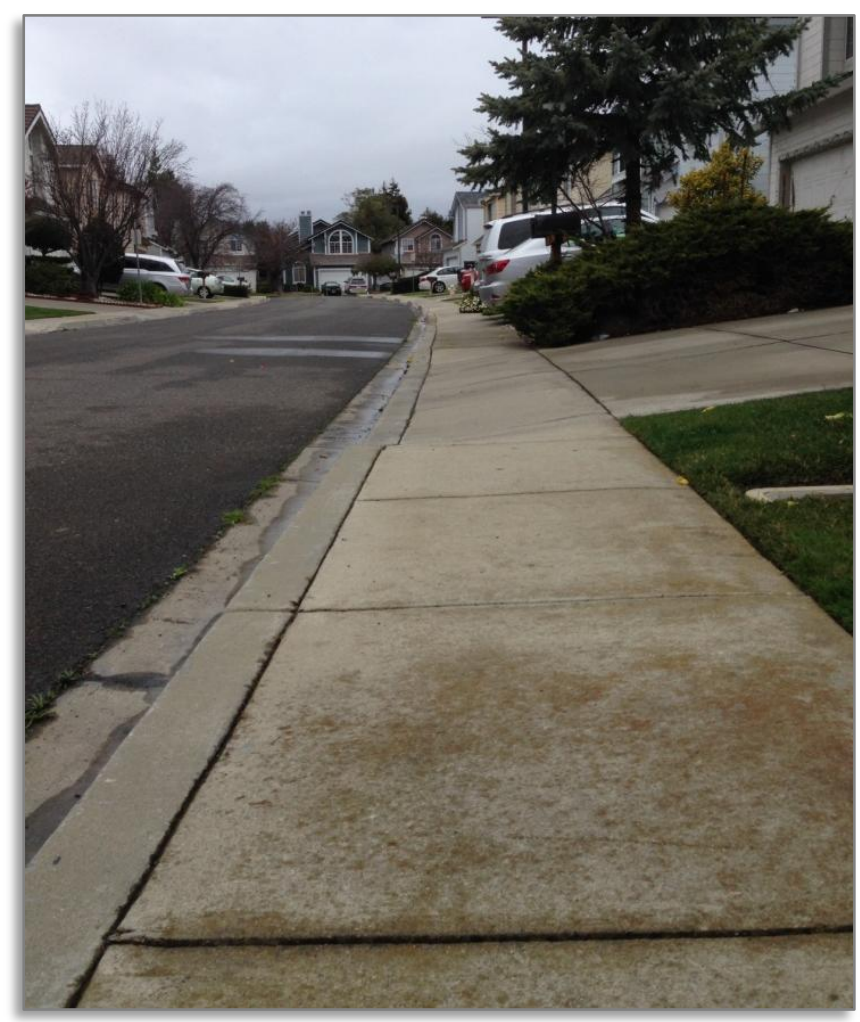

Figure 15. Four-foot sidewalk on residential segment.

Even newer residential areas like this one near 34252 Xanadu Ter do not have the recommended 5 -foot sidewalks.

(Photo by Brish Miller, February 8, 2014)

It is also interesting to note that while residential sidewalks were more complete, less obstructed, slightly more flat, and slightly more likely to be in good condition, they were narrower and less likely to have curb cuts. Wider sidewalks in non-residential areas were expected and could be a result of adherence to the rationale by the FHW and ITE discussed in section 2.1. However, the narrower residential widths is also a reflection of much of the city's built environment dating back to the 1950's and 60's when 4-foot sidewalk widths were widely accepted as the standard for residential areas. ${ }^{144}$ Because much of Fremont is residential, this presents the challenge of most sidewalks in the city being narrower than the modern standard of

\footnotetext{
${ }^{144}$ American Society of Planning Officials, Planning Advisory Service.
} 
five feet (see figure 15). City-wide widening efforts could therefore be a missing, albeit essential component of the City's goal of ensuring its residents can walk "comfortably and pleasurably."145 Any adult with experience passing another adult on a 4-foot sidewalk can testify to the increased comfort level that would be provided with an addition foot of breathing room.

Despite residential areas having surprisingly fewer curb cuts, segments ending with curb cuts were actually quite common, with four-fifths of all audited sidewalks having them. While this could be seen as an encouraging observation for proponents of equal accessibility and pedestrian comfort, it also means that 1 in 5 of the audited sidewalks currently do not have curb cuts. Additionally, it was observed that among residential segments, curb cuts-and crosswalks - are most common in the newer Fremont neighborhoods.

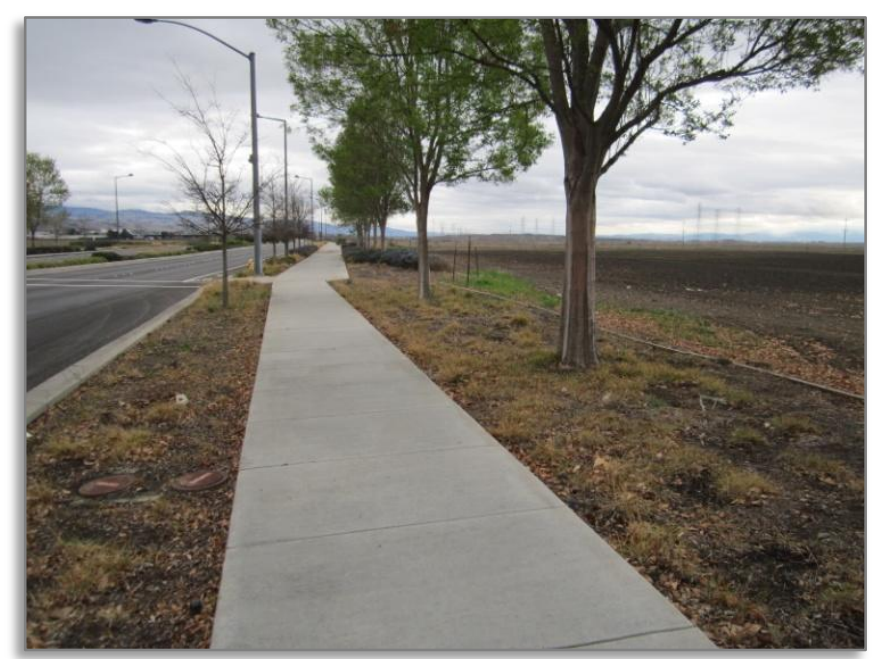

Figure 16. Immaculate new sidewalk in industrial area. Many of Fremont's nicest sidewalks are, ironically, in industrial areas like this one near 4400 Cushing Pkwy, where pedestrian activity is very low. This 1-mile path is wider than five feet, welllit, clean, flat, surrounded by nature... and yet a great distance from any developed parcels. (Photo by author, February 9, 2014)

These observations may bring into question the City's prioritization of improving pedestrian infrastructure in commercial areas, as discussed in section 1.7. Fremont's older, commercial "Main Streets" are already more supportive of walking than its low density, residential neighborhoods - a phenomenon consistent with the national trend identified by Blumenberg et al., ${ }^{146}$ Cullingworth and Caves, ${ }^{147}$ Litman, ${ }^{148}$ and Taylor. ${ }^{149}$

\footnotetext{
${ }^{145}$ City of Fremont, Fremont Pedestrian Master Plan, 1-1.

${ }^{146}$ Evelyn Blumenberg et al., 15, 23.

${ }^{147}$ Barry Cullingworth and Roger W. Caves, 252-5.
}

Therefore, directing the focus to areas which already excel, as the City's Pedestrian Master Plan advocates, could exacerbate walkability deficiencies. In other words, in light of audited residential areas having narrower sidewalks and fewer crosswalks and curb cuts, the City may be rushing ahead to create wonderful pedestrian access in its commercial areas-which is needed - only to leave its enormous residential areas even further behind.

Overall, the findings from this audit suggest that basic sidewalk provision and quality is generally higher in residential areas, but that crucial network connectivity is lower there. This may warrant some pause on the part of City whose stated goal is ensuring that "facilities are fully integrated," connecting to "a variety of destinations." ${ }^{150}$ Residential sidewalks were better than expected, but safe and consistent connectivity seems to be a problem.

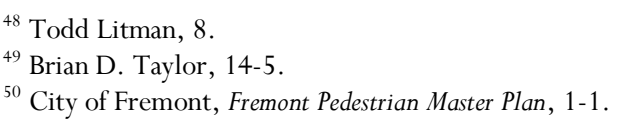




\subsection{Discussion and implications of variation by income}

As tables 3 and 4 indicate, the spatial analysis of median household income revealed that only 12 of the 100 selected segments were in Low Income block groups. Meanwhile, segments selected from Medium Income block groups equated to two-thirds of all segments. This resulted in a lopsided sample of predominately middle income segments which, coincidently, is reflective of Fremont's income stratification. While auditing a random, or "blind" selection of segments was the objective of this case study, it is recommended that small-scale investigations of this kind consider selecting an even number of segments from each defined income category. Having not done that here, this sample is certainly representative of Fremont demographics yet likely insufficient for engaging in anything more than modest policy discussion. Several interesting observations about Fremont sidewalks can made from the findings nonetheless. For example, High Income block groups had the fewest curb cuts and crosswalks. They were also the narrowest, which is consistent with Neckerman et al. ${ }^{151}$ Furthermore, nearly half of the High Income sidewalks were in fair condition - the largest proportion that was observed. Meanwhile, 100 percent of Low Income segments had sidewalks, which is consistent with the findings of Zhu and Lee. ${ }^{152}$ These were also the flattest.

On these very basic measures of provision and quality, it would seem that higher income areas of the city may be underserved in terms of pedestrian infrastructure. However, eight of the 22 High Income segments were in non-residential areas, which could lead to speculation that these segments are inferior because they are in auto-oriented areas like industrial zoning districts. As discussed in sections 3.1 and 4.1, non-residential sidewalks fared slightly worse in this study which could give credence to such a theory. Yet at the same time, High Income sidewalks were also most likely to be complete and unobstructed - two critical features of walkability. This means that any conclusions on this point are only conjecture.

Medium Income segments, on the other hand, were observed to have the most variability, while still being in

\footnotetext{
${ }^{151}$ Kathryn M. Neckerman, et al., 273.

${ }^{152}$ Xuemei Zhu and Chanam Lee, 289.
}

good overall condition. Because this category had the largest sample size, and represents the median income of Fremont residents, these findings may be more worthy of consideration than those of the other two categories. For instance, it may be relevant that they were just as likely as High Income segments to have no sidewalks and to be obstructed, suggesting relatively consistent provision across the city. This would also be in line with findings from Frank and from Wells and Yang regarding uniform, car-oriented suburban land use such as that exists in Fremont. ${ }^{153}$

Additionally, the observation of insufficient width and high rate of obstruction in this category was, anecdotally, very representative of the entire audit experience. It may also be true that the large proportion of Medium Income segments lacking crosswalks is representative of current conditions. In other words, the Medium Income findings may accurately reflect the challenges that pedestrians in Fremont generally must face: narrow sidewalks of widely-varying design which frequently end without a crosswalk.

Larger questions of equity may need to be withheld here, but if Medium Income segments were to be taken as the average and the Low and High Income segments as the outliers, then the implication would be that provision in Fremont is fairly equitable, albeit somewhat inadequate. Additional research would be required to draw a definitive conclusion, yet preliminary findings from this study seem to support such an assertion. Given Fremont's relatively high median income and the large segment of its population that falls into the Medium Income range, findings may also be related to the trend discussed in section 1.5 of a decrease in walking as income rises. If the observed trend is in fact generalizable, then one could expect Fremont residents to walk less as a result of both their high income and their car-oriented, suburban built environment. Findings would thus be consistent with Clifton and Handy, ${ }^{154}$ Pucher and Renne, ${ }^{155}$ and the others.

\footnotetext{
${ }^{153}$ Nancy M. Wells and Yizhao Yang, 314; Lawrence D. Frank.

${ }^{154}$ Kelly Clifton and Susan Handy, 8.

155 John Pucher and John L. Renne, "Socioeconomics of Urban Travel: Evidence from the 2001 NHTS," Transportation Quarterly 57, No. 3 (Summer 2003): 59.
} 


\section{5 | POLICY RECOMMENDATIONS AND CONCLUSIONS}

\subsection{Policy recommendations for MTC}

This research sought to explore whether the level and quality of sidewalk provision in Fremont demonstrates a need for stronger regional and, by extension, State and federal sidewalk requirements. What is best illustrated by the findings presented here is the legitimacy of placing the burden of responsibility on local municipalities. Even in the relatively uniform, suburban built environment of a city like Fremont, there is a great deal of variability in pedestrian infrastructure so decisions regarding things like the location of improvements and modifications are best made locally.

The question is then whether the noble goals set by MTC to increase walking in the region are trickling down fast enough to Fremont. The MPO cannot force a city to become "walkable" but it can encourage this by providing social, environmental, and economic incentives. Because non-residential areas fared worse in this study, MTC may be right in supporting Fremont's policy of first targeting commercial areas for improvement. Without more definitive findings suggesting otherwise, MTC would do well to continue assisting Fremont in the build-up of its downtown and other key commercial areas, as it has recently done through grant money.

However, because most of Fremont's large, established residential areas have older, narrow sidewalks which are not connected to the broader network via crosswalks, MTC may need to find creative ways to earmark the funds it disperses so that needs like this can simultaneously be addressed. Understanding local conditions would be imperative with such a strategy, but independently gathering sufficient data on all the region's cities may not be viable. To better tailor regional improvements, MTC could, therefore, require that grant applicants submit citywide assessments, such as the one performed here, and then make their case for focusing on specific areas in light of the broader conditions within their jurisdiction. For Fremont, the city would need to show that its priority areas overlap with the needs shown in their assessment, such as the generally insufficient width and high rate of obstruction found on sidewalks in Medium Income block groups. 


\subsection{Policy recommendations for City of Fremont}

Whether pedestrian infrastructure in Fremont is going to be excellent or just adequate can only be decided by the City of Fremont, its residents, and property owners. The basic standards mandated by the State and federal governments will only go so far in meeting the needs of pedestrians; the buck stops with the City.

Fremont faces many impediments to walkability as a result of its low-density, car-oriented built environment. Regardless, the City articulates a vision of excellence, therefore, it is prudent to hold it to such a standard. In light of this study's findings, limited as they are, three recommendations could be made to the City of Fremont for enhancing the provision and maintenance of sidewalks in the city.

1. Emphasize the importance of bringing residential sidewalks up to a higher level of quality rather than focusing almost exclusively on improving commercial areas. The City cannot create a walkable network if the starting point is not where people live. The installation of curb cuts and crosswalks where none exist should be made a top priority, with funds and policy directed toward that end.

2. Incentivize or fund the widening and set-back of sidewalks, particularly in residential areas. While potentially controversial, both of these types of improvements seem to be needed within residential areas and Medium Income block groups. Inequity does not appear to be a glaring issue for the city as a whole, yet Fremont's 'middle class' appears to need paths with more protection from automobiles and more walking space.

3. Encourage existing non-residential property owners to improve sidewalks abutting their property through creative incentives. The findings from this study validate the City's concern for non-residential areas. However, rather than putting so many of its eggs in the basket of new development for the creation of high quality pedestrian infrastructure (e.g., Warm Springs/South Fremont BART Station, Pacific Commons shopping center, etc.), or waiting for development funds from MTC, current property owners need to understand the City's vision for walkability and be encouraged to get on board. For example, if Fremont stimulates the creation of the downtown it is dreaming of, property values will increase as the area becomes more walkable. Current property owners will benefit from this and should be encouraged to participate, taking it upon themselves to improve sidewalks and not wait for the City to step in. 


\subsection{Final thoughts}

One of the nicest sidewalks observed in this study was located along Costco in one of the new, somewhat remote shopping plazas mentioned in section 1.7. It was extremely wide, fully shaded by well-maintained foliage, smooth, flat, a comfortable distance from the curb, and complete with marked crosswalks and curb cuts with new, clean truncated domes at both ends of the segment. It was so nice it has been featured on the cover of this report to serve as a both best practice and talking point. The irony is that this is a sidewalk that is unlikely to see much foot traffic.

Cutting through this path at one point is a wide driveway leading into Costco's behemoth parking lotno pedestrian paths lead into the lot. Who, then, is this path for? Surely not Costco customers; they clearly prefer to drive there, as evidenced by its lot being filled to capacity. And surely not nearby residents; the closest residential development is over a mile away. Indeed, not a single pedestrian was spotted on this or any adjacent sidewalk during the 5 minutes the path was being audited, despite the streets and parking lots being packed with cars.

In many ways this sidewalk offers a lesson for those concerned with pedestrian infrastructure in Fremont and in general: creating nice sidewalks in a small area of a city does not mean that area will be pedestrian friendly, or even utilized by pedestrians at all. Sidewalks such as this may ultimately just serve the purpose of looking nice from a moving vehicle. But installing nice sidewalks is about more than just creating the perception of an idyllic neighborhood or quaint downtown. What is at stake is whether transportation infrastructure is supporting all modes of travel or only catering to cars and trucks, and whether or not this occurs in an equitable manner. As this report has pointed out, if walking is unsafe or inefficient then it's not going to happen, and frequently this has a disproportionate effect on the least privileged within a community. Thus, it was very telling that when asked about their experience assessing Fremont sidewalks, one of the data collection assistants remarked, "My first thought was children... if there's not a consistent barrier [between cars and the sidewalk] it doesn't feel safe," and, "Nicer neighborhoods seemed to have nicer looking sidewalks." At some time perhaps all of us have made anecdotal observations like this when walking in our city. Some sidewalks look and feel nicer than others. Some are newer, some are better maintained, and some make us feel safer. If it is commonplace for differences to exist should we not do something about it? But what should be done? It is easy to conclude that “it's just the way it is," but the built environment didn't happen to us; we built it and we can change it. ${ }^{156}$

Finally, this report does not attempt to convince the reader of the public health, economic, and environmental consequences which result when a society is so dependent on the automobile that the only walking many individuals do is to and from their car. On the contrary, this research takes these facts for granted. There is a great wealth of material available which demonstrates the urgency of getting Americans out of their cars. Relaying it here was simply not the objective. Interested readers are encouraged to consult the sources listed at the end of this report for more information.

\footnotetext{
${ }^{156}$ Richard J. Jackson and Stacy Sinclair, Designing Healthy Communities (San Francisco: John Wiley \& Sons, 2012), 161.
} 


\section{BIBLIOGRAPHY}

Advocacy Advance. Navigating MAP-21: Transportation Alternatives Advocacy Tool Kit. http://www.advocacyadvance.org/site_images/content/Navigating_MAP21_toolkit_FINAL_revised_923.pdf (Accessed December 2, 2013).

America Bikes. "Analysis of the New Transportation Bill, MAP-21.” http://www.americabikes.org/analysis_of the new transportation_bill_map_21 (Accessed December 2, 2013).

American Society of Planning Officials, Planning Advisory Service. "Sidewalks in the Suburbs." Information Report 95, February 1957. http: //www.planning.org/pas/at60/report95.htm (Accessed February 24, 2014).

Besser, Lilah M., and Andrew L. Dannenberg. "Walking to Public Transit: Steps to Help Meet Physical Activity Recommendations.” American Journal Of Preventive Medicine 29, no. 4 (April 2005): 273-280.

Blumenberg, Evelyn, Moira Donahue, Susan Handy, Kristin Lovejoy, Caroline Rodier, Susan Shaheen, and James Volker. "Travel of Diverse Populations.” California PATH Working Paper, UCB-ITS-PWP-2007-5, September 2007.

Boarnet, Marlon, Ann Forsyth, Kristen Day, and J. Oakes. "The Street Level Built Environment and Physical Activity and Walking." Environment and Behavior 43, no. 6 (November, 12011 ): 735-775.

Booth, Gillian L., Maria I. Creatore, Rahim Moineddin, Peter Gozdyra, Jonathan T. Weyman, Flora I. Matheson, and Richard H. Glazier. "Unwalkable Neighborhoods, Poverty, and the Risk of Diabetes Among Recent Immigrants to Canada Compared With Long-Term Residents.” Diabetes Care 36, no. 2 (February 2013): 302-308.

Bostock, Lisa. "Pathways of Disadvantage? Walking as a Mode of Transport Among Low-Income Mothers." Health \& Social Care in the Community 9, no. 1 (January 2001): 11-18.

Brownson, Ross C., Christine M. Hoehner, Laura K. Brennan, Rebeka A. Cook, Michael B. Elliott, and Kathleen M. McMullen. "Reliability of Two Instruments for Auditing the Environment for Physical Activity." Journal of Physical Activity and Health 1 (2004): 189-207.

Buman, Matthew P., Sandra J. Winter, Jylana L. Sheats, Eric B. Hekler, Jennifer J. Otten, Lauren A. Grieco, and Abby C. King. "The Stanford Healthy Neighborhood Discovery Tool: A Computerized Tool to Assess Active Living Environments.” American Journal of Preventive Medicine 44, no. 4 (April 2013): 41-47.

Bureau of Transportation Statistics, National Transportation Library. "Intermodal Surface Transportation Efficiency Act of 1991 - Summary.” http://ntl.bts.gov/DOCS/ste.html (Accessed December 1, 2013).

Caspi, Caitlin E., Ichiro Kawachi, S. V. Subramanian, Reginald Tucker-Seeley, and Glorian Sorensen. “The Social Environment and Walking Behavior among Low-Income Housing Residents.” Social Science \& Medicine 80 (March 2013): 76-84. 
Chaudhury, Habib, Ann F. I. Sarte, Yvonne L. Michael, Atiya Mahmood, Erin M. Keast, Cristian Dogaru, and Andrew Wister. "Use of a Systematic Observational Measure to Assess and Compare Walkability for Older Adults in Vancouver, British Columbia and Portland, Oregon Neighbourhoods." Journal of Urban Design 16, no. 4 (November 2011): 433-454.

City of Fremont. Fremont Pedestrian Master Plan. Prepared by Alta Planning + Design. 2007.

http://www.fremont.gov/DocumentCenter/Home/View/941 (Accessed May 8, 2013).

City of Fremont. "Grant Will Kick-Start Downtown Enhancements.” City News 62 (Winter 2013).

City of Fremont. General Plan. December 2011. http://fremont.gov/index.aspx?nid=398 (Accessed May 8, 2013).

City of Fremont. "Public GIS Mapping Application.” February 2013.

http:/ /gis.ci.fremont.ca.us/public/mapindex.cfm (Accessed February 1, 2013).

City of Fremont. Think Fremont California, South Fremont / Warm Springs Strategy: Building Tomorrow's EmploymentFocused Transit Oriented Development Today. Promotional pamphlet. October 2012.

https://www.fremont.gov/DocumentCenter/View/18691 (Accessed October 17, 2012).

City of Fremont, Planning Division. “Fre_Zoning.shp.” GIS shapefile. October 8, 2013.

City of Fremont, Office of Economic Development. Fremont Community Profile 2014. Informational report. January 21, 2014. http://www.fremont.gov/DocumentCenter/Home/View/6859 (Accessed March 3, 2014).

City of Fremont HelpDesk, I.T. Services. Email message. September 23, 2013.

Clifton, Kelly J. “PEDS Instrument v.2.” http://www.kellyjclifton.com/PEDS/PEDSInstrument.v.2.pdf (Accessed February 16, 2013).

Clifton, Kelly J. "PEDS - Pedestrian Environment Data Scan.” http://kellyjclifton.com/products/peds/ (Accessed December 1, 2013).

Clifton, Kelly J., Andréa D. Livi Smith, and Daniel Rodriguez, "The Development and Testing of an Audit for the Pedestrian Environment," Landscape and Urban Planning 80, no. 1-2 (March 2007): 95-110.

Clifton, Kelly and Susan Handy. "Limits on Access in Low-Income Neighborhoods and the Travel Patterns of LowIncome Households.” Research Report, University of Texas at Austin, Center for Transportation Research and Southwest Region University Transportation Center, Texas Transportation Institute, September 2001. http://d2dtl5nnlpfr0r.cloudfront.net/swutc.tamu.edu/publications/technicalreports/167502-1.pdf (Accessed October 21, 2013).

Congress for the New Urbanism. "Charter of the New Urbanism.” http://www.cnu.org/charter (Accessed February 13, 2013).

Cullingworth, Barry and Roger W. Caves. Planning in the USA: Policies, Issues, and Processes (Third Edition). New York: Routledge, 2009. 
De Benedetti, Chris. "Fremont Leaders, Congressmen Tout City's Tech Companies, Planned Warm Springs BART Development Development.” The Argus. May 5, 2013.

http://www.fremont.gov/documentcenter/view/19984 (Accessed August 31, 2013).

De Meester, Femke, Delfien Van Dyck, Ilse De Bourdeaudhuij, Benedicte Deforche, and Greet Cardon. "Do

Psychosocial Factors Moderate the Association Between Neighborhood Walkability and Adolescents' Physical Activity?" Social Science \& Medicine 81, (March 15, 2013): 1-9.

Dessauer, Mark. "Low Income Populations and Physical Activity: An Overview of Issues Related to Active Living." Document prepared for Together on Diabetes Summit in Atlanta, February 28-29, 2012. http://www.bms.com/documents/together on diabetes/2012-Summit-Atlanta/Physical-Activity-forLow-Income-Populations-The-Health-Trust.pdf (Accessed November 14, 2013).

Esri and City and County of San Francisco, Department of Telecommuncations and Information Services. Sfbay. GIS feature class file. September 9, 2008.

Fuller, Daniel, Lise Gauvin, and Yan Kestens. "Individual- and Area-Level Disparities in Access to the Road Network, Subway System and a Public Bicycle Share Program on the Island of Montreal, Canada.” Annals of Behavioral Medicine 45, (February 2, 2013): 95-100.

Frank, Lawrence D. "Economic Determinants of Urban Form: Resulting Trade-Offs Between Active and Sedentary Forms of Travel." American Journal of Preventive Medicine 27, no. 3, Supplement (October 2004): 146-153.

Glaeser, Edward L., Matthew E. Kahn, and Jordan Rappaport. "Why Do the Poor Live in Cities? The Role of Public Transportation.” Journal of Urban Economics 63, no. 1 (May 2008): 1-24.

Google. "Privacy and Security." http://www.google.com/maps/about/behind-the-scenes/streetview/privacy/ (Accessed February 16, 2014).

Google Maps. http://maps.google.com (Accessed March 4, 2014).

Guo, Zhan and Becky P. Y. Loo. "Pedestrian Environment and Route Choice: Evidence from New York City and Hong Kong.” Journal of Transport Geography 28 (April 2013): 124-136.

Harruff, Richard C., Anne Avery, and Amy S. Alter-Pandya. “Analysis of Circumstances and Injuries in 217 Pedestrian Traffic Fatalities.” Accident Analysis \& Prevention 30, no. 1 (January 1998): 11-20.

Hepler, Lauren. "Life After Solyndra: Fremont Pumps its Cleantech Agenda." Silicon Valley Business Journal. May 3, 2013. http://www.fremont.gov/documentcenter/view/19990 (Accessed August 31, 2013).

Hine, Julian, Md. Kamruzzaman, and Neale Blair. "Weekly Activity-Travel Behaviour in Rural Northern Ireland: Differences by Context and Socio-Demographic.” Transportation 39, no. 1 (January 2012): 175-195.

Iseki, Hiroyuki, Michael Smart, Brian D. Taylor, and Allison Yoh. "Thinking Outside the Bus." ACCESS Magazine 40 (Spring 2012): 9-15.

Jackson, Richard J. and Stacy Sinclair. Designing Healthy Communities. San Francisco: John Wiley \& Sons, 2012. 
Kelly, C. E., M. R. Tight, F. C. Hodgson, and M. W. Page. "A Comparison of Three Methods for Assessing the Walkability of the Pedestrian Environment.” Journal of Transport Geography 19, no. 6 (November 2011): 1500-1508.

Kelly, Cheryl M., Mario Schootman, Elizabeth A. Baker, Ellen K. Barnidge, and Amanda Lemes. "The Association of Sidewalk Walkability and Physical Disorder with Area-Level Race and Poverty." Journal of Epidemiology \& Community Health 61, no. 11 (November 1, 2007): 978-983.

Koh, Puay Ping and Yiik Diew Wong. "Comparing Pedestrians' Needs and Behaviours in Different Landuse Environments.” Journal of Transport Geography 26 (January 2013): 43-50.

Lee, Chanam, Marcia Ory, Jeongjae Yoon, and Samuel Forjuoh. "Neighborhood Walking among Overweight and Obese Adults: Age Variations in Barriers and Motivators." Journal of Community Health 38, no. 1 (February 2013): 12-22.

Litman, Todd. "Smart Congestion Relief: Comprehensive Analysis of Traffic Congestion Costs and Congestion Reduction Benefits.” Paper presented at the Transportation Research Board 2012 Annual Meeting, P125310, September 12, 2012: 8.

Manjoo, Farhad. “The Genius of Tesla.” Slate Magazine. May 10, 2013. http://www.slate.com/articles/technology/technology/2013/05/tesla_model_s the electric_car_comp any is a little bit apple a little bit.html (Accessed August 31, 2013).

Metropolitan Transportation Commission. Transportation 2035 Plan for the San Francisco Bay Area. April 2009. http://www.mtc.ca.gov/planning/2035 plan/FINAL/T2035 Plan-Final.pdf (Accessed May 1, 2013).

Metropolitan Transportation Commission. Draft Plan Bay Area. March 2013. http://onebayarea.org/pdf/Draft_Plan_Bay_Area_3-22-13.pdf (Accessed May 1, 2013)

MTC-ABAG Library, Bay Area Census. "Race/Ethnicity Percentage by County, 1980-2010.” http://www.bayareacensus.ca.gov/historical/shrcorace.htm (Accessed August 31, 2013).

Neckerman, Kathryn M., Gina S. Lovasi, Stephen Davies, Marnie Purciel, James Quinn, Eric Feder, Nakita Raghunath, Benjamin Wasserman, and Andrew Rundle. "Disparities in Urban Neighborhood Conditions: Evidence from GIS Measures and Field Observation in New York City.” Journal of Public Health Policy 30 (March 2, 2009): 264-285.

Noss, Amanda, U.S. Census Bureau. Household Income: 2012, American Community Survey Briefs. September 2013. https://www.census.gov/prod/2013pubs/acsbr12-02.pdf (Accessed March 2, 2014).

Öström, Mats and Anders Eriksson. "Pedestrian Fatalities and Alcohol.” Accident Analysis \& Prevention 33, no. 2 (March 1, 2001): 173-180.

Pikora, Terri J., Fiona C. L. Bull, Konrad Jamrozik, Matthew Knuiman, Billie Giles-Corti, and Rob J. Donovan. "Developing a Reliable Audit Instrument to Measure the Physical Environment for Physical Activity." American Journal of Preventive Medicine 23, no. 3 (October 2002): 187-194. 
Pucher, John, and John L. Renne. "Socioeconomics of Urban Travel: Evidence from the 2001 NHTS.” Transportation Quarterly 57, No. 3 (Summer 2003): 49-77.

http: / / fmip.ornl.gov/2001/articles/socioeconomicsOfUrbanTravel.pdf (Accessed October 22, 2013).

Rain, Belinda, U.S. National Archives and Records Administration. Untitled photograph. 1972.

http://upload.wikimedia.org/wikipedia/commons/0/05/CALIFORNIA-

NEAR SAN FRANCISCO BAY - NARA - 544723.jpg (Accessed December 1, 2013).

Rundle, Andrew G., Michael D. M. Bader, Catherine A. Richards, Kathryn M. Neckerman, and Julien O. Teitler. "Using Google Street View to Audit Neighborhood Environments." American Journal of Preventive Medicine 40, no. 1 (January 2011): 94-100.

San Francisco Bay Area Rapid Transit District. "Warm Springs Extension Construction Updates.” http://www.bart.gov/about/projects/wsx/updates (Accessed December 7, 2013).

Santa Clara Valley Transportation Authority. InnerBayStreets.shp. GIS shapefile. February 21, 2014.

Scholl, Lynn. "Transportation Affordability for Low-Income Populations: A Review of the Research Literature, Ongoing Research Projects, and San Francisco Bay Area Transportation Assistance Programs.” PPIC Working Paper, Public Policy Institute of California, October 2002. http://www.mtc.ca.gov/planning/lifeline/Affordability_ref.pdf (Accessed October 21, 2013).

Shelton, Rachel C., Lorna H. McNeill, Elaine Puleo, Kathleen Y. Wolin, Karen M. Emmons, and Gary G. Bennett. "The Association Between Social Factors and Physical Activity Among Low-Income Adults Living in Public Housing." American Journal of Public Health 101, no. 11 (November 2011): 2102-2110.

Sierra Club. "Sierra Club Conservation Policies: Transportation.” May 8, 1994.

http://www.sierraclub.org/policy/conservation/trans.aspx (Accessed February 14, 2013).

Sisson, Susan B., James J. McClain, and Catrine Tudor-Locke. "Campus Walkability, Pedometer-Determined Steps, and Moderate-to-Vigorous Physical Activity: A Comparison of 2 University Campuses.” Journal of American College Health 56, no. 5 (March 2008): 585-592.

Southern Alameda County GIS Authority and City of Fremont. Fre_Jurisdiction.shp. GIS shapefile. October 8, 2013.

Staron, Lawrence A. untitled correspondence. http://www.fhwa.dot.gov/infrastructure/parambler.cfm (Accessed December 2, 2013).

State of California. Streets and Highways Code. Sections 5610 and 5875, http://www.leginfo.ca.gov/.html/shc table of contents.html (Accessed October 7, 2013).

State of California, California Department of Transportation. Caltrans Highway Design Manual, Sixth Edition. By the Division of Design. May 7, 2012. http://www.dot.ca.gov/hq/oppd/hdm/pdf/english/HDM Complete 07Mar2014.pdf (Accessed February 14, 2013). 
State of California, California Department of Transportation. Local Assistance Procedures Manual: Processing Procedures for Implementing Federal and/or State Funded Local Public Transportation Projects. Central Publication Distribution Unit. 2008.

http://www.dot.ca.gov/hq/LocalPrograms/lam/prog_p/LAPM\%20Complete\%2004-26-11.pdf (Accessed April 1, 2013).

Taylor, Brian D. “Rethinking Traffic Congestion.” ACCESS Magazine 21 (Fall 2002): 8-16.

U.S. Census Bureau, American FactFinder. "Selected Economic Characteristics, 2012 American Community Survey 1-Year Estimates."

http: / / factfinder2.census.gov/faces/tableservices/jsf/pages/productview.xhtml?src=bkmk $($ Accessed March 3, 2014).

U.S. Census Bureau, Geography. TIGER/Line Shapefiles Pre-joined with Demographic Data, 2008-2012 American Community Survey 5-year estimates, California Geodatabase. February 6, 2014. http://www.census.gov/geo/maps-data/data/tiger-data.html (Accessed February 28, 2014).

U.S. Department of the Interior, U.S. Geological Survey. National Hydrography Dataset. GIS files. May 2013.

U.S. Department of Transportation, Federal Highway Administration. Transportation Equity Act for the 21 st Century: Moving Americans into the 21 st Century. http:/ / www.fhwa.dot.gov/tea21/sumenvir.htm\#btapw (Accessed December 1, 2013).

U.S. Department of Transportation, Federal Highway Administration. "A Summary of Highway Provisions in SAFETEA-LU.” By Office of Legislation and Intergovernmental Affairs, Program Analysis Team. August 25, 2005. https://www.fhwa.dot.gov/safetealu/summary.htm (Accessed December 2, 2013).

U.S. Department of Transportation, Federal Highway Administration. "Designing Sidewalks and Trails for Access." 4.3.3 Width.

http://www.fhwa.dot.gov/environment/bicycle_pedestrian/publications/sidewalks/chap4a.cfm (Accessed February 23, 2014).

U.S. Department of Transportation, Federal Highway Administration. "Policy Statement on Bicycle and Pedestrian Accommodation Regulations and Recommendations."

http://www. fhwa.dot.gov/environment/bicycle pedestrian/overview/policy accom.cfm (Accessed February 11, 2013).

U.S. Department of Transportation, Federal Highway Administration. "Safety Benefits of Walkways, Sidewalks, and Paved Shoulders.” http://safety.fhwa.dot.gov/ped_bike/tools_solve/walkways trifold/ (Accessed December 1, 2013).

U.S. Department of Transportation. National Highway Traffic Safety Administration. Pedestrian Roadway Fatalities. April 2003. http://www-nrd.nhtsa.dot.gov/Pubs/809-456.pdf (Accessed February 16, 2013)

U.S. News \& World Report. "Fremont Unified School District.” http://www.usnews.com/education/best-highschools/california/districts/fremont-unified-school-district (Accessed August 31, 2013). 
United States Access Board. “Accessible Sidewalk Video Series.” Adobe Flash video files. http: //www.accessboard.gov/guidelines-and-standards/streets-sidewalks/public-rights-of-way/guidance-andresearch/accessible-sidewalks-video-series (Accessed April 7, 2013).

United States Access Board. “ADA Standards.” http://www.access-board.gov/guidelines-and-standards/buildingsand-sites/about-the-ada-standards/ada-standards-single-file (Accessed December 3, 2013).

United States Access Board. “Architectural Barriers Act (ABA) of 1968.” http://www.access-board.gov/theboard/laws/architectural-barriers-act-aba (Accessed December 3, 2013).

United States Access Board. "Revised Draft Guidelines for Accessible Public Rights-of-Way.” http:/ /www.accessboard.gov/guidelines-and-standards/streets-sidewalks/public-rights-of-way/background/revised-draftguidelines (Accessed December 3, 2013).

University of California, Los Angeles, Center for Occupational and Environmental Health. “About P.E.Q.I.” http://www.peqiwalkability.appspot.com/about.jsp (Accessed December 1, 2013).

University of North Carolina Highway Safety Research Center, National Center for Safe Routes to School. "How Wide Should a Safe Routes to School Sidewalk be to Meet ADA Specifications?" http://www.saferoutesinfo.org/program-tools/how-wide-should-safe-routes-school-sidewalk-be-meetada-specifications (Accessed February 23, 2014).

University of North Carolina Highway Safety Research Center, Pedestrian and Bicycle Information Center. "Audits." http://www.pedbikeinfo.org/planning/tools audits.cfm (Accessed April 16, 2013).

University of North Carolina Highway Safety Research Center, Pedestrian and Bicycle Information Center. "Economic Benefits." http://www.walkinginfo.org/why/benefits economic.cfm (Accessed December 2, 2013).

University of North Carolina Highway Safety Research Center, Pedestrian and Bicycle Information Center. "Environmental/Energy Benefits." http://www.walkinginfo.org/why/benefits environment.cfm (Accessed December 2, 2013).

University of North Carolina Highway Safety Research Center, Pedestrian and Bicycle Information Center. "Sidewalks and Walkways." http://www.pedbikeinfo.org/planning/facilities ped sidewalks.cfm (Accessed February 23, 2014).

University of North Carolina Highway Safety Research Center, Pedestrian and Bicycle Information Center. “Transportation Benefits." http://www.walkinginfo.org/why/benefits transportation.cfm (Accessed December 2, 2013).

Urban Land Institute. A ULI Advisory Services Panel Report: Strategies for the Development around the Warm Springs/South Fremont Station. June 11-14, 2012. http://www.fremont.gov/DocumentCenter/View/18322 (Accessed November 18, 2012).

Urban Land Institute. "Report on Warm Springs/South Fremont Area Positioned as 21st Century Workplace, Mixed Use Transit-Oriented Development.” Presentation to City of Fremont officials and community members. June 14, 2012. http://www.youtube.com/watch?v=YEzeXcgN6NE\&feature=plcp (Accessed October 3, 2012). 
Wang, Fang, Ruoping Zhang, Shisheng Dong, and Lei Liang. "Urban Planning and Design of Pedestrian Space from Perspectives of Fitness.” Procedia Engineering 21 (2011): 363-367.

Weinstein, Asha. "Traveler or Pesky Impediment to Travel? Pedestrians and Traffic Regulations in the U.S. and France, 1870-1930.” Paper presented at the 46th Annual Conference of the Association of Collegiate Schools of Planning. October 27-30, 2005. Kansas City, MO.

Wells, Nancy M., and Yizhao Yang. "Neighborhood Design and Walking: A Quasi-Experimental Longitudinal Study.” American Journal of Preventive Medicine 34, no. 4 (April 2008): 313-319.

World Media Group, LLC. “California Population Density City Rank.” http://www.usa.com/rank/californiastate--population-density--city-rank.htm (Accessed December 5, 2013).

Zhu, Xuemei and Chanam Lee. "Walkability and Safety Around Elementary Schools: Economic and Ethnic Disparities.” American Journal of Preventive Medicine 34, no. 4 (April 2008): 282-290. 


\section{APPENDICES}

\section{Appendix 1: Institutional Review Board (IRB) exemption letter}

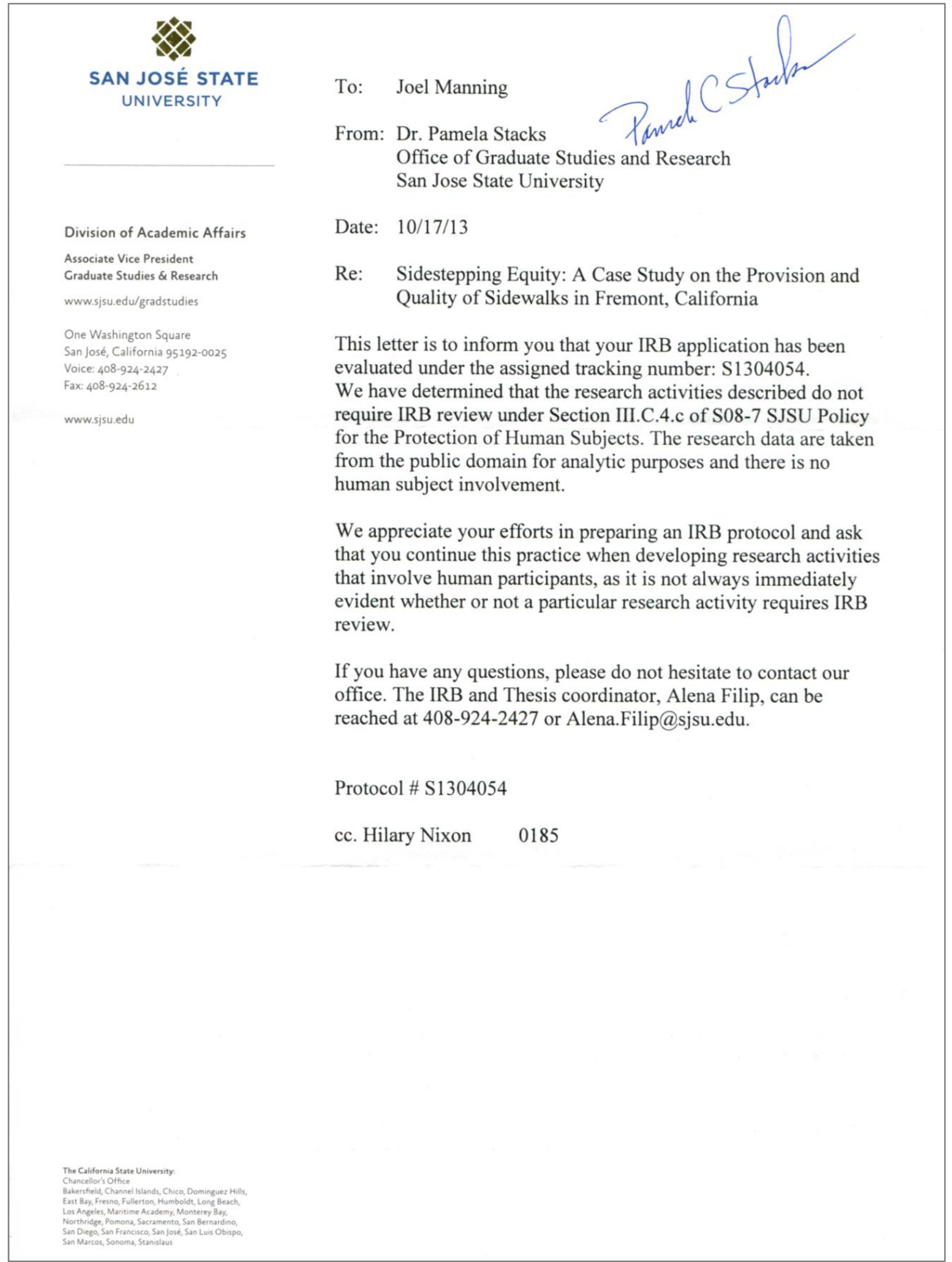


Appendix 2: Pedestrian Environmental Data Scan (PEDS) full audit instrument, Version 2, by Kelly J. Clifton, PhD and Andrea D. Livi Smith, PhD

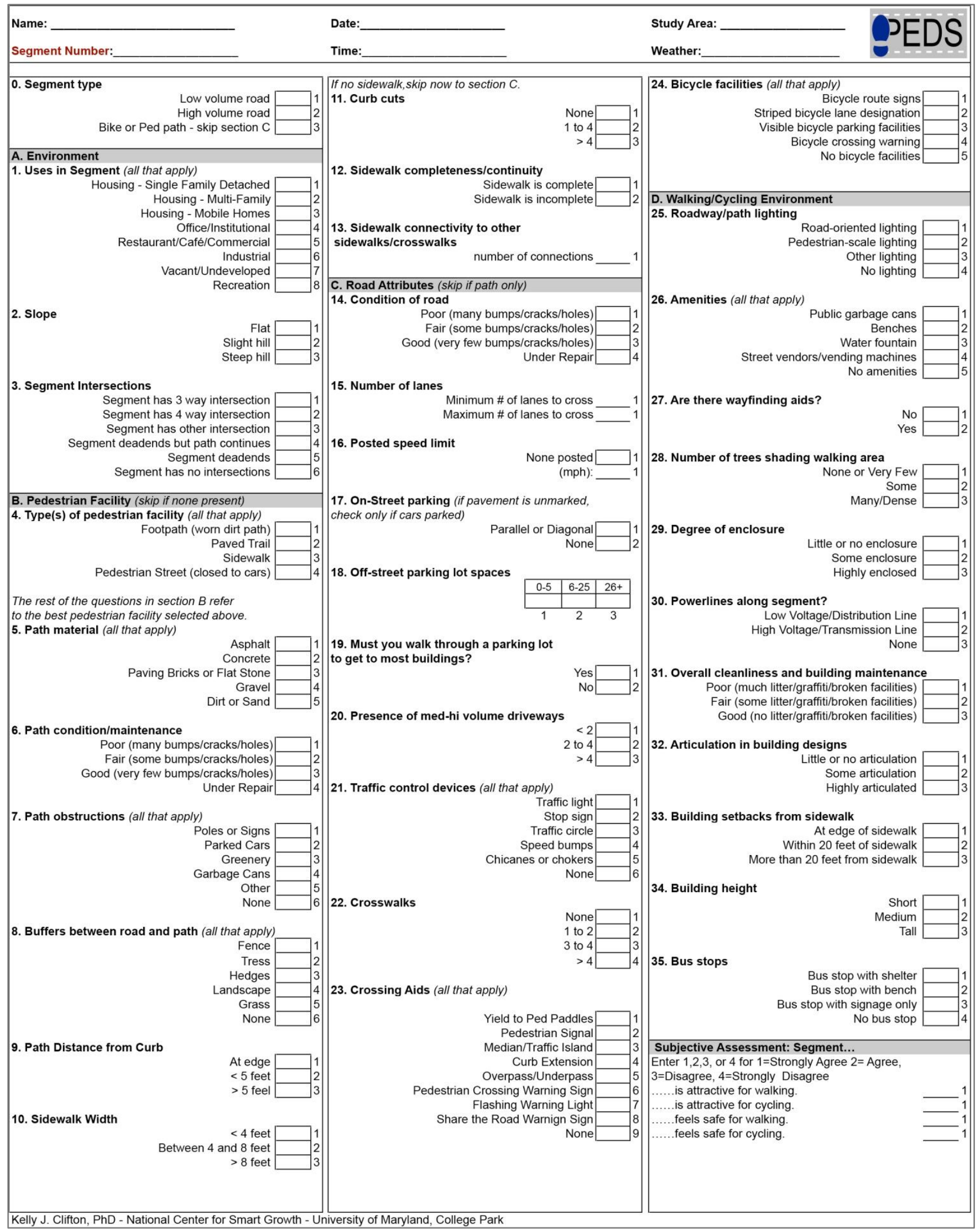


Appendix 3: Audited Fremont street segments without sidewalks, by zoning

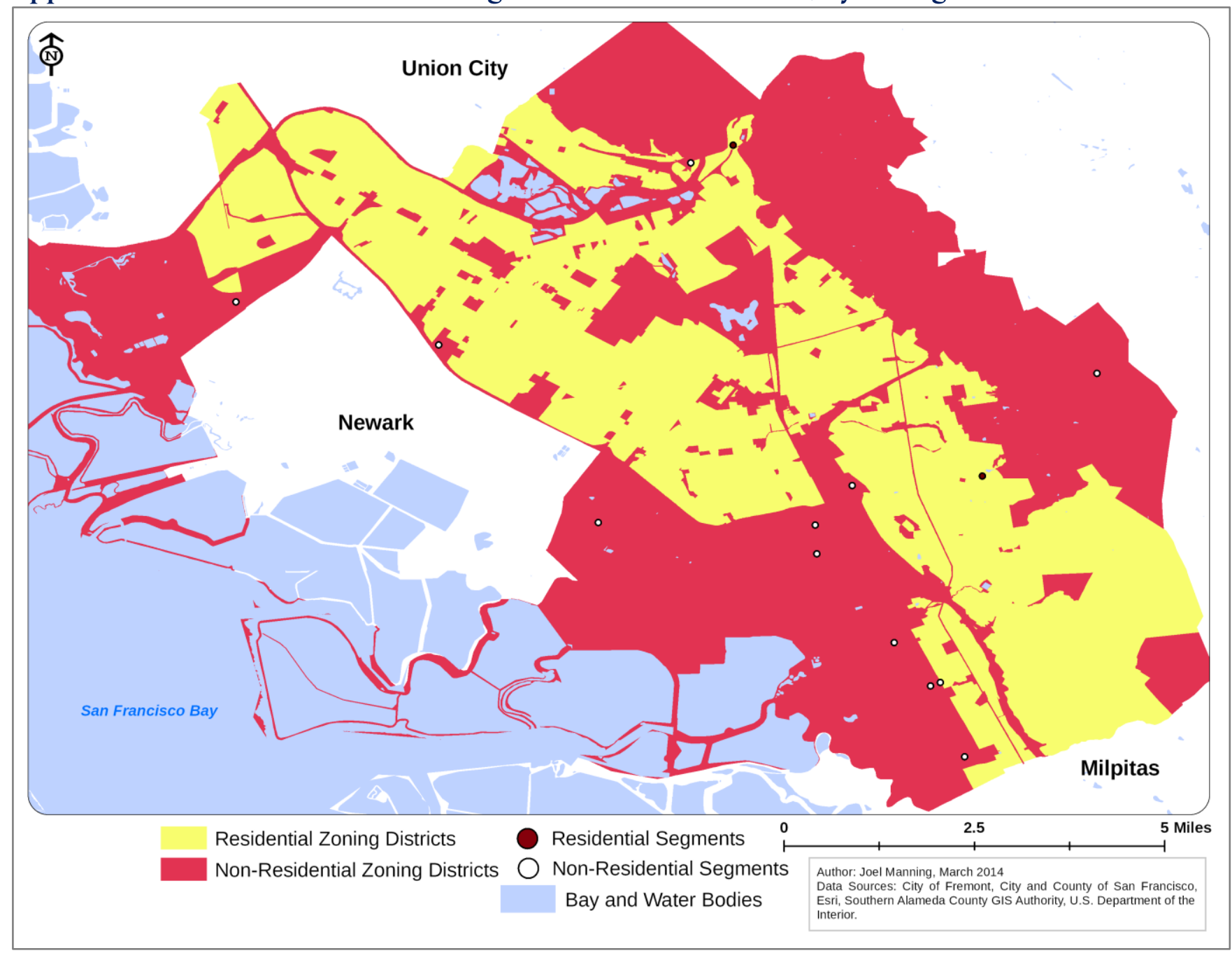


Appendix 4: Audited Fremont street segments without crosswalks, by zoning

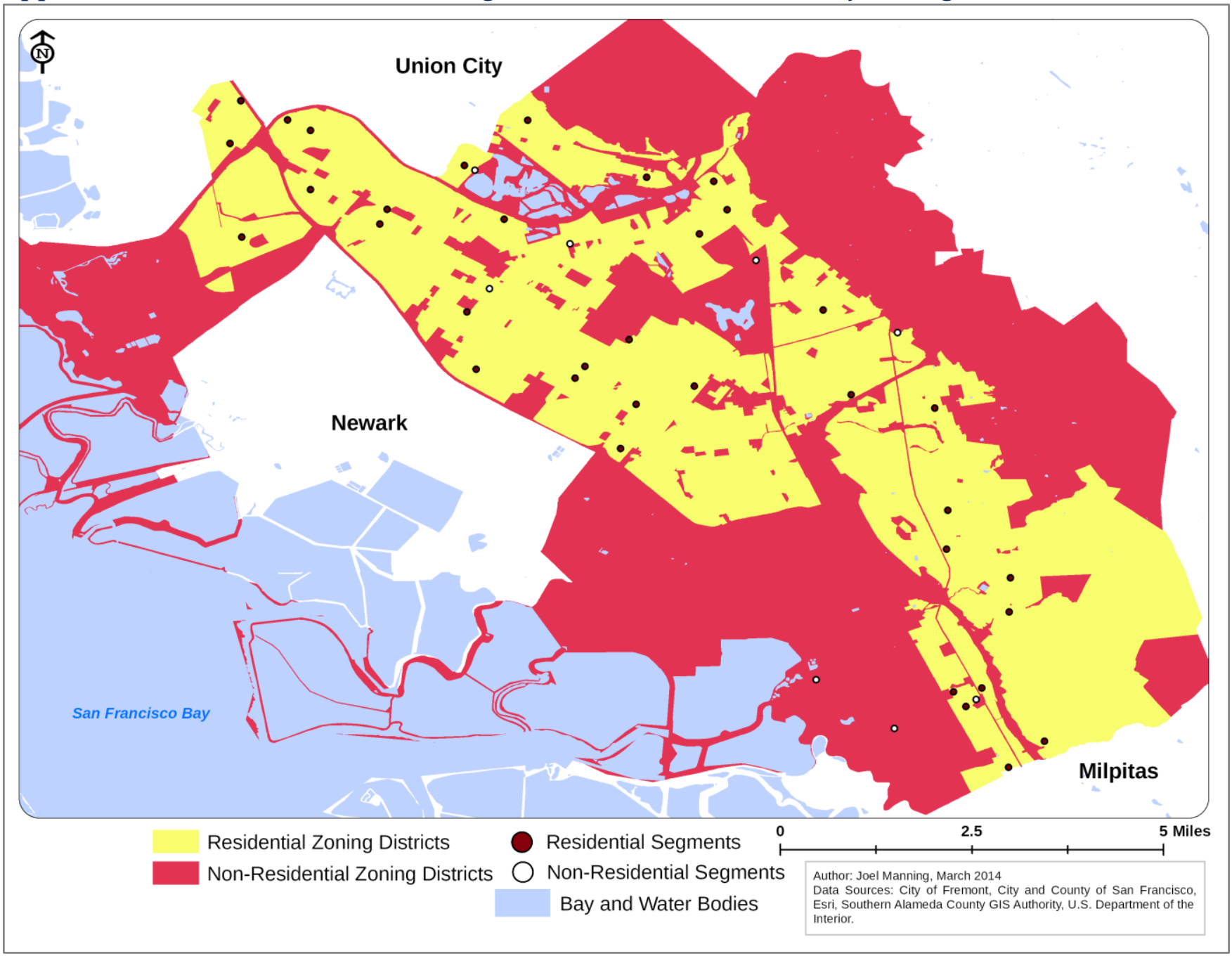


Appendix 5: Fremont sidewalks in poor to fair condition or under construction, by zoning

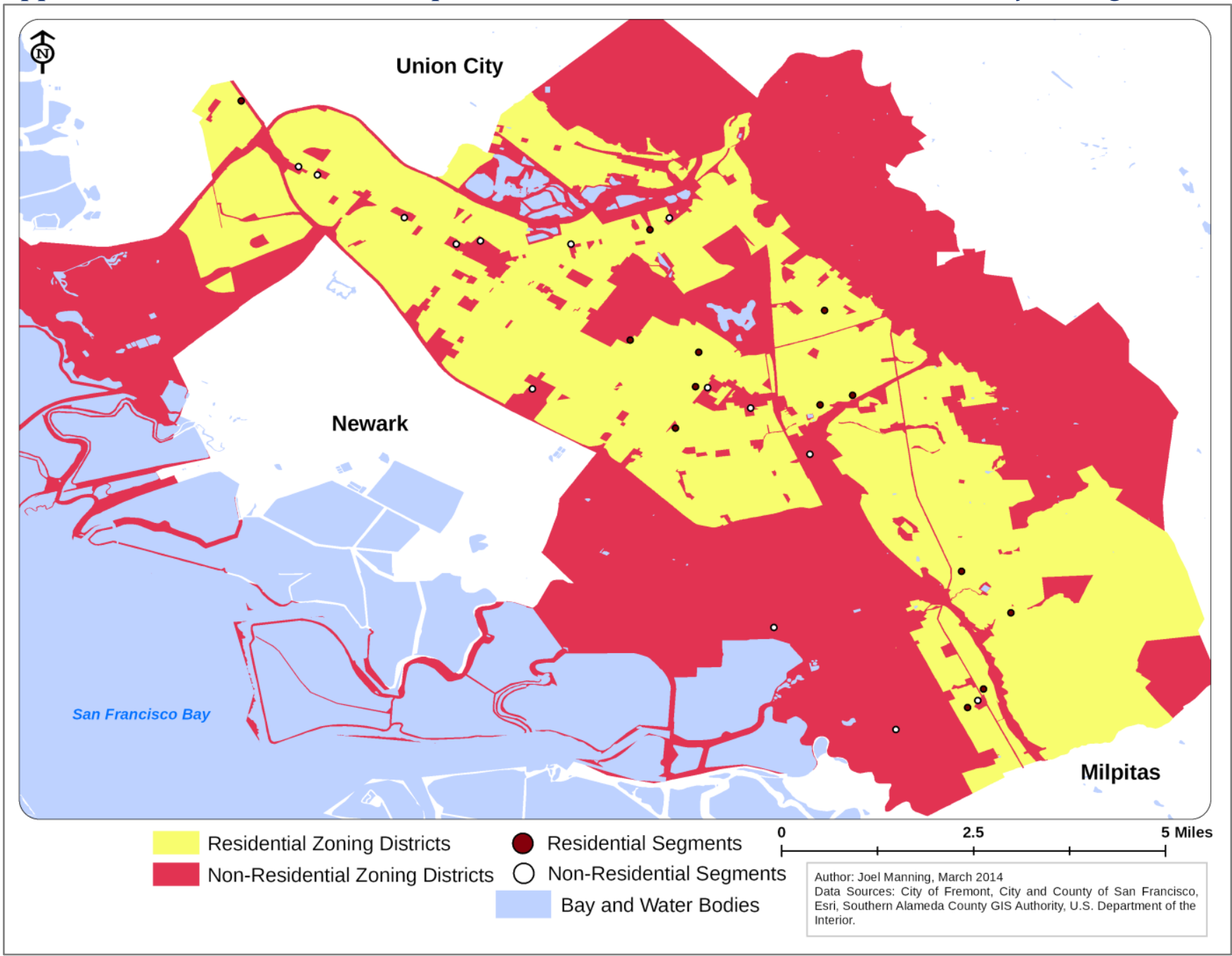


Appendix 6: Fremont sidewalks in poor to fair condition or under construction, by income

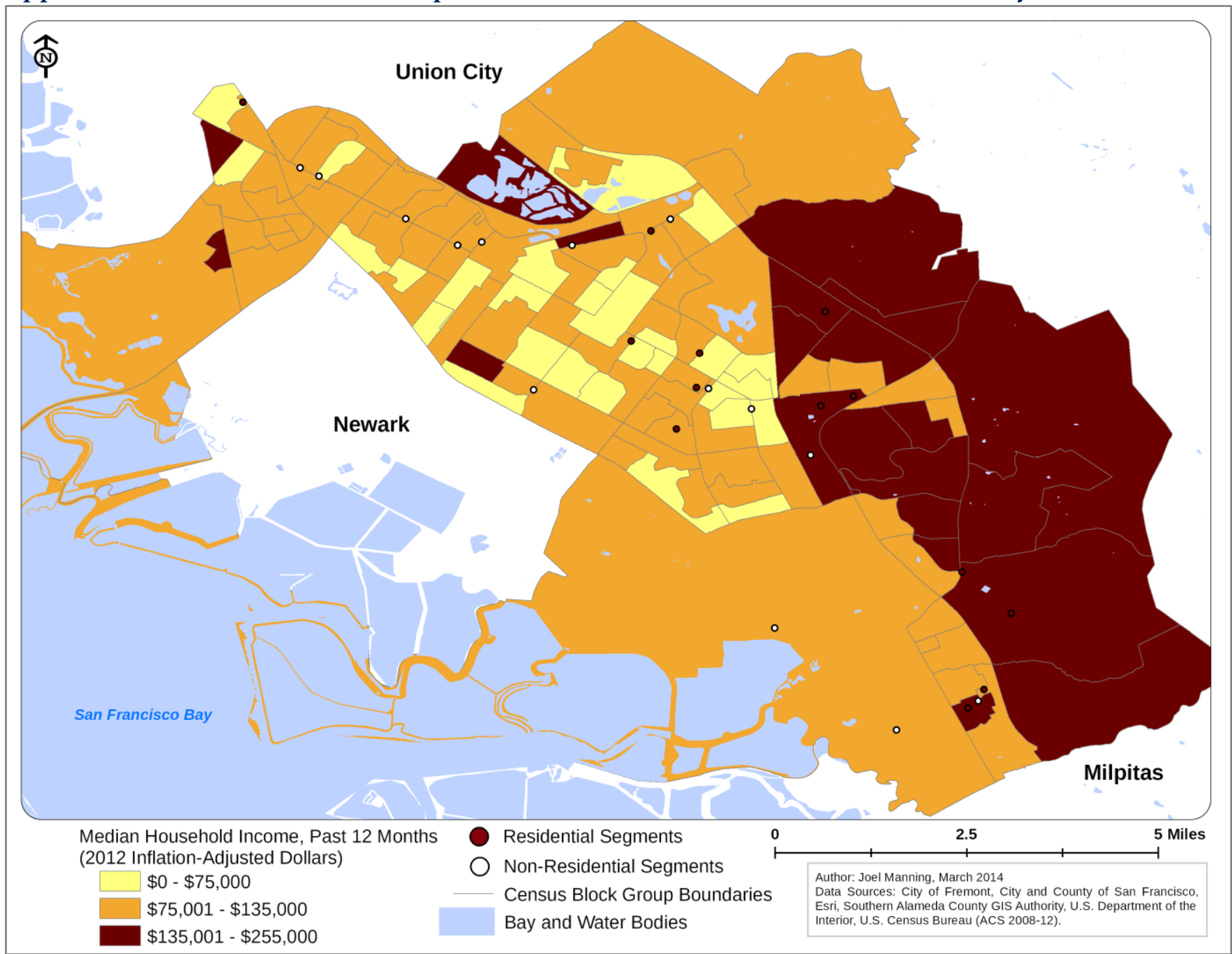

